University of Rhode Island

DigitalCommons@URI

Open Access Dissertations

2000

\title{
A Mediational Coping Model of Sociopersonal Well-Being and Quality of Life
}

William Burton Disch

University of Rhode Island

Follow this and additional works at: https://digitalcommons.uri.edu/oa_diss

\section{Recommended Citation}

Disch, William Burton, "A Mediational Coping Model of Sociopersonal Well-Being and Quality of Life" (2000). Open Access Dissertations. Paper 952.

https://digitalcommons.uri.edu/oa_diss/952

This Dissertation is brought to you for free and open access by DigitalCommons@URI. It has been accepted for inclusion in Open Access Dissertations by an authorized administrator of DigitalCommons@URI. For more information, please contact digitalcommons-group@uri.edu. 


$$
\begin{aligned}
& 8+57 \\
& 5.5 \\
& 0573 \\
& 2000
\end{aligned}
$$

A MEDIATIONAL COPING MODEL OF

SOCIOPERSONAL WELL-BEING AND QUALITY OF LIFE

BY

WILLIAM BURTON DISCH

A DISSERTATION SUBMITTED IN PARTIAL FULFILLMENT OF THE REQUIREMENTS FOR THE DEGREE OF DOCTOR OF PHILOSOPHY

$\mathbb{N}$

PSYCHOLOGY

THE UNIVERSITY OF RHODE ISLAND

SPRING 2000 


\section{Abstract}

The current study assessed relationships between composite and latent measures of stress, coping, and sociopersonal well-being and quality of life. A latent variable mediational coping model was proposed and it was hypothesized that coping would be a significant mediator between measures of stress and measures of quality of life. The process of mediational coping is theoretically explained using a pragmatic and teleological application of need motivation and goal directed behavior (Maslow, 1968, 1971), and behavioral specificity, delay of gratification, and context (Mischel, 1973, 1986). Social learning and humanistic concepts are synthesized within a discussion of ontological, epistemological, and methodological congruence and parallelism. Exploratory, confirmatory, and latent variable mediational analyses were performed. Results indicated that relationships among 10 composite variables formed a well-fitting 3-factor confirmatory model $(\mathrm{CFI}=.93)$. The factors were: 1$)$ sociopersonal well-being and quality of life (past, current, future satisfaction with life; existential well-being; mental/physical health satisfaction), 2) stress (perceived psychological stress, physical symptoms, anxiety), and 3) coping (perceived coping, cognitive processing). Testing several competing latent variable models, results revealed that a partial mediational model, with an additional direct path from stress to well-being and quality of life fit well for both men and women $(\mathrm{CFI}=.93)$. Multiple sample analysis indicated that the parameter estimates were significantly different for men and women. The final gender specific models indicated that the model for women held up $(\mathrm{CFI}=.91)$, and all parameters were significant. However, for men, the path from coping to well-being and 
quality of life was not statistically significant $(\mathrm{CFI}=.93)$. Post hoc analyses on the differential gender effects of perceived coping and cognitive processing (broken out of the latent coping variable and used as two separate measured variables) indicated that cognitive processing was more strongly related to stress for men than for women and was not a significant direct predictor of well-being for either sex. Multiple analysis of variance (MANOVA) by gender, corrected for familywise error, revealed significant differences on five of the 10 composite variables. Mean scores indicated that women reported significantly higher levels of perceived psychological stress and physical symptoms, and significantly lower levels of past satisfaction with life, current satisfaction with life, and mental/physical health and esteem than men. However, there were no significant gender differences related to future satisfaction with life, existential well-being (including meaning and purpose in life), and cognitive processing indicating that despite the differential in two of the three stress variables, there were no significant gender differences on variables related to future life direction and satisfaction expectations. The results are discussed in terms of multivariate quality of life and well-being assessment. Methodological issues related to theory, context, micro/macro level quality of life variables, and interpretation of results related to reliability and validity are discussed. Finally, the results are currently being used for psychometric normalization work on several versions of the Quality of Life and Satisfaction (QOLAS) family of instruments (SQOLAS for students, A-QOLAS for athletes, and QOLAS for adults). 


\section{Acknowledgments}

My gratitude and appreciation extend to several individuals for their support, assistance, encouragement, and above all, patience:

Dr. Lisa Harlow, my extremely patient major professor.

Dr. Jim Campbell and Dr. Larry Grebstein, my core committee members who emphasized balance.

Dr. Pat Burbank and Dr. Al Lott, my additional committee members, who imposed philosophical, theoretical, and practical wisdom.

Dr. Tom Dougan and Dr. John McCray, Jr., my employers, who were more than generous with their resources and support.

Dr. Grant Willis, Dr. Greta Cohen, Dr. Lisa Bowleg, Dr. Bernice Lott, Dr. Wayne Velicer, Dr. Kat Quina, Dr. Joe Fava, and Dr. Al Silverstein, Dr. Dominic Valentino, and Dr. Paul DeMesquita who were fantastic influences, whether they know it or not!

And above all, my wife, Jennifer, my daughters, Megan Winter and Holly Meadow, and a few wonderful friends and family members who provided immeasurable richness, meaning, and purpose during my academic journey.

William B. Disch, Spring 2000

Vad det är skönt att leva! 


\section{Preface}

The following dissertation is organized in manuscript format as follows: Chapter 1 contains a brief introduction to the area of sociopersonal well-being and quality of life. Included are some basic elements, conceptual frameworks, and theoretical overviews. The introduction concludes with the overall research hypotheses.

Chapter 2, the first manuscript, consists of a philosophy of science component that highlights the ontology, epistemology, and methodology related to sociopersonal wellbeing and quality of life. It is posited that a teleologically pragmatic linking of specific components of Maslow's concepts of need motivation and goal-directed behavior, and Mischel's concepts of behavioral specificity and delay of gratification are sufficient and necessary for describing and explaining a broad model of quality of life and well-being. As proposed by Kahneman, Diener, and Schwarz (1999), an optimal model for the study of well-being and quality of life attempts to assess a multivariate spectrum of life's elements, from the basic physiological components at the neuronal level, to national, institutional, cultural, and social and economic components at the global level.

Chapter 3, the second manuscript, consists of a study examining a hypothesized mediational coping model of sociopersonal well-being and quality of life. There is an extensive section that includes the design, development, measures, and psychometrics related to the study. It is posited that coping and related measures mediate, and act as a "filter" between measures of life stress and measures of quality of life and well-being. It is also posited that there are significant mean score gender differences associated with 
relationships among stress, coping, and well-being measures, especially in terms of the perceptual and experiential aspects of stress.

Finally, Chapter 4 includes a general discussion section summarizing the results and implications of the study, and the proposal of a teleological and pragmatic approach to studying sociopersonal well-being and quality of life across a diverse array of contexts in the future.

The University of Rhode Island, Division of Student Affairs, has published several portions of this dissertation as a series of tech reports related to the sociopersonal wellbeing and quality of life of young people. Additionally, portions of this dissertation and research were presented at the meeting of the New England Psychological Association in Providence, Rhode Island (October 1998), the meeting of the International Society of Quality of Life Research in Williamsburg, Virginia (December 1998), the meeting of the New England Psychological Association in Baltimore, Maryland (March 2000), and the meeting of the Society of Behavioral Medicine in Nashville, Tennessee (April 2000). Finally, an article from the SQOLAS research project has been accepted for publication in the peer reviewed journal, Social Indicators Research. 


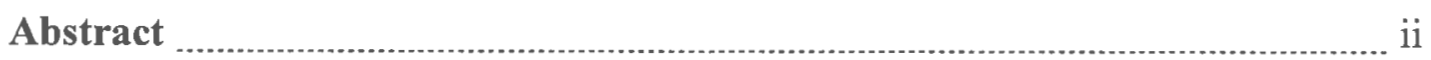

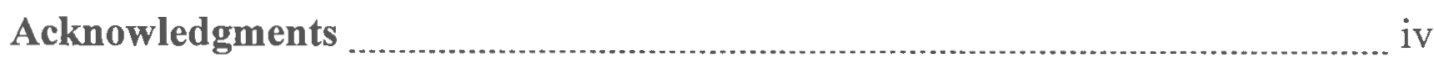

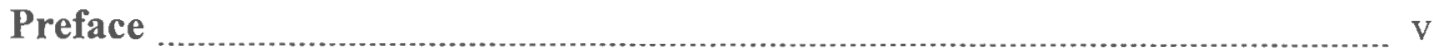

Table of Contents

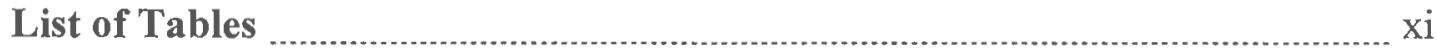

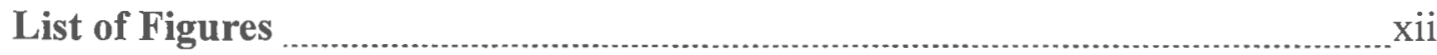

Chapter 1: Introduction …………………………………........................... 1



Chapter 2: Integrating Theories of Sociopersonal Well-Being,

Optimal Functioning, and Quality of Life:

The Ontology, Epistemology, and Methodology .......................... 6

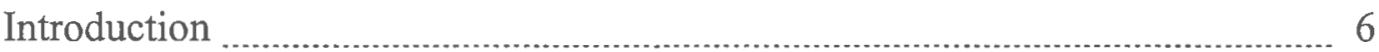

The Context of Happiness, Quality of Life, and Well-Being …......................... 7

Overview of Systematic Philosophical Inquiry .................................................. 11

Relationships between Realism, Relativism, Objectivism, and Subjectivism ......14

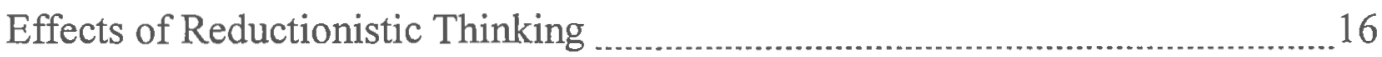

Parallelism and Congruence among Theories of Happiness and Well-Being _....... 17

Implied Congruence and Teleological Pragmatism ……….................................22

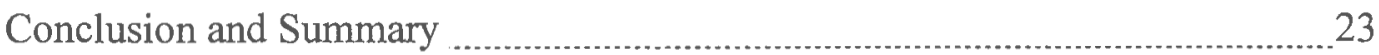

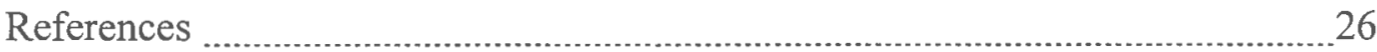

Glossary of Major Terms

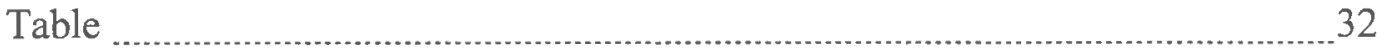


Figure

Appendix: Overview and Comparison of Social Behavioristic,

Phenomenological, and Teleologically Pragmatic

Theories Related to the Study of Quality of Life and

Well-Being

Chapter 3: A Mediational Coping Model of

Sociopersonal Well-Being and Quality of Life 38

Introduction 38

Overriding Theoretical Framework

Marco and Micro Theoretical Frameworks

Concepts Related to Sociopersonal Well-Being,

Optimal Functioning, and Quality of Life

Cognition and Affect 48

Cognitive Processing 49

Quality of Life and Well-Being 50

Life Satisfaction, Direction, and Purpose

Research Goals

Method 55

Participants 55

Design and Procedures

Materials and Measures

Demographics

Temporal Satisfaction with Life 57

Concern and Importance Areas 
Existential Well-Being 58

Stress, Coping, and Physical Symptoms of Stress 59

Level of Negative Cognitive Processing 60

Counseling and Mental Health Issues 60

Depression and Anxiety 60

Sociopersonal Well-Being 61

Procedure 61

Results 62

Exploratory Analysis 62

Inferential Gender Analysis 66

Confirmatory Analysis 67

Structural Equation Modeling 68

Full Stress and Coping Model with an Additional Direct Path from Stress to Well-Being 69

Nested Models: Mediated Coping Only,

Stress Only, and Coping Only Models 70

Mediated coping nested model 70

Stress only nested model 71

Coping only nested model 71

Multiple Sample Analysis 72

Post Hoc Latent Variable Modeling 72 
Discussion

Limitations

References

Tables

Figures

Chapter 4: General Discussion

Limitations 114

Appendix

Bibliography 
2-1 Some Major Research Areas from Previous Work Related to

Sociopersonal Well-Being, Quality of Life, and Optimal Functioning

3-1 Comparison of the Overall Concern and Importance Area

Rankings from Three Independent Samples

3-2 Demographics by Overall and Gender

3-3 Component Loadings (C), Alpha ( $\alpha$ ), and Percents of Total

Variance for Principal Components Extraction using Direct

Oblimin (Oblique) Rotation on 35 Variables Related to Past

Satisfaction with Life (SWL), Current SWL, Future SWL,

Religious Well-Being (RWB), Perceived Coping, Perceived

Psychological Stress, and Depression

3-4 Component Loadings (C) and Alpha ( $\alpha$ ) for Principal Components

Extraction on Variables Related to Anxiety, Existential Well-Being

(EWB), Negative Cognitive Processing, Physical Symptoms of

Stress, and Mental/Physical Health and Esteem (MPH)

3-5 Correlations between the Major Composite Variables from the

Total Set of Composite Measures including: Past Satisfaction

with Life (SWL), Current SWL, Future SWL, Religious

Well-Being (RWB), Perceived Coping, Perceived Psychological

Stress, Depression, Anxiety, Existential Well-Being (EWB),

Negative Cognitive Processing, Physical Stress Symptoms, and

Mental/Physical Health and Esteem

3-6 Component Loadings (C), Alpha ( $\alpha$ ), and Percents of Total

Variance for Principal Components Extraction Using Direct

Oblimin (Oblique) Rotation on 10 Composite Variables

Related to Stress, Coping/Negative Cognitive Processing, and

Sociopersonal Well-Being and Quality of Life

3-7 Means, Standard Deviations, and Adjusted and Nonadjusted

Significance of the 10 Composite Variables by Gender 100

3-8 Summary and Results of Confirmatory Factor Analysis and

Structural Equation Modeling including Nested Models and

Chi Square Difference Tests 


\section{List of Figures}

2-1 Suggested Levels in the Analysis of Quality of Life and

Well-Being

3-1 Standard Parameters for 3 Correlated Components Related to

Stress, Coping/Negative Cognitive Processing, and Sociopersonal

Well-Being and Quality of Life

3-2 Simple Hypothesized Mediational Coping Model of

Sociopersonal Well-Being and Quality of Life

3-3 Standardized Parameter Values for the Full Model

$(\underline{\mathrm{N}}=400,200$ men and 200 women)

3-4 Standardized Parameter Values for the Mediational Coping

(direct path from stress to quality of life $=0$ ) Nested Model

$(\underline{N}=400,200$ men and 200 women)

3-5 Standardized Parameter Values for the Stress Only (coping

paths $=0)$ Nested Model $(\underline{\mathrm{N}}=400,200$ men and 200 women $)$ 106

3-6 Standardized Parameter Values for the Coping Only (paths

from stress to quality of life and stress to coping $=0$ ) Nested

Model $(\underline{N}=400,200$ men and 200 women)

3-7 Standardized Parameter Values for the Final Full Model

for Men $(\underline{\mathrm{N}}=200)$

3-8 Standardized Parameter Values for the Final Full Model

for Women $(\underline{N}=200)$

3-9 Standardized Parameter Values for the Full Coping/

Negative Cognitive Processing Model for Men $(\underline{N}=200)$

3-10 Standardized Parameter Values for the Full Coping/

Negative Cognitive Processing Model for Women $(\underline{N}=200)$ 


\section{Chapter 1}

Introduction

Research specifically on sociopersonal well-being, satisfaction, and quality of life has been rapidly growing in popularity since the 1980 's; the January 2000 volume of the American Psychologist was entirely devoted to happiness, excellence, and optimal human functioning. Many studies have assessed satisfaction with life in relation to domains such as physical and mental health, financial and economic issues, social and personal relationships, esteem and self-worth, work and career issues, inter- and intrapersonal support, and cross-cultural (national and international) correlates of life satisfaction (e.g., Argyle, 1999; Diener, 2000; Diener \& Diener, 1995; Diener \& Suh, 1997; Diener, Suh, Lucas, \& Smith, 1999; Kahneman, Diener, \& Schwarz; 1999; Meyers, 2000; Pavot, Diener, \& Suh, 1998; Pavot \& Diener, 1993, Valliant, 2000; Veenhoven, 1991, 1994, \& 1995).

Although comprehensive in scope, many of the aforementioned studies stress the need for further research into the design, formulation, and development of relational assessment models in order to help determine large-scale patterns and associations among variables that influence sociopersonal satisfaction, quality of life, and well-being (Kahneman et al., 1999; Seligman \& Csikszentmihalyi, 2000). Specifically, scant information exists related to coping-related mediational models that link satisfaction and well-being, and relationships between sets of quality of life measures (e.g., Diener, 2000; Diener \& Diener, 1995; Diener et al., 1999; Disch, Harlow, Campbell, \& Dougan, in 
press; Kahneman et al., 1999; Pavot et al., 1998; Pavot \& Diener, 1993; Ryff, 1989; Waterman, 1993).

Another growing body of literature has focused on variables related to relationships among stress, coping, and overall well-being and satisfaction with life (e.g., Argyle, 1999; Cantor \& Sanderson, 1999; Csikszentmihalyi \& Larson, 1984; Fava, Ruggiero, \& Grimley, 1998; Lazarus, 1966; Lazarus \& Folkman, 1984; Lucas \& Diener, 1999; Seligman \& Csikszentmihalyi, 2000). Constructs associated with stress and coping include behavioral, cognitive, physiological, psychopathological, and psychological components that are all part of theoretical frameworks warranting consideration when attempting to create systematic and parsimonious models of stress, coping, and wellbeing (e.g., Ayers, Sandler, West, \& Roosa, 1996; Ensel \& Lin, 1991; Kahneman et al., 1999; Sandler, Wolchick, MacKinnon, Ayers, \& Roosa, 1997).

In college students, well-being and satisfaction at the individual and personal level have been well-studied in terms of relationships to optimal academic and non-academic performance, as well as specific and overall sociopersonal functioning (e.g., Bartling, 1988; Britton \& Tesser, 1991; Disch et al., in press; Disch, Dougan, Shapiro, \& Nolan, 1999; Douglas et al., 1997; Illovsky, 1997; Maney, 1990; Schmeck, Geissler-Brenstein, \& Cercy, 1991; Solomon \& Rothblum, 1984). These studies have also included many variables that are related to increases and decreases in, and which variables and variable sets hinder, as well as benefit and maximize academic and personal functioning and performance. Common threads throughout the aforementioned literature are associations among stress and coping, student satisfaction, well-being, and quality of life. 
A related collection of research has looked specifically at the needs and concerns of young people related to personal satisfaction and well-being (e.g., Disch et al., in press; Disch et al., 1999; Disch \& Olick, 1998; Harlow \& Newcomb, 1990; Menzies \& Boak, 1994; Myers \& Diener, 1995; Staats, Armstrong-Stassen, \& Partilo, 1995). Several of these studies point to variables that affect young people on both short-term and long-term dimensions. For example, preoccupation with issues such as stress, alcohol use, and depression are related to lower subjective levels of well-being and less optimism towards the future (Disch et al., in press). Conversely, higher levels of satisfaction and well-being, along with lower levels of psychological and physical concerns, are related to greater optimism about the future and increased quality of life (e.g., Disch et al., in press; Staats et al., 1995).

\section{$\underline{\text { Research Goals }}$}

The purpose of this study is to assess college students using a variety of measures related to sociopersonal well-being and quality of life. The primary goal is to create predictive and mediational models that will optimally reflect the complex multivariate relationships between these constructs, and show that the variables and constructs related to coping are mediators of quality of life and sociopersonal well-being (Ayers et al., 1996; Diener et al., 1999; Disch et al., in press; Kahneman et al., 1999; Sandler et al., 1997). The mediational models will support social learning based theories and the associations with humanistic oriented optimal person functioning. The ultimate goal, or teleological purpose, is to produce mediational models that reflect an optimal "snapshot" of sociopersonal well-being and quality of life in young people, with coping and related constructs as the primary mediators. 
The goals of this study are to answer the following questions:

(1) In the exploratory phase using several measures of quality of life and well-being, can it be determined that coping mediates, and is predictive of sociopersonal wellbeing and quality of life? In the confirmatory phase, if coping is a primary mediator, is it possible to explore multivariate relationships in a manner that can theoretically and realistically produce a mediational model or models that best reflect "optimal functioning" related to quality of life and well-being in young people?

(2) Are there differences between men and women, and levels of stress and coping related to quality of life and well-being?

It is hypothesized that important significant relationships will emerge from the analyses and that the results will lead to a mediational coping model of overall sociopersonal well-being and quality of life. For example, those participants who rate themselves as coping well with stress will show greater overall well-being and predictive quality of life scores.

The final goal of the study is to use the results to continue to work on the psychometric properties of the family of Quality of Life and Satisfaction (QOLAS) instruments including the SQOLAS (students) and the A-QOLAS (athletes), (Disch et al., in press; Disch et al., 1999), especially related to the creation of models in order to best fit theoretical constructs related to optimal human functioning, quality of life, and wellbeing. Modifications to the instrument will be suggested in order to improve the reliability, validity, and other psychometric properties. The result will be a quality of life and satisfaction instrument that can assess, predict, and parsimoniously describe and 
explain optimal functioning related to sociopersonal well-being and quality of life across an array of heterogeneous groups in the future. 


\section{Chapter 2}

Integrating Theories of Sociopersonal Well-Being, Optimal Functioning, and Quality of Life: The Ontology, Epistemology, and Methodology

Throughout history, one of the major pursuits of philosophers and pseudophilosophers has been to explain, describe, predict, and control a plethora of ideas, entities, and practices related to optimal human functioning. Optimal human functioning can include happiness, subjective well-being, sociopersonal satisfaction, flow, peak experience, positive affect, eudaimonia, hedonism, spiritual well-being, positive illusions, and many other ideas, concepts, and theoretical frameworks (e.g., Argyle, 1999; Csikszentmihalyi, 1999; Diener, 1984; Disch, Harlow, Campbell, \& Dougan, in press; Ellison, 1983; Meyers \& Diener, 1995; Ryff, 1989; Seligman \& Csikszentmihalyi, 2000; Taylor \& Brown, 1988; Waterman, 1993).

From the soothsayer to the rigid logical positivist, happiness, quality of life, wellbeing, spirituality, and the good life have all been actively studied, contemplated, marketed, and somewhat elusively pursued (e.g., Csikszentmihalyi, 1999; Kahneman, Diener, \& Schwarz, 1999; Markus, 1998a, 1998b; Messick, 1998; Meyers \& Diener, 1995; Seligman \& Csikszentmihalyi, 2000). See Table 2-1. Organized religion, cults, and theological and philosophical groups have posited several theories and paradigms related to happiness and optimal functioning. The science and study of these various belief systems, including their epistemological and ontological explanations and descriptions, have produced debates going back to the earliest recorded history (Guba, 1990; Hwang, 1996; Markus, 1998a; Messick, 1998; Tashakkori \& Teddlie, 1998). Throughout the 
dynamic evolution of the various optimal human functioning movements, the epistemological and ontological arguments and debates have remained constant.

This paper explains and describes some of the major current ideologies comprising optimal functioning and well-being theories and paradigms. The suggestions of Kahneman et al. (1999) are presented including a multi-level and multidisciplinary approach for the assessment and study of quality of life and well-being. See Figure 2-1. In terms of congruence, which is the logical integration of underlying assumptions of theory, philosophy, and methodology (Miller \& Burbank, 1994), most of the humanistic and social learning oriented theories and conceptual frameworks are sufficiently congruent, yet their broad paradigms are not.

In this paper, specific delay of gratification and behavioral specificity ideas from social learning theory (Mischel, 1968, 1979, 1993) and need motivation and goal-directed behavioral ideas from the humanistic perspective (Maslow, 1968, 1970, 1971) are presented as a theoretical starting point. Issues related to whether or not congruence is sufficient and necessary for theories and paradigms are discussed. In addition, it is argued that congruence is preferable and desirable on a theoretical level, but not necessary at the paradigmatic level. Finally, it is posited that a teleological (purposeful) and pragmatic approach be taken in the study of quality of life and well-being where the concepts and issues are salient for the particular context of interest.

\section{The Context of Happiness, Quality of Life, and Well-Being}

One of the most profound areas of interest within quality of life and well-being research is the study of happiness and those variables and constructs that relate to, and can thus predict happiness (Csikszentmihalyi, 1999). Along the scientific, philosophical, 
and explanatory continuum, there is materialism on one extreme and spirituality on the opposite end. The materialists claim that happiness is related to external conditions, whereas the spiritualists posit that mental attitude and "contents" offer sufficient explanations.

Happiness is a very broad domain that includes several related constructs and theoretical perspectives including subjective well-being, optimal functioning, life satisfaction, and sociopersonal well-being (e.g., Diener, 1984; Diener \& Lucas, 1999; Disch et al., in press; Meyers, 1999; Meyers \& Diener, 1995; Ryff, 1989; Waterman, 1993). For example, in a study that assessed meaning and satisfaction in life in young people, Harlow and Newcomb (1990) found that one "meta-construct" comprised of several composite variables was sufficient for explaining and describing several facets of well-being in young people.

Similarly, happiness is defined as the transient and dynamic state of an individual when the positive internal and external components outweigh the negative (Diener, 1984; Veenhoven, 1988; Waterman, 1993); the terms well-being, sociopersonal satisfaction, optimal functioning, subjective well-being, and others can be collectively described as semantic derivatives of "happiness."

For the purposes of this paper, the aforementioned terms will be used interchangeably. The reason for doing this is to continually remind the reader that although the specific scope of many of the major and minor theories related to quality of life and well-being may be appear to be different, the overall notions and intentions, and perhaps even an overall "truth" (that can be relative or realistic, and subjective or objective - depending 
on the individual), is to convey that collectively, the components of each of the various theories tend to point to a "best fitting" model or description of happiness and well-being.

The goal of this paper is threefold. First, a brief overview of philosophical issues related to science and inquiry is presented. Guba (1990), Hwang (1996), and Tashakkori and Teddlie (1998) present guidelines for the systematic assessment of paradigms and theories, which involve breaking down the respective ontologies, epistemologies, and methodologies. Additionally, ideas related to congruence (logical integration of philosophy, theory, and method), according to Miller and Burbank (1994), Munhall (1982), and Tinkle and Beaton (1983) are discussed in relation to various theories and paradigms.

Second, several major and minor theories of well-being, happiness, and quality of life are presented and discussed in terms of their ontological, epistemological, and methodological components. A major theme used as a primary example is the relationship between materialism and happiness. Furthermore, many of the theories are described in terms of whether or not they are macro-level (sociologically and collectively oriented) or micro-level (personal and individual in scope). This is not to imply that there must be an "either/or" dichotomy related to subjective versus objective epistemology or real versus relative ontology, but simply to point out that various theoretical views may incorporate complex philosophical relationships.

For example, when Veenhoven (1988) and Michalos (1985) discuss macro-level dimensions of well-being and happiness, they focus on the social and cultural aspects of a collective "happiness" as opposed to delving into individual and personal aspects of wellbeing. The scope of their research is less psychological and more sociologically and 
economically focused with the teleological goal being policy change at the societal and governmental level.

Other researchers such as Argyle (1999), Meyers and Diener (1995), Waterman (1993), and Csikszentmihalyi (1999), focus almost exclusively on the micro-level theories and paradigms. This is to say that large-scale social policy is more or less removed from the discussion because of non-direct relevance, and the individual and personal aspects of happiness and well-being (e.g., esteem, affect, efficacy, physical and mental health) are the primary variables of interest.

The macro and micro theoretical elements do not necessarily compete, they are merely smaller parts of the larger quality of life and well-being "grand paradigm" that has become, in some circles, the "new" or "revised" area within psychology called "hedonic" or "positive" psychology (Kahneman et al., 1999; Seligman \& Csikszentmihalyi, 2000).

Third, the study of happiness, well-being, and sociopersonal satisfaction is summarized in terms of meaning and purpose. Ideas using teleological concepts (final cause and purpose) related to the study of human behavior (Rachlin, 1992), and pragmatism as a succinct philosophical approach related to purpose and meaning (Guba, 1990; Hwang, 1996; Tashakkori \& Teddlie, 1998) are discussed, as well as ideas concerning human values and science, and how they can relate to the investigation of happiness and well-being, especially related to predictability (Hempel 1998; Markus, 1998a, 1998b; Messick, 1998).

The theories and paradigms are briefly discussed in terms of congruence, and whether or not congruence is sufficient and necessary at the theoretical and paradigmatic levels (Miller \& Burbank, 1994; Munhall, 1982), and the relationship to scientific inquiry. 
Finally, suggestions are made regarding the current state of hedonic, positive, and happiness oriented psychology and the study of overall quality of life, happiness, and well-being on multiple levels (Kahneman et al., 1999; Parducci, 1995; Seligman \& Csikszentmihalyi, 2000), and what steps should be taken, especially related to the methodology, investigation, and validity issues related to generalization and dissemination.

\section{Overview of Systematic Philosophical Inquiry}

Most researchers believe that they come from a particular perspective and point of view that best provides the justification and set of values for their interests. This line of thinking is well-integrated and inherent within most of the theories of happiness, wellbeing, and sociopersonal satisfaction. Furthermore, coming from a particular "scope" corresponds with the explanations related to the systematic view of paradigms that are used to guide disciplined inquiry (Guba, 1990; Hwang, 1996; Miller \& Burbank, 1994; Tashakkori \& Teddlie, 1998). A systematic view is one that takes into account and tries to answer and address the ontological, epistemological, and methodological questions and issues at hand. Furthermore, a congruent view is one that attempts to logically link the philosophy, theory, and research methods. See the Glossary and Appendix at the end of this chapter for a brief structured overview of ontology, epistemology, methodology, and other philosophy of science related concepts.

According to Hwang (1996), ontology is the branch of metaphysics dealing with the nature of being, reality, or existence, and epistemology is the branch of philosophy concerned with the study or theory of the origin, nature, methods, and limits of knowledge. Guba (1990) describes ontology as the nature of "the knowable" or the nature 
of reality, and he describes epistemology as the nature of the relationship between the inquirer (the "knower") and what is known (or knowable). A realist ontology posits that a true reality exists that is determined by naturalistic laws and mechanisms, whereas a relativistic ontology implies that realities exist, but are individual or collective and strongly related to individual and social context and constructions.

Regarding epistemology, on one extreme there is the objectivistic view positing that the "knower" can be distant and value free when engaging in the act of inquiry. Conversely, there is the subjectivist view that implies that realities are simply the creation of the interaction between the inquirer and the inquired (Guba, 1990).

Returning to the study of happiness, the materialism versus spiritual dichotomy (Csikszentmihalyi, 1999) addresses the ontological and epistemological issues of whether or not a true reality or several realities exist in terms of well-being and quality of life. In other words, most of the theories and paradigms related to happiness and well-being directly or indirectly have a chosen or implied stand regarding whether or not happiness and well-being are relativistic (spiritual and subjective) or realistic (materialistic and objective). Some of the explanations are dichotomous in nature, and others impose more of a continuum.

According to Hempel (1998), Kahneman et al. (1999), Markus (1998a), and Seligman and Csikszentmihalyi (2000), relationships between the supposed opposing ontologies and epistemologies are more similar than different and can (and should) be employed in a complementary sense to better understand and integrate theories, paradigms, and basic and applied research practices with the teleological context of mutually beneficial understanding. They suggest and infer that multidisciplinary approaches to research and 
explanation be better integrated and pursued in order to have access to optimal information and conclusions.

An example of the benefits of the integration of multidisciplinary zeitgeists in psychology comes from research by Taylor and Brown (1988) and Atkinson (1977). It is argued that macro-level sociological norms are not congruent with micro-level individual research on the self, self-esteem, personal happiness, and expectations. Micro-level unrealistically high expectations of personal well-being, which are internalized as realist truth for many individuals, clash with the macro-level reality of another realist truth that subsumes all of the normal negative aspects of life such as financial woes, relationship problems, normal depression and sadness, death, old age, and common stress.

An example of non-congruence is what happens when individuals end up having intrapersonal clashes regarding how they should be, dictated by the unrealistic sociocultural expectations and erroneous norms, and what is normal, within the context of a normal individual experiencing a negative life event. Many people are under the assumption that if they are not feeling and "being" optimal, then something is wrong. In fact, normal human negative emotion and affect is often misinterpreted by many into something psychopathological (Taylor \& Brown, 1988).

Atkinson (1977) discusses the need for greater emphasis on basic research in order to bolster the foundation of our dynamic knowledge base and to influence social policy and social norms on a macro level. Social policy also includes the possibility of modifying unreal and inappropriate zeitgeists such as the extremely high ceiling of what is expected by many individuals related to their personal happiness and well-being (Csikszentmihalyi, 
1999; Kahneman et al., 1999; Kendler, 1999; Markus, 1998a; Messick, 1998; Taylor \& Brown, 1988).

\section{Relationships between Realism, Relativism, Objectivism, and Subjectivism}

Although Csikszentmihalyi (1999) writes mostly about his own ideas of subjective flow (the state of total involvement in an activity requiring complete concentration) to explain happiness and related research, he also emphasizes that flow is necessary, but not sufficient as a complete explanation for happiness and well-being. He is a good example of a consentual relativist that uses realist and somewhat objectivistic research methods, but who is also aware of the fact that his theory is adequate, yet incomplete in describing well-being and happiness. The theory of flow is congruent on a micro-theoretical level but is incomplete if used for explaining happiness and well-being on macro cultural and societal levels.

What is difficult for many researchers and theorists to accomplish is congruence related to the transition from realist and somewhat positivistic research methods and results, to the application and integration by individuals of research findings on a pragmatic and practical level, that also include personal meaning and purpose. For example, a crucial component within many studies and discussions of sociopersonal satisfaction and quality of life has to do with the relationship, or lack thereof, between materialism and happiness.

Specifically, depending on the context and research methods employed, studies have shown that on one hand there is little or no relationship between material rewards and happiness and sociopersonal satisfaction (Csikszentmihalyi, 1999; Diener, Horwitz, \& Emmons, 1985; Meyers, 1993; Michalos, 1985; Parducci, 1995). However, on the other 
hand, research shows that there is evidence for happiness to be somewhat contingent upon materialism, depending on the context (Diener, 1984; Maslow, 1968, 1971; Mischel, 1979, 1993; Stones \& Kozma, 1993; Taylor \& Brown, 1988).

Congruence begins to appear when materialistic and happiness aspects are studied within the context of satisfaction and well-being at the individual level. This does not imply that the ontology must be relativistic. Congruence occurs only when materialism is included within a larger context of the multivariate equation. What happens is that objective measures are thoughtfully used to test and measure, then explain how there is a realistic relationship between materialism and happiness within a multidimensional context. Of course, there is a relativistic and subjective component, but the thoughtful researcher can integrate a semblance of subjectivity into a more or less congruent realist research model.

Although materialistic rewards may only be indirectly correlated with happiness, the research indicates that social relationships with family and friends, stability, consistency of family and work issues, and having adequate time to pursue personal interests are some of the significant and direct indicators of well-being and quality of life (Harlow \& Newcomb, 1990; Meyers, 1993; Meyers \& Diener, 1995).

In other words, it is safe to say that when the sociopersonal needs of an individual are sufficiently met, only then can the materialistic rewards be regarded as significantly related to their satisfaction, well-being, and happiness (Maslow, 1968, 1971; Mischel, $1979,1993)$. Conversely, the opposite can also be true, in that it is assumed that if one claims to be personally satisfied and happy, then the sociopersonal needs have been met, at least by one's subjective assessment. Furthermore, another reason that materialistic 
reasons are not sufficient as direct predictors of happiness and well-being is that every person subjectively processes the meaning, weight, and significance of each materialistic piece of the puzzle (Diener, 1984; Meyers, 1993; Stones \& Kozma, 1993; Taylor \& Brown, 1988). Materialistic relationships to happiness and well-being are thus dependent upon individual cognitions, affect, and subjective interpretations.

The aforementioned explanations are congruent in that they were all tested within a realist and objectivist framework. Furthermore, the instruments employed have been developed within a thoughtful and congruent relativistic model where the subjective views of individuals were pooled in order to obtain optimal information that could be quantified within positivistic research models. Finally, it appears as if congruence is highly dependent upon sound research methods and the logical applications and generalizations of those research results (Markus, 1998a; Kendler, 1999).

\section{Effects of Reductionistic Thinking}

Related to the zeitgeist in current beliefs and thinking pertaining to happiness and well-being, Csikszentmihalyi (1999) points out that Americans and Westerners have become so materialistically reductionistic that consciously and unconsciously we now use the dollar as the common metric to evaluate our actions, thus leading to the erroneous conclusion that well-being and happiness are significantly related to material rewards. In other words, we are not congruent when it comes to integrating our subconscious materialistic focus with our internal and spiritual beliefs. This fundamental reductionistic error seems to throw a wrench into the cogs of congruence.

It is posited that there are two components to the materialistic happiness fallacy (Csikszentmihalyi, 1999). First, socioculturally there is an increasing disparity in wealth 
that makes even the reasonably affluent feel poor, and a lack of culturally acceptable alternative values for lifestyles that could accommodate for less related to dollar value. For example, many individuals feel that important aspects of life must somehow include spending money. Second, psychologically, we tend towards unrealistically high expectations in a materialistic sense and thus are not satisfied for long with less. The amount of time and energy spent on acquiring materialistic rewards creates a selffulfilling dilemma where we feel that since we worked so hard for the particular reward, we must attempt to be happy, which is more often than not, completely untrue. This is a very good example of non-congruence that supports the work of Atkinson (1977) and Taylor and Brown (1988).

If materialism is not the key to happiness, what is? As stated earlier, social relationships and spiritual and psychological health and satisfaction have been found to be the strongest significant predictors related to happiness (Myers \& Diener, 1995). The question then becomes: Is the idea of happiness, sociopersonal well-being, and quality of life a mental and relativistic phenomenon, a materialistic external phenomenon, or combinations of the two? In addition, another question asks: How much does it really matter to any particular individual, and is this more of a topic of discussion than an issue related to actual human behavior?

\section{Parallelism among Paradigms and Theories of Happiness and Well-Being}

Several current theories and paradigms have attempted to look at explaining and describing sociopersonal satisfaction and well-being. Most of the theories are quantitative and fit the realist perspective, however a few of the theories are qualitative in nature and offer quite feasible explanations and descriptions. A broad psychologically-based 
perspective will be used here to present, explain, and describe the epistemology, ontology, and methodology related to some of these theories.

There are several common threads weaving most of the theories together. These common links appear to be cognitive and mentalistic in nature, although this does not imply that behavioristic, observable, and external components are eliminated (Csikszentmihalyi, 1999). The cognitive components such as attributions, attitudes, and perceptual conditions are all related to what "alters" how materialistic and other rewards are perceived as and internalized related to sociopersonal well-being and happiness.

Rachlin (1992) discusses the idea of teleological behaviorism, which falls into the traditional behavioristic paradigm. A teleological or "telic" perspective involves concepts of meaning, purpose, and final cause related to behavior. Traditional behaviorism is a paradigm in psychology that consists of a broad set of parallel and competing theories. The paradigm itself is not congruent. This is mainly because of the radical behaviorist's discounting of any recognition of mentalism. However, most of the theories within the behaviorist paradigm appear to be congruent, including Rachlin's (1992) ideas regarding teleological behaviorism.

One of the main points Rachlin (1992) makes is that the idea of final cause (e.g., the overall purpose and meaning) of behavior or a set of behaviors is the ultimate goal. He goes on to explain how hedonism and the pursuit of happiness is more than likely the final cause goal of intentional behavior. From a traditional realist and congruent behavioral perspective where research findings are derived from positivistic and postpositivistic laboratory experiments, Rachlin and others (e.g., Silverstein, 1995; Hwang, 
1996; Tashakkori \& Teddlie, 1998) are able to explain sociopersonal well-being, quality of life, and other phenomena using very realistic and mechanistic methodology.

Conversely, out of the phenomenological and humanistic paradigm comes many of the psychologically based theories of happiness and well-being based upon or related to Maslow's ideas of goal-directed behavior, motivation, and optimal functioning (Corey, 1986; Maslow, 1968, 1970, 1971). The humanistic and phenomenological paradigm appears to lean towards congruency because throughout the entire paradigm there is a focus on the self. However, whether or not the paradigm is congruent or not is not as important as the congruence of the specific theories within the paradigm.

One of Maslow's major points was that the average person often does not tap into his or her optimal potential related to self-actualization (Maslow, 1968, 1970). Another significant focus of Maslow's ideas was the shift from focusing on the sick and unwell side of human nature to a new focus on those who are perceived to be doing well in order to better find out how and why they are doing well. Many of Maslow's ideas also parallel Frankl's $(1959,1978)$ work that partially focuses on why and how individuals contextualize similar situations into life-positive or life-negative experiences and outcomes, thus influencing their quality of life and well-being.

Maslow $(1968,1970)$ shifted from the traditional American psychological focus of hostility, aggression, neurosis, and immaturities (i.e., problem-based psychology that is still the norm in most clinical and counseling psychological theories) to studying love, creativity, joy, and peak experiences. His findings and suggestions posit that the optimally functioning person possesses the following characteristics: a capacity for tolerance, the welcoming of uncertainty in their lives, acceptance of self and others, spontaneity and 
creativity, a need for solitude and privacy, autonomy, a capacity for deep and meaningful interpersonal relationships, genuine caring for others, a sense of humor, an intrinsic sense of directedness, and an open and objective attitude toward life (Corey, 1986; Maslow, 1971).

The incorporation of Maslow's (1971) phenomenological and humanistic ideas operates within a subjective and relativistic theoretical scope where one's sense of being, reality, and sociopersonal satisfaction and well-being are created and maintained by one's motivation within one's subjective reality.

Additionally, related to looking at the well instead of the sick, and looking at solutionbased approaches to optimal functioning as opposed to problem-based approaches, are the ideas of Frankl (1978) who posited that negative events and personal suffering in one's life can be turned into a positive and not self-defeating experience, depending on the subjective stand one takes regarding the interpretation of the experiences.

Both Maslow (1971) and Frankl $(1959,1978)$ posit that sociopersonal satisfaction and well-being are relative to the individual. Although relativistic in their ontologies, and subjectivistic in the epistemologies, much of the work of Maslow, Frankl, and others (i.e., humanists, phenomenologists) has been transformed into quantifiable measures that are used by both contextual realists (realists who do not discount relativism) and consentual relativists (relativists who do not discount realism). For the most part, congruence does exist when the research, the researchers, and the generalizations are true, honest, genuine, and methodologically sound (Hwang, 1996; Kendler, 1999; Markus, 1998a, 1998b; Messick, 1998). 
Related to the mostly relativistic ontological aspects of Maslow and Frankl are Mischel's ideas if interactionism. According to Mischel (1968, 1971, 1993), who comes from the social-cognitive paradigm, well-being is related to the interaction between one's internal personality traits that are relatively stable, and external environmental demands such as states and situations. The social-behavioral or social-cognitive paradigm is similar to the behaviorist model in that there exists a large set of similar theories. Unlike the humanists, there is not a core such as self. Instead, social-behaviorists focus on one of two major areas: the relationship between behavior and cognition, or the relationship between behavior, observation, and the environment. Therefore, there is little congruence within the social-behaviorist paradigm.

Mischel (1993) states that some of the phenomenological components of human behavior, especially related to optimal person-functioning, can easily be integrated into a testable socio-cognitive behavioral framework for study. Mischel's (1993) ideas parallel, and are contextually congruent with Maslow's ideas of actualization in that an individual who is managing daily tasks and hassles will have a clearer view when making decisions in a delay of gratification sense. Delay of gratification, in this context, implies that one is able to control impulsivity and make better decisions related to which choices will most maximize overall quality of life, especially related to future gain.

For example, for most individuals, when making a decision about the future such as monetary investments, a pending move, and choosing a graduate school, the outcome is dependent upon current and past issues and problems that may or not be posing psychological and physical stress on the mind and body (Mischel, 1993). The level of subjective state-dependent stressors will dictate whether or not one needs to focus more 
on the basic needs, which will in turn be more or less distracting, thus the decision about the future may be clouded by the stressful task at hand.

\section{Implied Congruence and Teleological Pragmatism}

Is it possible to combine the best of the realist and relativist worlds and explain happiness and well-being by using congruent theories and sub-theories within the existing paradigms? The answer is, for the most part, yes.

First, by using a teleological approach of meaning and purpose (Rachlin, 1992, 1996) to assess behavioral outcome, a researcher can operate in a behavioristic paradigm using a fairly strict realist ontology, an objectivistic epistemology, and experimental and manipulative research methods. What Rachlin is saying is similar to Hempel (1998), Markus (1998a), and Messick (1998), in that although we cannot directly observe many of the components of a particular outcome, we can thoughtfully approximate them. Related to the study of happiness and well-being, this implies that a teleological final cause theory can be employed that is also congruent.

Additionally, congruence can be assumed when utilizing a combination of the humanistic aspects of Maslow's $(1968,1971)$ optimal functioning and the social behavioristic concepts of Mischel's (1993) state-specific behavioral choice contingencies. There will no doubt be some debate as to whether the semblance of congruence lies with the contextual realist (major with Mischel and minor with Maslow) perspective or the consentual relativist (major with Maslow and minor with Mischel) perspective, however, if philosophical, theoretical, and optimal methodological protocol are employed, congruence can be achieved. 
For example, within the contextual realist perspective, a framework can be utilized that employs a mostly realist ontology consisting of the sound quantification and measurement of subjective assessments concerning various states. In addition, an objectivist epistemology would also be used employing the same sound and careful application of the subjective and qualitative roots, and a methodology consisting mostly of self report measures and observational and situation-specific tasks.

\section{Conclusion and Summary}

What a fairly congruent collection of parallel theories of happiness, quality of life, and well-being lead up to are support for the ideas and suggestions posited by Kahneman et al. (1999) related to the assessment and study of these concepts within hedonistic and positive focused psychology. Their central theme posits that since there are so many mostly positive theories, sub-theories, and explanations for happiness and well-being, that the only way to properly conduct research is to attempt to integrate the optimal theories and methods.

Another important component to a collective assessment model of quality of life and well-being is the recognition that there are micro and macro levels that may or may not be compatible within the context of a particular study or methodology (Csikszentmihalyi, 1999; Kahneman et al., 1999, Kendler, 1999, Seligman \& Csikszentmihalyi, 2000). Furthermore, the use of thoughtful research methods and generalizations of findings, and the emphasis on being realistic in the limitations of what science can do and accomplish within a particular context (Hempel, 1998; Kendler, 1999; Markus, 1998a; Messick, 1998), make it possible to achieve logical congruence. 
Hempel (1998), Miller \& Burbank (1994), and Kendler (1999) explain that science can and should be used to objectively study issues so that the results can ultimately influence the morals and values espoused by individuals and groups. The statements can be generalized to the study of happiness and well-being, and quite possibly even address the issues mentioned by Taylor and Brown (1988) regarding unrealistic expectations and the non-congruence between some of the research findings and what is deemed socially acceptable behavior, including affect, thoughts, and feelings.

Furthermore, Hempel (1998) mentions that empirical evidence can be used to modify and assign values to prior knowledge and beliefs and suggests that what science needs to keep in mind is the idea of relative ultimates. Relative ultimates, or norms, are findings that are believed to be truth, but that are open to modification, and we need these relative ultimates in order for science to progress.

Finally, if happiness and well-being are viewed as relative ultimates that are open to modification, then sound scientific inquiry can be used to assign value judgments to belief systems (e.g., happiness, well-being, quality of life), and thus control, or at least provide some realistic guidelines as to what might be valued by some regarding what happiness and well-being mean and consist of (e.g., Kendler, 1999; Markus, 1998a).

At this point, realistic happiness and well-being appear to be much more within reach. Thoughtful and sound research leads to better access to the realistic conceptions of individual well-being and happiness and opens the door to the idea that if one employs a congruent set of parallel theories, then the ontological, epistemological, and methodological differences lead not to debate, but to an optimal and comprehensive set of beliefs and practices. 
Perhaps, reading between the lines, this is the ultimate teleological goal of the positive and hedonistic psychological movements. 


\section{References}

Argyle, M. (1999). Causes and correlates of happiness. In D. Kahneman, E. Diener, and N. Schwarz (Eds.), Well-being: The foundations of hedonic psychology (pp. 353373). New York, NY: Russell Sage Foundation.

Atkinson, R. C. (1977). Reflections on psychology's past and concerns about its future. American Psychologist, 32, 205-210.

Corey, G. (1986). Theory and practice of counseling and psychotherapy $\left(3^{\text {rd }} \mathrm{ed}.\right)$. Pacific Grove, CA: Brooks/Cole.

Csikszentmihalyi, M. (1999). If we are so rich, why aren't we happy? American Psychologist, 54(10), 821-827.

Diener, E. (1984). Subjective well-being. Psychological Bulletin, 95(3), 542-575.

Diener, E., Horwitz, J., \& Emmons, R. A. (1985). Happiness of the very wealthy. Social Indicators, 16, 263-274.

Diener, E., \& Lucas, R. E. (1999). Personality and subjective well-being. In D. Kahneman, E. Diener, and N. Schwarz (Eds.), Well-being: The foundations of hedonic psychology (pp. 213-229). New York, NY: Russell Sage Foundation.

Disch, W. B., Harlow, L. L., Campbell, J. T, \& Dougan, T. R. (in press). Student functioning, concerns, and sociopersonal well-being. Social Indicators Research.

Ellison, C. W. (1983). Spiritual well-being: Conceptualization and measurement. Journal of Psychology and Theology, 11(4), 330-340.

Frankl, V. (1978). The unheard cry for meaning. New York, NY: Simon \& Schuster (Touchstone). 
Guba, E. G. (1990). (Ed.). The paradigm dialog. Newberry Park, CA: Sage.

Harlow, L. L., \& Newcomb, M. D. (1990). Towards a general hierarchal model of meaning and satisfaction in life. Multivariate Behavioral Research, 25(3), 387-405.

Hempel, C. G. (1998). Science and human values. In E. D. Klemke, R. Hollinger, D. W. Rudge, \& D. A. Kline (Eds.), Introductory readings in the philosophy of science $\left(3^{\text {rd }}\right.$ ed., pp. 499-514). Amherst, NY: Prometheus.

Hwang, A. (1996). Positivist and constructivist persuasions in instructional development. Instructional Science, 24, 343-356.

Kahneman, D., Diener, E. \& Schwarz, N. (1999). (Eds.). Well-being: The foundations of hedonic psychology. New York, NY: Russell Sage Foundation.

Kendler, H. H. (1999). The role of value in the world of psychology. American Psychologist, 54(10), 828-835.

Markus, K. A. (1998a). Science, measurement, and validity: Is completion of Samuel Messick's synthesis possible? Social Indicators Research, 45, 7-34.

Markus, K. A. (1998b). Validity, facts, and values sans closure: Reply to Messick,

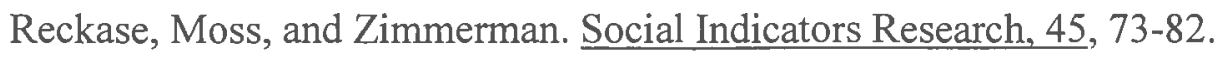

Maslow, A. (1968). Toward a psychology of being (rev. ed.). New York, NY: Van Nostrand.

Maslow, A. (1970). Motivation and personality (rev. ed.). New York, NY: Harper \& Row.

Maslow, A. (1971). The farther reaches of human nature. New York, NY: Viking.

Messick, S. (1998). Test validity: A matter of consequence. Social Indicators

Research, 45, 35-44. 
Michalos, A. C. (1985). Multiple discrepancy theory (MDT). Social Indicators Research, 16, 347-413.

Miller, J. R., \& Burbank, P. M. (1994). Congruence among philosophy, theory, and method in nursing research. In Workgroup of European Nurse Researchers, The contribution of nursing research: past, present, future, Vol. II. Proceedings at the $7^{\text {th }}$ Biennial Conference, Oslo, Norway: Falch Hurtigtrykk (pp. 704-709).

Mischel, W. (1968). Personality and assessment. New York, NY: Wiley.

Mischel, W. (1979). On the interface of personality and cognition: Beyond the personsituation debate. American Psychologist, 34, 740-754.

Mischel, W. (1993). Introduction to personality $\left(5^{\text {th }}\right.$ ed.). Fort Worth, TX: Harcourt, Brace, Jovanovich.

Munhall, P. L. (1982). Nursing philosophy and nursing research: In apposition or opposition? Nursing Research, 31(3), 176-177, 181.

Myers, D. G. (1993). The pursuit of happiness. New York, NY: Avon.

Myers, D. G. (1999). Close relationships and quality of life. In D. Kahneman, E. Diener, and N. Schwarz (Eds.), Well-being: The foundations of hedonic psychology (pp. 374-391). New York, NY: Russell Sage Foundation.

Myers, D. G., \& Diener, E. (1995). Who is happy? Psychological Science, 6, 10-19.

Parducci, A. (1995). Happiness, pleasure, and judgment. Mahwah, NJ: Erlbaum.

Rachlin, H. (1992). Teleological behaviorism. American Psychologist, 47, 1371-1382.

Rachlin, H. (1996). Can we leave cognition to cognitive psychologists? Comments on an article by George Lowenstein. Organizational Behavior and Human Decision Processes, 65(3), 296-299. 
Ryff, C. (1989). Happiness is everything, or is it? Explorations on the meaning of psychological well-being. Journal of Personality and Social Psychology, 57(6), 10691081.

Seligman, M. P., \& Csikszentmihalyi, M. (2000). Positive psychology: An introduction. American Psychologist, 55, 5-14.

Silverstein, A. (1995). Teleological behaviorism and internal control of behavior. Behavior and Brain Sciences, 18, 142-143.

Stones, M. J., \& Kozma, A. (1993). The relationships of affect intensity to happiness. Social Indicators Research, 31, 159-173.

Tashakkori, A., \& Teddlie, C. (1998). Mixed methodology: Combining qualitative and quantitative approaches. Thousand Oaks, CA: Sage.

Taylor, S. E., \& Brown, J. D. (1988). Illusion and well-being: A social psychological perspective on mental health. Psychological Bulletin, 103(2), 193-210.

Tinkle, M. B., \& Beaton, J. L. (1983). Toward a new view of science: Implications for nursing research. Advances in Nursing Science, 5(2), 27-36.

Veenhoven, R. (1988). The utility of happiness. Social Indicators Research, 20, 333354.

Waterman, A. S. (1993). Two conceptions of happiness: Contrast of personal expressiveness (eudaimonia) and hedonic enjoyment. Journal of Personality and Social Psychology, 64(4), 678-691. 


\section{Glossary of Major Terms}

Epistemology: The study or theory of the origin, nature, methods, and limits of knowledge. A branch of philosophy that investigates the origin, methods, nature, and limits of human knowledge and the conditions for acquiring it, especially concerning its methods and validation.

Ontology: The branch of metaphysics dealing with the nature of being or reality (i.e., phenomenology); the study of the nature of existence or being, as distinct from material existence, spiritual existence, etc.

Pragmatism: A doctrine about meaning and a theory about truth. The succinct focus on what effects have practical bearings on the issue at hand. Can include both realist and relative ontologies and objective and subjective epistemologies. Values exist and are important in conclusive processes. Explanations are chosen based upon desired outcomes. Causal relationships exist but may never be known.

Realism: A doctrine that universals have objective reality, as opposed to nominalism. The doctrine that material objects exist in themselves, apart from the mind's consciousness of them, as opposed to idealism. The doctrine that universals have a real objective existence. Objects of sense perception have an existence independent of the act of perception. The doctrine that universals or abstract concepts have an objective existence.

Relativism: The theory of ethics or knowledge which maintains that the basis of a judgment is relative, differing according to events, persons, etc; existence only in relation to a thinking mind. The theory that all knowledge is relative to the mind, or that things can be known only through their effects on the mind, and that consequently there can be 
no knowledge of reality as it is in itself. Any theory holding that criteria of judgment are relative, varying with individuals and their environments. The belief that knowledge is relative, not absolute.

Teleology: The explanation of phenomena by the purpose they serve rather than by postulated causes. The doctrine of design and purpose in the material world. The study of final causes. The fact or quality of being directed toward a definite end or of having an ultimate purpose, especially as attributed to natural processes. A belief, as that of vitalism, that natural phenomena are determined not only by mechanical causes but also by an overall design or purpose in nature, as opposed to mechanism. 
Table 2-1

Some Major Research Areas from Previous Work Related to Sociopersonal Well-Being, Quality of Life, and Optimal Functioning

Research/Interest Area Significant Researcher(s)/Author(s)

Adaptive Mental Mechanisms Valliant

Autonomy/Self Determination

Deci \& Ryan, Schwarz

Delay of Gratification/Behavioral Specificity

Mischel

Dispositional Optimism

Scheier \& Carver

Illusions

Taylor

Ego Resiliency

Block \& Block

Eudaimonia/Personal Expressiveness

Waterman

Excellence and Virtue

Baltes \& Staudinger

Flow

Csikszentmihalyi

Happiness \& Utility

Myers \& Veenhoven

Hedonics

Kahneman, Diener, \& Schwarz

Learned Optimism

Seligman

Objective Happiness

Kahneman

Personality Integration

Seeman

Positive Emotionality

Diener

Religious Well-Being

Ellison, Myers

Self Actualization/Peak Experiences

Maslow

Sociocultural Well-Being and Satisfaction

Michalos, Veenhoven

Spiritual Well-Being

Ellison, Moberg, \& Frankl

Teleology/Teleological Behaviorism

Rachlin

Note. As proposed by Kahneman, Diener, and Schwarz (1999), an optimal model for the study of wellbeing and quality of life contains a complete spectrum of life's elements from basic physiological components at the neuronal level, to national, institutional, cultural, and social and economic components at the global level. 
Figure 2-1

Suggested Levels in the Analysis of Quality of Life and Well-Being




Appendix

Overview and Comparison of Social Behavioristic, Phenomenological, and Teleologically Pragmatic

Theories Related to the Study of Quality of Life and Well-Being

\begin{tabular}{|c|c|c|c|}
\hline $\begin{array}{l}\text { Underlying } \\
\text { Assumptions } \\
\text { Related to } \\
\text { Quality of } \\
\text { Life (QOL) } \\
\text { and Well- } \\
\text { Being (WB) }\end{array}$ & $\begin{array}{l}\text { Mischel: } \\
\text { Social Behaviorism } \\
\text { Social Learning } \\
\text { Social Cognition }\end{array}$ & $\begin{array}{l}\text { Maslow: } \\
\text { Phenomenological } \\
\text { Humanistic } \\
\text { Existentialism }\end{array}$ & $\begin{array}{l}\text { Pragmatic Teleology: } \\
\text { Teleological Behaviorism } \\
\text { Ultimate Purpose/Goals }\end{array}$ \\
\hline $\begin{array}{l}\text { Base units of } \\
\text { behavior }\end{array}$ & $\begin{array}{l}\text { Behavior in the } \\
\text { situation/context. } \\
\text { Which behaviors, } \\
\text { situations, and contexts } \\
\text { are most and least } \\
\text { associated with WB and } \\
\text { QOL? }\end{array}$ & $\begin{array}{l}\text { Self-experience, personal } \\
\text { constructs and self- } \\
\text { concepts. } \\
\text { Subjective feeling and } \\
\text { perceptions; attributions. } \\
\text { How can one best } \\
\text { collectively quantify } \\
\text { subjectivity related to } \\
\text { overall QOL and WB? }\end{array}$ & $\begin{array}{l}\text { Situation and context } \\
\text { specific behaviors, } \\
\text { operationally defined, but } \\
\text { dependent upon the goals } \\
\text { of the observation and/or } \\
\text { self-report related to } \\
\text { practical application of } \\
\text { the particular behavior(s) } \\
\text { of interest. } \\
\text { What is the } \\
\text { point/purpose? Which } \\
\text { aspects of WB and QOL } \\
\text { are practically significant } \\
\text { related to the behavior(s) } \\
\text { of interest? }\end{array}$ \\
\hline $\begin{array}{l}\text { Determinants } \\
\text { of behavior }\end{array}$ & $\begin{array}{l}\text { Prior learning, } \\
\text { expectations, and cues in } \\
\text { situation and context } \\
\text { (including behavior of } \\
\text { others). Reciprocal } \\
\text { influence of } \\
\text { personal/cognitive } \\
\text { behavior, and } \\
\text { environment. }\end{array}$ & $\begin{array}{l}\text { Self-concepts and } \\
\text { underlying feelings and } \\
\text { conflicts; attributions, and } \\
\text { expectations. } \\
\text { Free (not mechanistic or } \\
\text { predetermined) choices; } \\
\text { what one "makes of } \\
\text { oneself." }\end{array}$ & $\begin{array}{l}\text { Sometimes not important } \\
\text { or relevant. } \\
\text { If important, dependent } \\
\text { on the goal and purpose of } \\
\text { the particular behavior or } \\
\text { behaviors, and goals of } \\
\text { the inquiry. }\end{array}$ \\
\hline $\begin{array}{l}\text { Favored data } \\
\text { and/or data } \\
\text { source }\end{array}$ & $\begin{array}{l}\text { Direct observation of } \\
\text { behavior in target } \\
\text { situations, experiments, } \\
\text { and questionnaires. }\end{array}$ & $\begin{array}{l}\text { Self-disclosure and } \\
\text { personal constructs (about } \\
\text { self and others), self- } \\
\text { reports. }\end{array}$ & $\begin{array}{l}\text { Whatever is deemed } \\
\text { relevant to the particular } \\
\text { research question. Can } \\
\text { include quantitative } \\
\text { and/or qualitative } \\
\text { measures and } \\
\text { experimental and/or non- } \\
\text { experimental inquiry, } \\
\text { dependent upon the } \\
\text { purpose of the outcome. }\end{array}$ \\
\hline
\end{tabular}


Appendix (cont.)

$\underline{\text { Overview and Comparison of Social Behavioristic, Phenomenological, and Teleologically Pragmatic }}$

Theories Related to the Study of Quality of Life and Well-Being

\begin{tabular}{|c|c|c|c|}
\hline $\begin{array}{l}\text { Underlying } \\
\text { Assumptions } \\
\text { Related to } \\
\text { Quality of } \\
\text { Life (QOL) } \\
\text { and Well- } \\
\text { Being (WB) }\end{array}$ & $\begin{array}{l}\text { Mischel: } \\
\text { Social Behaviorism } \\
\text { Social Learning } \\
\text { Social Cognition }\end{array}$ & $\begin{array}{l}\text { Maslow: } \\
\text { Phenomenological } \\
\text { Humanistic } \\
\text { Existentialism }\end{array}$ & $\begin{array}{l}\text { Pragmatic Teleology: } \\
\text { Teleological Behaviorism } \\
\text { Ultimate Purpose/Goals }\end{array}$ \\
\hline $\begin{array}{l}\text { Research } \\
\text { focus }\end{array}$ & $\begin{array}{l}\text { Behavior change; analysis } \\
\text { of conditions controlling } \\
\text { behavior; self-control. } \\
\text { Which of these are } \\
\text { most/least associated with } \\
\text { QOL and WB? }\end{array}$ & $\begin{array}{l}\text { Self-concepts; self- } \\
\text { awareness and expression. } \\
\text { Human potential and self- } \\
\text { actualization; emotion and } \\
\text { attribution. } \\
\text { Which of the available } \\
\text { components can be } \\
\text { quantified, measured, and } \\
\text { associated with QOL and } \\
\text { WB? }\end{array}$ & $\begin{array}{l}\text { Practicality. Do the } \\
\text { research results postulate } \\
\text { anything that "sufficiently } \\
\text { explain" thoughts and } \\
\text { behaviors related to QOL } \\
\text { and WB? If yes, validity } \\
\text { is increased. If no, it } \\
\text { probably was not } \\
\text { sufficiently important } \\
\text { and/or related in the first } \\
\text { place. } \\
\text { Is there a more practical } \\
\text { way to conduct the } \\
\text { research? }\end{array}$ \\
\hline $\begin{array}{l}\text { Approach to } \\
\text { change }\end{array}$ & $\begin{array}{l}\text { Change conditions and } \\
\text { experiences, modify } \\
\text { expectations and values, } \\
\text { and alter self-reactions } \\
\text { and self-efficacy. } \\
\text { Goal is (usually) to } \\
\text { increase QOL and WB. }\end{array}$ & $\begin{array}{l}\text { Increase awareness, } \\
\text { personal honesty, internal } \\
\text { consistency, and self- } \\
\text { acceptance. } \\
\text { Goal is (usually) to } \\
\text { increase QOL and WB. }\end{array}$ & $\begin{array}{l}\text { Change anything deemed } \\
\text { to be sufficiently related } \\
\text { to QOL and WB, and do } \\
\text { not spend time on issues } \\
\text { that are not meaningful } \\
\text { and purposeful to the } \\
\text { practical goal. }\end{array}$ \\
\hline $\begin{array}{l}\text { Role of } \\
\text { situation/ } \\
\text { context }\end{array}$ & $\begin{array}{l}\text { Provides important } \\
\text { information. } \\
\text { Interacts reciprocally with } \\
\text { individual. }\end{array}$ & $\begin{array}{l}\text { As the context for } \\
\text { experience and choice; } \\
\text { focus on situation as } \\
\text { perceived. }\end{array}$ & $\begin{array}{l}\text { Useful if there is a } \\
\text { practical reason to do so. }\end{array}$ \\
\hline
\end{tabular}


Appendix (cont.)

Overview and Comparison of Social Behavioristic, Phenomenological, and Teleologically Pragmatic

Theories Related to the Study of Quality of Life and Well-Being

\begin{tabular}{|c|c|c|c|}
\hline $\begin{array}{l}\text { Underlying } \\
\text { Assumptions } \\
\text { Related to } \\
\text { Quality of } \\
\text { Life (QOL) } \\
\text { and Well- } \\
\text { Being (WB) }\end{array}$ & $\begin{array}{l}\text { Mischel: } \\
\text { Social Behaviorism } \\
\text { Social Learning } \\
\text { Social Cognition }\end{array}$ & $\begin{array}{l}\text { Maslow: } \\
\text { Phenomenological } \\
\text { Humanistic } \\
\text { Existentialism }\end{array}$ & $\begin{array}{l}\text { Pragmatic Teleology: } \\
\text { Teleological Behaviorism } \\
\text { Ultimate Purpose/Goals }\end{array}$ \\
\hline $\begin{array}{l}\text { Ontology } \\
\text { What is the } \\
\text { nature of } \\
\text { knowing? } \\
\text { What is the } \\
\text { nature of } \\
\text { reality? }\end{array}$ & $\begin{array}{l}\text { Realist. } \\
\text { Consists of positivists } \\
\text { (radical behaviorists), } \\
\text { post-positivists (social } \\
\text { behaviorists), and a } \\
\text { smattering of consentual } \\
\text { relativists (subjective } \\
\text { state-dependent } \\
\text { behaviorists). } \\
\text { In the context of WB and } \\
\text { QOL, measurement and } \\
\text { quantification posit that } \\
\text { there is an "ultimate" WB } \\
\text { and QOL that can be used } \\
\text { as a benchmark. }\end{array}$ & $\begin{array}{l}\text { Realist. } \\
\text { Many would believe they } \\
\text { are consentual relativists } \\
\text { because of the subjective } \\
\text { aspect, but there is still a } \\
\text { "general" albeit unknown } \\
\text { truth because of the use of } \\
\text { measurement and } \\
\text { quantification. } \\
\text { Consists mostly of post- } \\
\text { positivists and consentual } \\
\text { relativists (can perform } \\
\text { quantifiable research } \\
\text { within a subjectivistic } \\
\text { relativistic paradigm), but } \\
\text { the "bulk" of the } \\
\text { inferences lean toward a } \\
\text { "universal and grand" idea } \\
\text { of QOL and WB. }\end{array}$ & $\begin{array}{l}\text { The reality or "truth" does } \\
\text { really matter. All that } \\
\text { matters is the postulate of } \\
\text { the task at hand based on } \\
\text { the meaning and purpose } \\
\text { of the activity within the } \\
\text { context of a particular } \\
\text { study, } \\
\text { What is the practical } \\
\text { purpose of knowing and is } \\
\text { it relevant? }\end{array}$ \\
\hline $\begin{array}{l}\text { Epistemology } \\
\text { What is the } \\
\text { relationship } \\
\text { between the } \\
\text { knower and } \\
\text { the knowable? }\end{array}$ & $\begin{array}{l}\text { Mostly objectivists, some } \\
\text { dualists, and modified } \\
\text { objectivists. }\end{array}$ & $\begin{array}{l}\text { Mostly modified } \\
\text { objectivists and some } \\
\text { "quantified subjectivists" } \\
\text { (self-report is the norm). }\end{array}$ & $\begin{array}{l}\text { Not important unless } \\
\text { objectivity versus } \\
\text { subjectivity is somehow } \\
\text { practically significant } \\
\text { related to the task at hand. }\end{array}$ \\
\hline
\end{tabular}


Appendix (cont.)

Overview and Comparison of Social Behavioristic, Phenomenological, and Teleologically Pragmatic

Theories Related to the Study of Quality of Life and Well-Being

\begin{tabular}{|c|c|c|c|}
\hline $\begin{array}{l}\text { Underlying } \\
\text { Assumptions } \\
\text { Related to } \\
\text { Quality of } \\
\text { Life (QOL) } \\
\text { and Well- } \\
\text { Being (WB) }\end{array}$ & $\begin{array}{l}\text { Mischel: } \\
\text { Social Behaviorism } \\
\text { Social Learning } \\
\text { Social Cognition }\end{array}$ & $\begin{array}{l}\text { Maslow: } \\
\text { Phenomenological } \\
\text { Humanistic } \\
\text { Existentialism }\end{array}$ & $\begin{array}{l}\text { Pragmatic Teleology: } \\
\text { Teleological Behaviorism } \\
\text { Ultimate Purpose/Goals }\end{array}$ \\
\hline $\begin{array}{l}\text { Methodology } \\
\text { How should } \\
\text { the inquirer go } \\
\text { about finding } \\
\text { out } \\
\text { knowledge? }\end{array}$ & $\begin{array}{l}\text { Experimental, } \\
\text { manipulative, and } \\
\text { modified manipulative (to } \\
\text { account for cognitive } \\
\text { processes, observational } \\
\text { learning, etc.). }\end{array}$ & $\begin{array}{l}\text { Same as social } \\
\text { behaviorism but with much } \\
\text { more emphasis on the } \\
\text { "quantification" of } \\
\text { subjective components. }\end{array}$ & $\begin{array}{l}\text { Same as previous two, } \\
\text { although the underlying } \\
\text { assumption is that one } \\
\text { uses the most practical } \\
\text { methodology available } \\
\text { related to the "purpose" of } \\
\text { the study in the first place. }\end{array}$ \\
\hline $\begin{array}{l}\text { Congruent? } \\
\text { Ontology, } \\
\text { epistemology, } \\
\text { and } \\
\text { methodology } \\
\text { must be } \\
\text { interrelated in } \\
\text { order to be } \\
\text { linked }\end{array}$ & $\begin{array}{l}\text { No. } \\
\text { Most of social } \\
\text { behaviorism consists of } \\
\text { related but separate areas } \\
\text { of study within the context } \\
\text { of social behaviorism. } \\
\text { Contain "sets" of grand } \\
\text { and mid-level theories. }\end{array}$ & $\begin{array}{l}\text { No, but begins to } \\
\text { approximate congruence } \\
\text { because the "core" issues } \\
\text { with related theories and } \\
\text { concepts, all which involve } \\
\text { the "self" as the "primary" } \\
\text { area of interest. }\end{array}$ & $\begin{array}{l}\text { Not really important, } \\
\text { BUT congruence between } \\
\text { Mischel and Maslow } \\
\text { related to WB and QOL is } \\
\text { definitely possible in a } \\
\text { "practically relevant" } \\
\text { sense because only the } \\
\text { purposeful and } \\
\text { meaningful components } \\
\text { are being used for any } \\
\text { study and/or } \\
\text { interpretation. }\end{array}$ \\
\hline
\end{tabular}




\section{Chapter 3}

\section{A Mediational Coping Model of}

Sociopersonal Well-Being and Quality of Life

Research specifically on sociopersonal well-being, satisfaction, and quality of life has been rapidly growing in popularity since the 1980 's; the January 2000 volume of the American Psychologist was entirely devoted to happiness, excellence, and optimal human functioning. Many studies have assessed satisfaction with life in relation to domains such as physical and mental health, financial and economic issues, social and personal relationships, esteem and self-worth, work and career issues, inter- and intrapersonal support, and cross-cultural (national and international) correlates of life satisfaction (e.g., Argyle, 1999; Diener, 2000; Diener \& Diener, 1995; Diener \& Lucas, 1999; Kahneman, Diener, \& Schwarz; 1999; Meyers, 1999, 2000; Pavot, Diener, \& Suh, 1998; Pavot \& Diener, 1993; Valliant, 2000; Veenhoven, 1991, 1994, 1995).

Although comprehensive in scope, many of the aforementioned studies stress the need for further research into the design, formulation, and development of relational assessment models in order to help determine large-scale patterns and associations among variables that influence sociopersonal satisfaction, quality of life, and well-being (Kahneman et al., 1999; Seligman \& Csikszentmihalyi, 2000). Specifically, scant information exists related to coping-related mediational models that link satisfaction and well-being, and relationships between sets of quality of life measures (e.g., Diener, 2000; Diener \& Diener, 1995; Diener \& Lucas, 1999; Disch, Harlow, Campbell, \& Dougan, in 
press; Kahneman et al., 1999; Pavot et al., 1998; Pavot \& Diener, 1993; Ryff, 1989; Waterman, 1993).

Another growing body of literature has focused on variables related to relationships among stress, coping, and overall well-being and satisfaction with life (e.g., Argyle, 1999; Cantor \& Sanderson, 1999; Fava, Ruggiero, \& Grimley, 1998; Lazarus, 1966; Lazarus \& Folkman, 1984; Diener \& Lucas, 1999; Seligman \& Csikszentmihalyi, 2000). Constructs associated with stress and coping include behavioral, cognitive, physiological, psychopathological, and psychological components that are all part of theoretical frameworks warranting consideration when attempting to create systematic and parsimonious models of stress, coping, and well-being (e.g., Ayers, Sandler, West, \& Roosa, 1996; Ensel \& Lin, 1991; Kahneman et al., 1999; Sandler, Wolchick, MacKinnon, Ayers, \& Roosa, 1997).

In college students, well-being and satisfaction at the individual and personal level have been well-studied in terms of relationships to optimal academic and non-academic performance, as well as specific and overall sociopersonal functioning (e.g., Bartling, 1988; Britton \& Tesser, 1991; Disch et al., in press; Disch, Nolan, Shapiro, Dougan, \& Campbell, 1999; Douglas et al., 1997; Illovsky, 1997; Maney, 1990; Schmeck, GeisslerBrenstein, \& Cercy, 1991; Solomon \& Rothblum, 1984). These studies have also included many variables that are related to increases and decreases in, and which variables and variable sets hinder, as well as benefit and maximize academic and personal functioning and performance. Common threads throughout the aforementioned literature 
are associations among stress and coping with student satisfaction, well-being, and quality of life.

A related collection of research has looked specifically at needs and concerns of young people related to personal satisfaction and well-being (e.g., Disch et al., in press; Disch et al., 1999; Disch \& Olick, 1998; Harlow \& Newcomb, 1990; Menzies \& Boak, 1994; Myers \& Diener, 1995; Staats, Armstrong-Stassen, \& Partilo, 1995). Several of these studies point to variables that affect young people on both short-term and long-term dimensions. For example, preoccupation with issues such as stress, alcohol use, and depression are related to lower subjective levels of well-being and less optimism towards the future (Disch et al., in press). Conversely, higher levels of satisfaction and well-being, along with lower levels of psychological and physical concerns, are related to greater optimism about the future and increased quality of life (e.g., Disch et al., in press; Staats et al, 1995).

The purpose of the proposed study is to explore data collected from a college undergraduate student population using specific measures related to sociopersonal satisfaction, well-being, and quality of life in order to create an optimal mediational coping model that will best support the hypothesis that coping is the "buffer" or "filter" that links stress-related measures of quality of life and well-being. A secondary purpose is to confirm and propose, using latent variable model testing, that the utilization of complex multivariate mediational models is, in fact, a parsimonious and desirable research strategy to assess and present the relational nature among these broad constructs. 
Specifically, the first goal is to use exploratory analyses to assess individuals on their subjective ratings of sociopersonal well-being and satisfaction with life (including past, present, and future measures); religious and spiritual well-being; stress and coping perceptions and related physical symptoms; physical and mental health; esteem, affect, and a set of demographic variables.

The second goal is to use confirmatory analyses and latent variable model testing to assess relationships among the variables and constructs in order to create a multivariate mediational model showing that coping, and those variables and constructs related to coping, are sound and robust constructs that function as mediators between a variety of stressors that can help or hinder quality of life and measures of sociopersonal satisfaction and well-being. The ultimate goal, or teleological purpose, is to produce a mediational model that reflects an optimal snapshot of sociopersonal well-being and quality of life in young people with coping as the primary mediator.

As previously mentioned, research on sociopersonal satisfaction, quality of life, and well-being, has been rapidly growing in popularity since the 1980's. Much of this increase in activity and focus evolved from failures of the social well-being and health promotion movements from the 60's and 70's that were not able to grasp concepts that related tangible well-being to intangible quality of life including concepts such as spirituality (Bufford, Paloutzian, \& Ellison, 1991; Ellison, 1983). According to Csikszentmihalyi (1999) and Kahneman et al. (1999), there is much confusion and discrepancy as to best assess and measure the various aspects of quality of life and wellbeing. 
One of the major problem areas has been trying to include the more intangible measures such as religion, spirituality, and subjectivism. In addition, a void in the literature still exists related to sociopersonal well-being and quality of life variables that are most closely related to spirituality and religion, both in a definitional sense, and in practical and applied sense (e.g., Bufford et al., 1991; Csikszentmihalyi, 1999; Ellison, 1983; Meyers \& Diener, 1995; Moberg, 1979; Ross, 1995).

Another major area related to sociopersonal well-being and quality of life includes stress and coping, and there has been much recent attention in the literature given to the physiological symptoms (or lack thereof) related to satisfaction and well-being (e.g., Ayers et al., 1996; Clark et al., 1999; Disch \& Campbell, 1997; Ensel \& Lin, 1991; Fava et al., 1998; Folkman \& Lazarus, 1985; Kahneman et al., 1999; Lazarus, 1966; Lazarus \& Folkman, 1984; Sandler et al., 1997; Taylor \& Brown, 1988; Taylor et al., 2000). Within this framework, an individual will respond to stressors in ways that will affect his or her well-being, physical and mental health, and quality of life in either a positive or a negative manner. A key to successful managing of the stressors, and resulting impact on quality of life, has to do with appraisal of the stimuli and the resulting coping responses (Cohen, Kamarck, \& Marmelstein, 1983; Cohen, Kessler, \& Gordon, 1995; Lazarus \& Folkman, 1984; Selye, 1956).

A related collection of research has looked at the needs and concerns of young people related to personal satisfaction and well-being (Disch et al., in press; Disch \& Olick, 1998; Harlow \& Newcomb, 1990; Menzies \& Boak, 1994; Myers \& Diener, 1995; Staats et al., 1995). Many of these studies have had the common theme of attempting to best 
describe, establish relationships, and predict why young people, students in particular, perform and function the way they do, especially related to identification of which factors are most associated with stress, coping, and optimal functioning. For example, time management, stress, and prioritization of tasks (Britton \& Tesser, 1991), counseling and the addressing of negative coping skills (Illovsky, 1997; Solomon \& Rothblum; 1984), modification of learning styles (Bartling, 1988; Schmeck, Geissler-Brenstein, \& Cercy, 1991), and responsible use of alcohol and awareness of other high-risk behaviors (e.g., dealing with sociopersonal issues related to negative consequences from high-risk behaviors), (Disch et al., in press; Maney, 1990), are examples of the applications of tools which enhance optimal student functioning and performance.

Disch et al. (in press) and Disch et al. (1999) found that there were significant links between student concerns and needs regarding quality of life, and current student performance and functioning status. It was also found that concerns about the future (e.g., career, employment, and financial security issues) were significantly related to the current performance, functioning, and well-being of students. Moreover, the highest ranked items of concern and interest for these participants related to past and present counseling and mental health issues were stress, relationships, time management, physical health, and mental health (Disch et al., 1999; in press; Disch \& Campbell, 1997).

\section{Overriding Theoretical Framework}

Theoretically, links between functioning and performance-type variables and need and concern variables are addressed in Maslow's $(1968,1971)$ theory of goal-directed functioning (i.e., need motivation theory) and aspects social learning theory (i.e., 
behavioral specificity, context dependent behavioral choice, and delay of gratification), (Mischel, 1973, 1984, 1986). Goal directed behavior related to decision making and situation specific determinants of behavioral choice, through consequences, are directly related to quality of life, and help to create a framework into which personal, social, cognitive, and behavioral variables interact to form an overall model of satisfaction and well-being.

Mischel (1984) emphasizes that there is considerable overlap between several of the phenomenological theories of human functioning and the theories espoused by the cognitive behaviorists. Furthermore, a combination of performance and functioningrelated variables and need variables can dictate, and thus assist in predicting one's overall sense of well-being, life quality, and sense of happiness (e.g., Mischel, 1986; Myers, 1995; Staats et al., 1995).

According to Mischel $(1884,1986)$, self-perception variables (e.g., esteem, actualization, concept, self worth) can be predictors of behavioral outcome by way of delay of gratification (e.g., the relationship between esteem and being able to forego immediate gratification knowing the delayed rewards are potentially greater). The delay of gratification leads to more global related decision making in terms of quality of life and well-being. For example, an individual would not postpone applying to graduate school or a new position because of high self-regard, esteem, focus, and connectedness. In addition, the person would have the vision of tangible long-term goals concerning the enhancement of career, financial, educational, and personal goals, plus the learned 
behavioral pattern of future-directedness, related to consequences, which affects overall quality of life.

\section{Macro \& Micro Theoretical Frameworks}

For the purposes of this study, several competing and parallel theoretical models related to well-being and satisfaction are divided into two broad groups: the biological, psychological, and social models, and the macro-social models. See Table 2-1 (p. 32) at the end of Chapter 2 for an overview of some of the theoretical and conceptual areas (including researchers and authors) related to the study of quality of life and well-being.

The biological, psychological, and social theories include many variations of Selye's (1956) life stress paradigm (Ensel \& Lin, 1991). Although several parallel theories exist in this category, they all have in common fairly simple combinations of two and three primary interacting factors (e.g., social, psychological, and physical) where an individual's well-being is an outcome mediated by various forms of coping (e.g., Ayers et al., 1996; Ensel \& Lin, 1991; Sandler et al., 1997). For example, how daily hassles are handled on cognitive and behavioral levels (Folkman \& Lazarus, 1985), how role strain is dealt with on a functioning level (Pearlin, et al., 1981), and how appraisal results in motivational behavior (Skinner \& Wellborn, 1994), are variations in coping and wellbeing models. Although these theoretical models are well-defined, well-tested, and quite applicable, they fail to consider global variables. For example, they explain much about the individual but not the group or society as a whole. Another way of looking at this is through the moderator versus mediator view presented by Baron and Kenny (1986). In this case, stress can be conceptualized from a set of moderator components such as 
occupation, income, SES, psychological, and behavioral variables that influence the magnitude or direction of a predictor through a mediational "filter" such as coping (Clark et al., 1999). The criterion components in this example are sociopersonal well-being and quality of life.

The macro-social models consist primarily of moderator variables, are broader in scope then the aforementioned models, and include several social indicator variable sets such as economic well-being, income, socio-economic status, and various institutional measures including educational systems and quality, social welfare systems, health-care systems, and community support systems (Diener et al., 1999; Diener \& Lucas, 1999; Kahneman et al., 1999). Within these broad-based macro-models, there are many parallel theories related to overall quality of life and well-being.

One set of theories looks at quality of life and well-being from a purely sociological functioning standpoint (Diener et al., 1999; Kahneman et al., 1999). For example, Veenhoven (1995) describes three primary competing quality of life and well-being theories: 1) comparison theory, where current quality of life and well-being standards are weighted against ideal standards, 2) folklore theory, where quality of life and well-being are based upon societal majority notions related to the national character, and 3) liveability theory, where subjective appreciation of life depends upon objective quality of life; the better the living conditions in a country; the happier the inhabitants will be. These theoretical models, like the biological, psychological, and social theories, are welltested and documented but fail to take into account individual variables related to intrapersonal functioning and well-being. 
According to Argyle (1999), Diener and Lucas (1999), Diener et al. (1999), and Kahneman et al. (1999), sociopersonal well-being, happiness, and quality of life need to be assessed using more sophisticated multivariate methodologies, and be able to bridge the gaps between the macro-socio theoretical models and the more biological, psychological, and social individual-specific theories. See Figure 2-1 (p. 33) at the end of Chapter 2 for an overview of a suggested hierarchy of inquiry related to quality of life and well-being. Social indicators alone do not define nor predict quality of life (Csikszentmihalyi, 1999; Diener et al., 1999; Diener et al., 1995). Conversely, affect, esteem, behavior, and cognitions cannot predict quality of life when taken out of the larger macro-socio context (Diener et al., 1999).

In order to optimally describe, explain, and predict well-being and sociopersonal satisfaction, Diener et al. (1999) and Kahneman et al. (1999) advocate for: 1) greater emphasis on theories that stress psychological factors, especially dispositional influences, goals, adaptation, and coping strategies, 2) integration and comprehension of the interaction of psychological factors and life circumstances including social indicators, going beyond relational analyses, and 3) develop multivariate predictive pathways to happiness and well-being.

Concepts Related to Sociopersonal Well-Being, Optimal Functioning, and Quality of Life

The literature shows continued and consistent multivariate relationships between issues related to the personal self (e.g., esteem, perception, satisfaction, well-being), the social self (e.g., support, adjustment, relationships), and cognitions, affect, depression, 
and anxiety, resulting from problems concerning the personal and social self, including suicidality, (Diener, 2000; Diener \& Lucas, 1999; Kahneman et al., 1999; Meyers, 2000).

Cognition and Affect. Solomon and Rothblum (1984) identified fear of failure, task aversiveness, depression, irrational cognitions, low self-esteem, delayed study behavior, anxiety, and lack of assertion as having cognitive-behavioral relationships to academic procrastination, thus impacting overall academic performance and success. Students who employed cognitive strategies in assessing and dealing with negative-related functioning variables showed better use of time and increased objectivity, and thus were more successful both academically and personally. A major point of the study was to show the complex interaction of behavioral, cognitive, and affective components that determine how individuals approach task management as it relates to use of time and the resulting academic performance. Additionally, Illovsky (1997) found that students who received counseling-based study skills training had significant improvement in grades and in retention after the counseling sessions. Disch et al. (1999) found that as stress, negative affect, and inter- and intra-personal problems increase, measures of sociopersonal satisfaction and well-being significantly decrease. In addition, as the problematic measures increase, so does the desire to seek help and counseling. Finally, in a longitudinal study assessing trends in issues most related so sociopersonal satisfaction and well-being, stress and relationships are the most frequently noted response choices (Disch et al., 1999; Disch \& Campbell, 1997).

Specifically related to depression and anxiety, a growing body of literature suggests that issues associated with personal satisfaction, social support, alcohol consumption, and 
esteem are related to depression, suicidality, and affect in young people (DeMan \& Leduc, 1995; DeSimone, Murray, \& Lester, 1994; Disch \& Campbell, 1997).

In a study looking at a social and personal perfectionism model of suicidal behavior that is stress and esteem-related, depression was found to be the greatest predictor of suicidal ideation (Dean \& Range, 1996). Similarly, DeMan and Leduc (1995) found that depression and self-esteem were the most powerful predictors of suicidal behaviors. These were followed by stress, physical and mental health, anomie, social support, and alcohol consumption. In college students, Oswalt and Finkleberg (1995) found that relationships, social adjustment, and academic performance were all significantly related to depression.

Cognitive Processing. Based upon levels of cognitive processing theory (Craik \& Lockhart, 1972; Craig \& Tulving, 1975), it has been shown that as class year increases, levels of cognitive processing significantly increase (Bartling, 1988; Schmeck, 1983; Schmeck, Geisler-Brenstein, \& Cercy, 1991; Schmeck \& Grove, 1979). For example, when the typical college student enters as a Freshperson, their critical thinking skills and deep and elaborative cognitive processing are not as advanced as Seniors and Graduate Students. Levels of cognitive processing are as related to academic performance as they are to stress management, coping, task assessment, and decision making (Disch et al., in press; Janis \& Mann, 1977). On the lower end of the cognitive processing scale are methodical study and fact retention where students simply follow direction, process some information, and conform to the academic structure and basic requirements of a course. Elaborative processing and deep processing are on the higher end of the scale. These two 
levels involve greater use of metacognitive learning strategies and memory techniques, integration of new material with older material, and the personal translation of information into a state that makes it easier to understand and integrate. Deep cognitive processing, the highest of the levels, involves extensive use of critical thinking, conceptual organization, and the comparing and contrasting of information.

\section{Quality of Life and Well-Being}

Spirituality has traditionally been a generic term related to quality of life, life meaning, happiness, and well-being. The term has puzzled not only psychologists, but sociologists, anthropologists, those in the medical profession, and others as well. Almost all of the disciplines have made attempts at defining spirituality, but there has never been an agreed upon definition (Ross, 1995). Definitions of spirituality cross over several theoretical areas, relating spirituality to personal belief systems, personal well-being, meaning in life, existentialism, and religiousness and religiosity (e.g., Csikszentmihalyi, 1999; Ellison, 1983; Frankl, 1959, 1978; Hasse, Britt, Coward, \& Leidy, 1992; Moberg, 1979; Ross, 1995).

For example, Ross (1995) described spirituality as an endeavor to find meaning and purpose in life, whereas Hasse et al. (1992) determined that an outcome of spirituality is finding meaning in life. These two studies, and Moberg's (1979) findings, describe spirituality as a type of guide toward finding values. Ellison (1983) referred to the experience of well-being occurring after finding meaning in life, whereas Frankl (1959) discussed the importance of finding meaning in each particular experience. 
Additionally, Myers and Diener (1995) and Meyers (1999) found that people with a strong faith in some type of personal belief system were able to retain higher levels of happiness and well-being, even when faced with a serious illness. Frankl $(1959,1978)$ felt that humans possess the ability to decide what they will become spiritually. $\mathrm{He}$ further stressed meaning and purpose in life defined as an individual's attitude about his or her own personal experience.

Moberg (1979) saw the importance of life meaning and purpose of existence in his theoretical model of spiritual well-being (SWB). He found that people who possessed high levels of meaning in life, self-harmony, happiness, and positive treatment towards others also possessed high levels of SWB. Although his components of spiritual wellbeing involve both religious and psychosocial aspects, he emphasized that religion is not a synonym for SWB, and that SWB is a continuous and multifaceted construct rather than dichotomous in nature.

Life Satisfaction, Direction, and Purpose. According to Bufford et al. (1991) and Ellison (1983), prior research on spirituality, life satisfaction, and well-being failed to assess religious well-being and one's need for transcendence, namely, existential wellbeing. The Spiritual Well-Being Scale (Ellison, 1983) resulted in the filling of a void and reliably assessed religious well-being, as well as existential components, namely, physical and mental health, assertiveness, and psychological adjustment. Specifically, life satisfaction, direction, and purpose were assessed with an existentialism subscale and religious well-being was assessed with a religious subscale. It was shown that as overall 
and subscale scores increased, belief and commitment to one's view and conceptualization of meaning in life significantly increased.

Specifically related to young people and college students, several studies have shown various relationships between quality of life and well-being and a combination of personal, social, cognitive, and behavioral factors. Harlow and Newcomb (1990) showed that 7 positively influenced primary factors (purpose in life, perceived opportunity, health and work satisfaction, and peer, family, and intimate relationships), and two negatively influenced primary factors (powerlessness and meaninglessness) were all significant building blocks supporting a model of life meaning in young people.

Staats et al. (1995) found in two temporally separated samples of college students $(1984,1992)$, that even though self-esteem and social support remained as consistent predictors of well-being, several significant changes occurred over the 8 year period. They found that students in the 1992 sample had lower expectations of what they should have materially and where they should be with their career and education than those from the 1984 sample. They also found that expectations and optimism about the future were lower in the 1992 sample. Additionally, they found relationships between declining health and recreation oriented activities from the 1992 sample and concluded that more emphasis on time use and a general shift in economic resources (e.g., increased competition compounded by less available time in order to acquire resources) were two of the primary associated factors. Finally, they found lower overall levels of subjective wellbeing in the 1992 sample over the 1984 sample. 
It is important to study quality of life and well-being in a global, multivariate framework that includes the more tangible issues such as what one chooses to do related to the environment, and the more intangible issues such as how one thinks and feels as opposed to studying univariate and bivariate models (Carney \& Savitz, 1980; Gallagher et al. 1992; Staats et al., 1995). By looking at larger sets of related variables (e.g., Disch et al., in press; Harlow \& Newcomb, 1990; Staats et al., 1995), it is thus possible to link theoretical constructs relating quality of life, sociopersonal satisfaction, and well-being to existing social and behavioral theories, thereby allowing for greater insight into this area of optimal functioning potential (Seligman \& Csikszentmihalyi, 2000; Kahneman et al., 1999; Staats et al., 1995).

\section{$\underline{\text { Research Goals }}$}

The purpose of the proposed study is to assess college students using a variety of measures related to sociopersonal well-being, and quality of life. The primary goal is to create predictive and mediational model that will reflect the complex multivariate relationships between these constructs and show that variables and constructs related to coping are strong mediators of sociopersonal well-being and quality of life (Ayers et al., 1996; Diener et al., 1999; Disch et al., in press; Sandler et al., 1997). The mediational model will support social learning-based theories (Mischel, 1973, 1986), humanistic theories (Maslow, 1968, 1971), and the associations with optimal person-functioning, sociopersonal well-being, and quality of life.

The goals of this study are to answer the following questions: 
(1) In an exploratory phase using several measures of satisfaction with life and wellbeing, can it be determined that coping mediates, and is predictive of sociopersonal well-being and quality of life? In a confirmatory phase, if coping is a primary mediator, is it possible to explore multivariate relationships in a manner that theoretically and realistically produces a mediation model or models that best reflect "optimal functioning" related to quality of life and well-being in young people?

(2) Are there differences, if any, between men and women, and levels of stress and coping related to quality of life and well-being?

It is hypothesized that important significant relationships will emerge from the analyses and that the results will lead to a mediational coping model of overall sociopersonal well-being and quality of life in young people. For example, participants who rate themselves as coping well with stress will show greater overall well-being and predictive satisfaction scores.

The final goal of the study is to use the results to continue to work on the psychometric properties of the Student Quality of Life and Satisfaction (SQOLAS), (Disch et al., in press; Disch et al., 1999) instrument, especially related to the creation of models in order to best fit theoretical constructs related to greater human functioning, quality of life, and well-being. Modifications to the SQOLAS survey will be suggested in order to improve the reliability, validity, and overall psychometric properties of the instrument (Cronbach, 1951; Cronbach \& Meehl, 1955). The result will be a quality of life and satisfaction instrument that can assess, predict, and parsimoniously describe and 
explain optimal functioning related to sociopersonal well-being and quality of life in young people. Suggestions will be made regarding use of the instrument for use across an array of heterogeneous groups.

\section{Method}

\section{$\underline{\text { Participants }}$}

Participants consisted of 720 University of Rhode Island undergraduate students who completed and returned the Student Quality of Life and Satisfaction Survey (SQOLAS). The data to be analyzed were collected during the spring of 1999 . The current study is a simultaneous and secondary analyses of a larger, IRB approved, SQOLAS study that included all of the measures used in the current analyses (Disch et al., 1999; Disch \& Campbell, 1999). Participants were randomly selected from the entire University of Rhode Island undergraduate population. The major goals related to sampling were to ensure the broadest age, class, ethnicity, and student status/work status participant pool possible. This increases generalizability and external validity of the findings by using a more heterogeneous sample in the analyses (Berkowitz \& Donnerstein, 1982; Graham, 1992; Tabachnick \& Fidell, 1996).

\section{Design and Procedures}

Initially, 1,350 surveys were administered to a stratified random sample of selected required general education courses, each containing 100 or more students. Students represented the entire university population and included all major and academic categories. It was crucial for the study that all majors and not merely social science majors were assessed in order to reduce participant bias. Surveyed course areas included 
animal and veterinary science, biology, business, chemistry, economics, food science and nutrition, nursing, philosophy, political science, psychology, sociology, and zoology.

Approximately 765 surveys were completed and returned, resulting in an initial response rate of $57 \%$. After careful screening of the surveys for a less-than $75 \%$ completion ratio, random responding, and other dubious issues, 720 surveys remain for analyses, thus, the final return rate was $53 \%$. See the attached SQOLAS Survey (the final Appendix) for the complete set of instructions and informed consent. Incentives included $\$ 100$ cash or gift certificate prizes. Winners were determined by a random drawing. Twenty percent $(\underline{n}=144)$ of the participants received extra course credit from instructors as incentive for filling out the survey

Human subjects approval from the Institutional Review Board was previously received in March 1999. The first page of the survey consisted of the instructions and an informed consent. Procedures were followed and the ethical guidelines were met in accordance with the recommendations by the American Psychological Association (1992). Finally, of utmost importance, was the anonymity and confidentiality of participants. No names or identifying information were used, as it was not necessary for the purposes of the study.

\section{Materials and Measures}

The SQOLAS instrument is a collection of assessments arranged in the following order/sections: demographic information; temporal satisfaction with life; concern and importance areas; existential well-being; stress and coping; negative cognitive processing; counseling and mental health; religious well-being; and physical symptoms of stress. Not 
all parts of the survey were used for this study. Those measures relevant to the current study are delineated below. All of the items are included in the main Appendix.

Demographics. The SQOLAS survey obtained extensive demographic information. Demographic variables collected were: age, gender, class year, work status, work hours, living status, college major and minor, current subjective GPA, overall subjective GPA (all college), number of current credits, average number of credits taken, academic program status, ownership of car and computer, average percent of textbooks sold back at the end of a semester, ethnicity, relationship status, and a note about quality of life concerns. A single item assessed academic program status and standing and read: "In my academic program, I am..." Response choices were "far behind," "behind," “on track," "ahead," or "far ahead in my academic program." Participants circled one of the 5 choices, with higher scores indicating greater academic progress.

Temporal Satisfaction with Life. The Temporal Satisfaction with Life Scale (TSWL, Pavot et al., 1998) is a 15-item Likert-scaled instrument that is a temporal extension of the original 5-item Satisfaction with Life Scale (SWLS, Diener et al., 1985) that assesses global life satisfaction. The original SWLS assesses life satisfaction in the present domain, while the TSWL slightly modifies the wording of the 5 "present tense items" so that 5 additional items assess past satisfaction with life and 5 additional items assess future projections of satisfaction with life. Higher scores indicate more positive indications of past, current, and future satisfaction with life. Test-retest coefficients were .83 ( 4 weeks), .88 (5 weeks), and .82 ( 9 weeks). The TSWL was moderately to strongly correlated with several measures of well-being, positive affect, and negative affect. 
Additionally, the overall 15-item TWL mean scores correlated between .74, for older adults, and .85 for college-age adults, with the original 5-item SWLS composite score. Coefficient alpha was .91 for the overall measure, and between .82 and .87 for the three temporal subscales of past, present, and future. Finally, the TSWL showed good convergent, divergent, and construct validity, as well as strong stability and reliability in relation to the temporal dimensions (Pavot et al., 1998; Pavot \& Diener, 1993).

Concern and Importance Areas. Concern and importance areas are covered extensively in Disch et al. (in press), and Disch and Olick (1998). They are briefly included here to highlight the hierarchy of concern and importance areas in young people. It was found that across three studies using different survey techniques (mail, $\underline{\mathrm{N}}=467$; small group with high response, $\underline{N}=100$; large group with moderate response, $\underline{N}=720$ ), the hierarchical rankings of concern and importance areas were almost identical. See Table 31. The highest ranked and most important items were related to future career issues, physical health, mental health, use of time and academic issues. The lowest ranked and least important items were drug use, sexual orientation, alcohol use crime and violence concerns. In addition, no social desirability effects were found (Disch \& Olick, 1998).

Existential Well-Being. The Spiritual Well-Being Scale (SWBS), according to the author (Ellison, 1983), avoids specific definitions of well-being in order to get at a much more broad and general overview of self-reported well-beingness. The SWBS results in two subscales: existential well-being (EWB) and religious well-being (RWB), which combine to yield an overall spiritual well-being score. Higher scores indicate higher levels of EWB and RWB. The EWB subscale assesses life meaning and purpose and 
attitude concerning future direction in life. The RWB subscale assesses religious belief and practice. Test-retest reliability has been found to be .86 , Cronbach's alpha was .78 , and support for good divergent, construct, and convergent validity have been found (Bufford et al., 1991; Paloutzian \& Ellison, 1982). For the purposes of this study, only the EWB subscale was used because of reported ceiling and floor effects found with the RWB scale (Bufford et al., 1991). However, a new RWB subscale was adapted from the original items with the hope of reducing response bias that was deemed problematic with many groups (Disch et al., 1999; Ellison, 1983).

Stress, Coping, and Physical Symptoms of Stress. The Rhode Island Stress and Coping Inventory (RISCI; Fava, et al., 1998) is a 10-item Likert scaled measure that assesses perceived stress and coping. Five of the items assess stress and 5 of the items assess coping. Coefficient alphas were .85 for the stress subscale and .87 for the coping subscale. Higher scores on the stress subscale indicate higher perceived stress in one's life. Higher coping scores indicate higher or better coping. The authors report correlations of .63 for stress, and -.67 for coping, with the 5-item Mental Health Inventory (MHI-5; Stewart, Hays, \& Ware, 1988), an inventory that includes at least one item from each of the 4 mental health domains of anxiety, depression, loss of behavioral/emotional control, and psychological well-being.

Physical symptoms of stress are measured using 10 physical self-evaluative items related to the most common physical complaints (Disch, Fava, \& Sarkin, 2000). The Rhode Island Physical Symptoms Inventory (RIPSI) is a new instrument. Each of the 10 items (e.g., headaches, general aches and pains, insomnia, stomach problems and nausea, 
irritability) are rated by the frequency of occurrence, and by the relative level of discomfort related to each symptom. A multiplicative composite is computed for each symptom, then the composites are summed to get the overall physical symptoms score.

Level of Negative Cognitive Processing. This construct is measured using one of several cognitive processing subscales from the Learning Styles Inventory (LSI), (Schmeck, 1983). The SQOLAS study used only a short version of the deep processing subscale that consisted of 10 five-point Likert-scaled items $(1=$ never, $5=$ always $)$. Testretest reliability has been found to be .88 and Cronbach's alpha was .82 (Albaili, 1993; Schmeck \& Ribich, 1977). Higher scores indicate increased difficulty and trouble with cognitive processing.

\section{Counseling and Mental Health Issues.}

Depression and anxiety. For the purposes of the current study, the first 7 items from the Beck Depression Inventory - Short Form (BDI-SF) were used. These items have previously been found to be the "cognitive core" of Beck's cognitive perceptual model of depression (Beck \& Beck, 1972; Beck, Rial, \& Rickles, 1974). The BDI-SF was developed for ease of use in medical, hospital, and psychiatric settings where brief and accurate screening was required (Gould, 1982; Volk, Pace, \& Parchman, 1993). The 2factor theoretical interpretation of the BDI-SF posits a somatic dimension and a nonsomatic dimension. Overall reliability coefficients range from .76 to .87 and correlation coefficients with the standard BDI range from .89 to .97 (Gould, 1982; Volk et al., 1993). The instrument also shows good validity and reliability with several other well-known 
measures of depression, loneliness, and self-esteem. Higher scores indicate higher levels of depressive symptoms.

Concerning anxiety, 7 items were adapted from a national college student anxiety screening tool (American Psychiatric Press, 1988; Guardino, 1995). Although psychometric information related to reliability is not available, the authors and publisher tout the instrument as being convergently and divergently valid with depression and stress screening measures, including short and long forms of the BDI. Coefficient alpha will be calculated for these 7 items using the current data.

Sociopersonal well-being. These were 5 separate and single 5-point Likert-scaled items. They were new items and have yet to be psychometrically tested. Participants were asked to rate their level of support from friends, level of support from family, level of self-esteem and self-worth, level of mental/psychological health satisfaction, and level of physical/physiological health satisfaction. Response choices ranged from poor to excellent or from unsatisfied to very satisfied. Coefficient alpha will be calculated for these 5 items using the current data.

\section{Procedure}

Before the data were entered, all of the surveys were checked by two or three individuals who looked for dubious and other response patterns and issues. As stated earlier, survey data from 720 participants remained for the final analysis. The data were analyzed using SPSS (1999) statistical software package. The data were screened for assumption violations of normality, linearity, and homoscedasticity, as well as possible multicollinearity and singularity. No transformations were necessary. Missing data were 
handled using the median replacement technique and were minimal. Of the variables that had missing data (i.e., several of each of the variables from several measures had missing cells with no identifiable pattern that might have been psychometrically suspect), no variables had more than 2.7 percent of cells missing.

\section{Results}

Demographic information is presented Table 3-2. Breakdowns are by overall $(\underline{\mathrm{N}}=$ $720)$, and gender. There were 204 men (28\%) and 516 women (72\%) in the sample. Overall, the mean age was 20 years and $80 \%(\underline{n}=579)$ of participants were between 18 and 20 years old. There were 322 (45\%) Freshpersons, 205 (29\%) Sophomores, 144 Juniors $(20 \%)$, and $7 \%$ Seniors $(7 \%)$. Fifty-eight percent $(\underline{\underline{n}}=419)$ of participants lived on-campus, and $74(10 \%)$ were fraternity or sorority members. Only $2 \%(\underline{n}=16)$ indicated that they were not "single," and 698 (97\%) indicated that they were full-time students. Five-hundred participants (69\%) noted they were "on-track" or "ahead" in their academic programs, while 78 (32\%) indicated being "behind" academically. Thirty-seven participants (5\%) worked full-time, $410(57 \%)$ worked part-time, and 271 (38\%) noted that they did not work. Finally, the average amount of hours worked per week was 13 for Freshpersons, 16 for Sophomores, and 17 for Juniors and Seniors. See Table 3-2 for more specific demographic breakdowns.

\section{Exploratory Analysis}

Principal component extraction using direct oblimin (oblique) rotation was performed as an exploratory statistical procedure in order to maximize correlations between components and to examine the component structure of the various measures from the 
SQOLAS included in the study (Disch et al., in press; Gorsuch, 1983; Tabachnick \& Fidell, 1996). Because of the large number of variables and the fact that several of the constructs have been previously psychometrically validated related to structure, the principal components analyses were performed in two phases. The first phase analyzed variables from the two instruments containing multiple subscales (TSWL; past, current, and future satisfaction with life; RISCI, perceived psychological stress, perceived coping), the 6 depression items, and the 7 items from a new religious well-being scale. The second phase included the independent component analysis of each construct to validate whether or not the items made up a single construct. These subscales included anxiety, EWB, negative cognitive processing, physical symptoms of stress, and mental/physical health and esteem. See Tables 3-3 and 3-4 for components, component loadings, coefficient alphas, and item and subscale descriptions by overall and gender.

For phase one, a calibration random sample of 150 men and 150 women (300 total) was used. Seven interpretable components using 35 variables emerged for both men and women. Both the scree test and the Kaiser Rule (number of components with eigenvalues greater than one) were used to decide which components to retain, as well as empirical and theoretical considerations (Cattell, 1966; Gorsuch, 1983). The components that emerged were past satisfaction with life (SWL), current SWL, future SWL, coping, perceived psychological stress, depression, and religious well-being. Overall (men and women combined), the 7 components accounted for $66 \%$ of the variance. With only the men, $66 \%$ of the variance was also accounted for and with only the women, $68 \%$ of the variance was accounted for. Three items from within the overall validation sample of 300 
needed to be excluded because of multiple loadings (two from the religious set, and one from the future SWL set). The number of variables per component ranged from 4 to 6 . Using pattern loadings (Gorsuch, 1983; Tabachnick \& Fidell, 1996), a cutoff of the absolute value of .30 or higher was set for variables on their respective components. The lowest loading for any variable onto its component was .52 for overall (men and women combined), .30 for men, and .37 for women. See Table 3-3 for the rotated pattern component loadings, coefficient alpha $(\alpha)$, and percents of variance.

The second phase used the same calibration sample of 300 (150 men and 150 women) and consisted of using independent principal components extraction for each of the remaining constructs (i.e., anxiety, EWB, negative cognitive processing, physical symptoms of stress, and mental/physical health and esteem). See Table 3-4 for the unrotated component loadings and coefficient alpha $(\alpha)$. Correlations between components using all of the measures can be seen in Tables 3-5 and 3-6.

In addition, the EWB, negative cognitive processing, and anxiety subscales were retained as unique components primarily because they have been psychometrically validated previously (see description of measures section). The physical symptoms of stress items were new and are currently being assessed in a validation study (Disch et al., 2000). Preliminary results indicate that the 10 physical items all load onto one component and the multiplicative product of the frequency and the degree of the individual items produce a highly reliable overall construct of physical symptoms of stress that possesses excellent convergent and divergent properties. Finally, in an earlier analysis of the mental 
health variables, it was found that the three mental/physical health and esteem items loaded onto a unique construct, thus their inclusion in the analysis (Disch et al., 1999).

After reliability assessment, the variables from the 12 constructs were transformed into composite variables for use in confirmatory and mediational structural equation analysis. In all cases, the new composite variables were formulated by summing all of the items that loaded highly on each of the respective components. An additional principal components extraction was performed on the 12 new composite variables in order to test the hypothesis that three components would emerge: 1) stress, 2) coping, 3) sociopersonal well-being and quality of life. The validation sample employed a random selection of 400 participants (200 men and 200 women) in order to maximize the total $\underline{n}$ of male participants (204). Results indicated that religious well-being did not load onto any component and depression produced rather low and equal loadings across the three hypothesized components. These variables were eliminated and an additional analysis resulted in three components accounting for 65.7 percent of the variance. See Table 3-6.

Further analysis by gender indicated that three components emerged accounting for 64.4 percent of the variance for men, and 67.0 percent of the variance for women. For men, negative cognitive processing loaded approximately equally onto the stress component and the coping component. It was decided to retain negative cognitive processing for theoretical considerations crucial to part of the latent variable modeling hypothesis (that negative cognitive processing would be a necessary part of the coping process). It was also decided to retain negative cognitive processing because of the strong and consistent correlations with the stress, coping, and quality of life variables. 


\section{Inferential Gender Analyses}

A multivariate analysis of variance (MANOVA) was conducted on the 10 composite variables from the exploratory analysis to investigate possible gender differences. Results indicated that the F-test, associated with Wilks' Lambda $(\lambda=.82)$, was statistically significant, $\underline{\mathrm{F}}(10,389)=8.45, \mathrm{p}<.001$ indicating that at least one composite variable differed by gender. See table 3-7 for the means, standard deviations, and significance of the composite variables by adjusted and nonadjusted p-values by gender. Follow-up pairwise comparisons on each of the composite variable mean scores resulted in 7 significant gender differences. However, when adjusted for familywise error using a significance level of .005 (10 variables divided by $.05=.005$ or less for statistical significance), (Howell, 1992), only 5 significant differences remained. Women $(\underline{M}=$ $14.3, \underline{\mathrm{SD}}=3.3$ ) had significantly higher levels of perceived psychological stress than men $(\underline{\mathrm{M}}=12.9, \underline{\mathrm{SD}}=3.3), \underline{\mathrm{F}}(1,398)=18.0, \mathrm{p}<.001 ;$ women $(\underline{\mathrm{M}}=47.5, \underline{\mathrm{SD}}=35.2)$ had significantly higher levels of physical stress symptoms than men $(\underline{M}=30.2, \underline{\mathrm{SD}}=27.4)$, $\mathrm{F}(1,398)=29.9, \underline{\mathrm{p}}<.001$; women $(\underline{\mathrm{M}}=21.0, \underline{\mathrm{SD}}=7.0)$ had significantly lower levels of past satisfaction with life than men $(\underline{\mathrm{M}}=23.1, \underline{\mathrm{SD}}=7.1), \mathrm{F}(1,398)=9.1, \mathrm{p}=.003$; women $(\underline{\mathrm{M}}=22.8, \underline{\mathrm{SD}}=6.7)$ had significantly lower scores on current satisfaction with life than men $(\underline{\mathrm{M}}=25.0, \underline{\mathrm{SD}}=6.3), \underline{\mathrm{F}}(1,398)=11.5, \underline{\mathrm{p}}=.001$; and women $(\underline{\mathrm{M}}=10.7$, $\underline{\mathrm{SD}}=2.7)$ had significantly lower scores on mental/physical health and esteem than men $(\underline{\mathrm{M}}=12.0, \underline{\mathrm{SD}}=2.6), \underline{\mathrm{F}}(1,398)=24.4, \mathrm{p}<.001$; Gender differences on the composite variables related to anxiety, future satisfaction with life, existential well-being, perceived coping, and negative cognitive processing were not statistically significant. 


\section{Confirmatory Analysis}

Confirmatory analysis (CFA) using EQS v. 5.7a (Bentler, 1995; Bentler \& Wu, 1995), and AMOS v. 4.0 (Arbuckle \& Wothke, 1999) statistical programs were performed on the 10 composite variables and 3 components extracted from the exploratory analysis. Data from the validation sample of 400 (200 men, 200 women) were analyzed. Maximum likelihood estimation was utilized. The hypothesized confirmatory model was a 3-factor confirmatory model with stress, coping, and quality of life as the three factors. This model, as well as a single-factor model were analyzed in order to evaluate which model would best fit the data using criteria based upon theoretical and empirical fit and parsimony (Bentler, 1995; Burkholder \& Harlow, 1996; Byrne, 1995; Hoyle \& Panter, 1995; Hu \& Bentler, 1995; Tabachnick \& Fidell, 1996; Schnoll et al., 1998). The best fitting and final model was the 3-factor correlated model with all of the factors being correlated (stress, coping/negative cognitive processing, and sociopersonal well-being and quality of life).

See Figure 3-1 for the standardized parameter values for the 3-factor correlated model. Circles represent latent constructs and the rectangles represent the measured variables. All of the measured variable paths were statistically significant. Relationships among constructs indicated that as stress increases, coping/negative cognitive processing (-.65), and quality of life (-.62) significantly decrease. In addition, as coping and negative cognitive processing increase, quality of life significantly increases (.62).

Empirically, a good fitting model can be assessed using several criteria including: a chi-square to degrees of freedom ratio less than 5.0, a CFI value greater than .90, a 
standardized squared residual value less than 0.06 , significant hypothesized parameters, and a high degree of explained variance (Bentler, 1995; Burkholder \& Harlow, 1996; Hu \& Bentler, 1995; Schnoll et al., 1998; Tabachnick \& Fidell, 1996). For the current model, a good fit to the data was evidenced by a chi-square-to-degrees of freedom ratio of 3.79, a CFI value of .93, and a standardized root mean square residual (SRMR) of .05. All of the hypothesized parameters were statistically significant.

Although all of the hypothesized parameters were also statistically significant for the single-factor model, the chi-square-to-degrees of freedom ratio of 8.36 was poor, the CFI value of .81 revealed a poor fit, and the SRMR was .08 , indicating higher than optimal residual error.

\section{Structural Equation Modeling}

Latent variable structural modeling was performed using EQS v. 5.7a (Bentler, 1995; Bentler \& Wu, 1995), and AMOS v. 4.0 (Arbuckle \& Wothke, 1999) statistical programs. The 10 composite variables and 3 latent variables extracted from the exploratory analysis and confirmed with the CFA were included. Data from the sample of 400 (200 men, 200 women) were analyzed and maximum likelihood estimation was utilized. Univariate and multivariate assumptions were again performed and no adjustments were necessary (see opening of results section). None of the measured variables were problematically skewed or kurtotic.

Several competing models were analyzed in order to evaluate which model would best fit the data using criteria based upon theoretical and empirical fit and parsimony (Arbuckle \& Wothke, 1999; Bentler, 1995; Burkholder \& Harlow, 1996; Hoyle \& Panter, 
1995; Hu \& Bentler, Tabachnick \& Fidell, 1996; Schnoll et al., 1998). A hypothesized mediational coping model of well-being and quality of life is presented in Figure 3-2. The model posits a negative direct path from stress to coping (higher stress leading to lower coping) and a positive direct path from coping to well-being and quality of life (higher coping leading to higher quality of life and well-being).

In addition to the mediational model, a full model was tested with an additional direct path from stress to well-being and quality of life (see Figure 3-3). Three additional nested models were tested: a mediated coping only nested model with the direct path from stress to quality of life fixed at zero (see Figure 3-4), a nested stress only model with the paths from stress to coping and from coping to quality of life fixed at zero (see Figure 3-5), and a coping only model with the stress to coping and stress to quality of life paths set to zero (see Figure 3-6).

The latent variable of stress included 3 indicators (perceived psychological stress, physical symptoms, and anxiety), the latent variable of coping had two indicators (coping and negative cognitive processing), and the latent variable of sociopersonal well-being and quality of life included five indicators (past satisfaction with life $\{\mathrm{SWL}\}$, current SWL, future SWL, existential well-being, and mental/physical health and esteem). Circles represent the latent variables, rectangles represent the measured variables, and lines connecting variables represent direct effects.

Full stress and coping model with an additional direct path from stress to well-being.

The full model with the additional direct path from stress to well-being is presented in Figure 3-3. This model is identical to the aforementioned mediational coping model with 
an additional negative direct path added from stress to quality of life. The reasons for this are twofold. First, it is plausible that coping cannot filter all stress (Lazarus \& Folkman, 1984; Selye, 1956) and a path is theoretically warranted, and second, nested models can be tested against the full model to assess the necessity of each of the paths.

Results supported a good fit to the data, indicated by a chi-square-to-degrees of freedom ratio of 3.79, a CFI value of .93, and an SRMR of .05. All of the hypothesized parameters were statistically significant. Assessment of $R^{2}$ indicated that $43 \%$ of the variance in coping was explained by stress, and $45 \%$ of the variance in well-being and quality of life was explained by the combined effects of coping and stress from the mediated path and stress alone from the direct path. Results indicate that stress is a significant negative predictor of coping (-.65), and with the combined effects of stress, coping is a significant positive predictor of well-being (.31), and stress is a significant direct predictor of well-being and quality of life (-.43).

Nested models: Mediated coping only, stress only, and coping only models.

Mediated coping nested model. The mediated coping model with the path from stress to well-being and quality of life fixed at zero is presented in Figure 3-4. Results revealed a good fit to the data as indicated by a chi-square-to-degrees of freedom ratio of 3.80, a CFI value of .93, and a SRMR of .05. All of the hypothesized parameters were statistically significant. Sixty-five percent of the variance in coping was explained by stress, and $56 \%$ of the variance in well-being was explained by the mediated combination of stress and coping. In addition, stress was a significant negative predictor of coping 
(-.81), and coping was a significant predictor of quality of life (.75). A chi-square difference test was performed to assess whether or not the direct stress-to-quality of life path fixed a zero were important to the full model. A significant difference between the models, $\chi^{2}(1)=8.09, \underline{p}<.05$ indicated that the zero-fixed direct stress path is significantly contributing and should be included in the model.

Stress only nested model. The stress only model with the paths from stress to coping and coping to quality of life fixed at zero is presented in Figure 3-5. Results revealed a poor fit to the data as indicated by a chi-square-to-degrees of freedom ratio of 6.31, a CFI value of .87 , and a SRMR of .14. All of the hypothesized parameters were statistically significant. Forty percent of the variance in well-being and quality of life was explained by stress, which is also a significant negative predictor of well-being (-.63). A chi-square difference test was performed to assess whether or not the mediated paths fixed a zero were important to the full model. A significant difference between the models, $\chi^{2}(2)=93.20, \underline{p}<.01$ indicated that the zero-fixed mediational paths are significantly contributing and should be included in the model.

Coping only nested model. The coping only model is presented in Figure 3-6. This model posits only a path from coping to quality of life and well-being with both paths from stress (stress to coping, stress to quality of life) fixed at zero. This model tests whether coping can stand alone without the effects of stress as a predictor of well-being and quality of life. Results revealed a poor fit, indicated by a chi-square-to-degrees of freedom ratio of 7.86, a CFI value of .83 , and a SRMR of .19. All of the hypothesized parameters were statistically significant and $37 \%$ of the variance in quality of life and 
well-being was accounted for by coping. In addition, coping was a significant positive predictor of well-being and quality of life (.75). A chi-square difference test was performed to assess whether or not the stress to quality of life and stress to coping paths fixed a zero were important to the full model. A significant difference between the models, $\chi^{2}(2)=144.88, \underline{p}<.01$ indicated that the zero-fixed paths from stress were significantly contributing and should be included in the model.

Multiple sample analysis.

To assess whether or not the pattern of relationships among the constructs was different for men and women, a multiple sample analysis was performed (Arbuckle \& Wothke, 1999; Goldman \& Harlow, 1993). This procedure tested the full model from Figure 3-3 and the data from final sample of 200 men and 200 women. The results indicated that the paths significantly varied across the data samples for men and women, $\chi^{2}(64)=167.13, p<.01$. Inspection of the standardized parameter values from the gender specific models revealed that all were similar and statistically significant except for the direct path from coping to quality of life and well-being, which was .17 (not significant) for men, and .35 (significant) for women. In addition, assessment of the standardized regression weights revealed that men were markedly different from women on negative cognitive processing (-.72 versus -.58$)$, and on coping (.39 for men, .64 for women). See Figure 3-7 (men) and 3-8 (women) for the final models.

\section{Post hoc latent variable modeling.}

Based upon the results of the multiple sample analysis, it was decided to break the composite variables of coping and negative cognitive processing out of the latent coping 
variable and use the variables as two separate mediators. The purpose was to assess whether or not differential gender effects by negative cognitive processing and coping could be detected. Two models using the two mediators are presented in Figure 3-9 (men) and 3-10 (women).

Results for men revealed a good fit, indicated by a chi-square-to-degrees of freedom ratio of 2.03, a CFI value of .95, and a SRMR of .05. All of the hypothesized parameters were statistically significant except the direct path from negative cognitive processing to well-being. Forty-one percent of the variance in quality of life and well-being was accounted for by coping, negative cognitive processing, and stress, $4 \%$ of the variance in coping was accounted for by stress, and $26 \%$ of the variance in negative cognitive processing was accounted for by stress. In addition, stress was a significant predictor of perceived coping (-.19) and negative cognitive processing (.51), and there was a significant correlation between negative cognitive processing and coping (-.22). Finally, both coping (.23) and stress (-.58) were predictors of well-being and quality of life. See Figure 3-9.

For women, results revealed a good fit, indicated by a chi-square-to-degrees of freedom ratio of 3.03, a CFI value of .91, and a SRMR of .05. See Figure 3-10. All of the hypothesized parameters were statistically significant except the direct path from negative cognitive processing to well-being. Forty-one percent of the variance in quality of life and well-being was accounted for by coping, negative cognitive processing, and stress, $12 \%$ of the variance in coping was accounted for by stress, and $13 \%$ of the variance in negative cognitive processing was accounted for by stress. In addition, stress was a significant 
predictor of perceived coping (-.35) and negative cognitive processing (.37), and there was a significant correlation between negative cognitive processing and coping $(-.28)$. Finally, both coping (.19) and stress (-.53) were predictors of well-being and quality of life.

Comparison of the two models indicates that although the explained variance in wellbeing and quality of life was identical for men and women, the differences lie in the differential relationships between stress, coping, and negative cognitive processing. For men, the association between stress and negative cognitive processing is strong (.51) relative to the coping (-.19) and as stress increases, negative thinking increases as well, and coping decreases. For women, the same directional relationships were found, although the relative weights are similar (-.35 for perceived coping and .37 for negative cognitive processing). In addition, the variance accounted for is evenly distributed for women (12\% for coping and $13 \%$ for negative cognitive processing), whereas the explained variance is much stronger for men with the negative cognitive processing (26\%) more heavily accounted for over the perceived coping (4\%).

\section{Discussion}

The results from the study offered moderate support for the research hypotheses and the overall goals of the study. Although it was posited that coping would be a significant mediator of well-being and quality of life, the final models indicated that theoretically and statistically, the direct effects of stress must also be included in the model (See Figures 33 and 3-4). Results indicated that both stress and coping (including negative cognitive processing) were significant predictors of quality of life. This finding supports the 
research of Ayers et al. (1996) and Sandler et al. (1997) showing that coping, as a response to stressors, affects well-being, physical and mental health, and quality of life in either a positive or a negative manner, and both directly ad indirectly. The finding that negative cognitive processing is also a mediator variable related to the coping process lends support to previous findings related to stress appraisal resulting coping responses, in this case, directly and indirectly on coping and quality of life (Cohen et al., 1983, 1995; Lazarus \& Folkman, 1984; Selye, 1956). Additionally, the relationships of negative cognitive processing to stress and coping support the notions of the appraisal processes.

These findings add support to the ideas of behavioral specificity and context specific aspects of behavior related to Mischel $(1984,1986)$. An individual does not assess, process, and manage a stressor or stressors consistently. A substantial part of the buffering and filtering processes are related to the context of the stressor and the physical and mental state of an individual at the time of the stress. For some individuals, as indicated by the results, high levels of negative cognitive processing indicate that excessive high-level thinking in a negative direction is highly related to increased stress.

As Maslow $(1968,1971)$ points out, need motivation and the resulting decision making is a function of the perceived need of the individual, however, if the individual is not focused on goal attainment (managing the stress and needs), be they short- or longterm, decision making may become difficult and hindered. For example, if an individual is not prepared to optimally assess stress that is a part of goal-directed behavior due to lack of sleep, hunger, negative affect, or other significant influences, then less-than- 
optimal decisional results, especially related to dealing with a stressor, are the most probable outcome, thus affecting well-being and quality of life.

It was also posited that if coping is a primary mediator between stress and well-being and quality of life, then it will be possible to explore multivariate relationships in a manner that theoretically and realistically produce a mediational model or models that reflect "optimal functioning" related to quality of life and well-being in young people. The results indicate that the strongest relationship between stress and quality of life is the direct and non-mediated path. This was found in both men and women. This finding supports previous results showing that overall, individuals that have optimal levels of well-being, quality of life, and satisfaction have an inverse relationship with stress in that mediated or not, their self-reported stress levels are lower (Diener \& Lucas, 1999; Myers, 1999, 2000; Meyers \& Diener, 1995).

This also fits into the theoretical underpinnings of Maslow $(1968,1971)$ and Mischel $(1973,1984)$ previously mentioned. For example, if one has an optimal level life satisfaction, then certain decisions have been made and certain needs have been met, based on a goal-directed system of motivation and behavior to attain that high level of quality of life. Furthermore, an optimally functioning individual who takes care of him or herself, especially related to adequate rest and diet, is going to be physiologically better able to appraise stressors, but also be able to handle the stress that is already existing (Maslow, 1971; Selye, 1956).

The second hypothesis dealt with gender differences concerning stress, coping, and measures related to quality of life and well-being. The gender differences had been 
hypothesized to be related more to the individual measures and not to the mediational model of coping. For men, it was found that the relationship of negative cognitive processing and stress was much stronger than for women, and the relationship between stress and coping was rather weak, although significant. Conversely, for women, the relationships between stress, perceived coping and negative cognitive processing were moderate in strength and similar. This is indicative of the high probability of differential coping mechanisms and strategies between men and women. These results should be interpreted with caution even though an individual's well-being has been found to be an outcome mediated by various forms of coping for both men and women (e.g., Ayers et al., 1996; Ensel \& Lin, 1991; Sandler et al., 1997).

The final findings add support to the idea that there may be important gender differences that need to be taken into consideration when discussing and studying stress, coping, and quality of life. The MANOVA, and corrected follow-up comparisons, indicated that women had significantly different mean scores on five of the 10 composite variables. Women reported significantly higher levels of perceived psychological stress, and physical stress symptoms, and significantly lower levels of past satisfaction with life, current satisfaction with life, and mental/physical health and esteem than men. However, an important finding that can easily be overlooked is that there were no significant gender differences related to future satisfaction with life, existential well-being, and negative cognitive processing.

Future satisfaction with life (Pavot et al., 1998; Pavot \& Diener, 1993) and existential well-being (Bufford et al., 1991; Ellison, 1983) are both related to one's subjective 
projection of the future related to satisfaction, meaning, and purpose in life. One possible question that can be asked is whether women are coping more efficiently than men are? This is a possible interpretation based upon the higher levels of stress and lower levels of coping for women. Perhaps women have more stress to cope with, as indicated by the results of the MANOVA, but feel that they are coping well enough based upon their nonsignificant differences on the "future" variables. Furthermore, there were no gender differences on negative cognitive processing.

The perception of future ratings of perceived quality of life and well-being further support the goal-directed behavior and need based decision making (Maslow, 1971) in that, despite the gender differential in stress, if the long-term goals are somewhat constant, and the lower level needs are adequately addressed, expectations of the future direction and satisfaction with life are rated similarly.

As shown by Solomon and Rothblum (1984), Illovsky (1997), and Disch et al. (1999), there is a complex interaction of behavioral, cognitive, and affective components at work that function as determiners of task management, decision making, and stress management. Future research is needed to investigate the underlying factors related to the gender differences that were found. As proposed by Kahneman et al. (1999), it is suggested and necessary to assess quality of life and well-being using multivariate research designs that can take all levels of all types of variables into consideration.

\section{Limitations}

As previously mentioned, multivariate models of well-being and quality of life are necessary, and should include a combination of the macro- and micro-theoretical 
constructs (Kahneman et al., 1999). The current study is considered a micro-study because of the focus on individual inter- and intrapersonal areas. What are missing are macro-level variables and constructs. This would be especially helpful and useful for understanding the meaning behind the differences in the mediational coping models of men and women and the differences in the composite variables (Michalos, 1985; Veenhoven, 1994, 1995). For example, it is highly likely that institutional (the education system), the socialization process, and underlying sociocultural norms, practices, and behaviors are significantly related to, and can sufficiently explain the gender differences that were found. Diener (2000) and Kahneman et al. (1999) emphasize that there are important differences and similarities across different groups and cultures, be they intranational or international.

A major goal of the current study was to use the results in order to present a parsimonious mediational coping model related to stress, coping, and well-being in young people. Much more research is needed between and within various and diverse groups of participants. The participants were all college undergraduates and most of them were Caucasian. How different would the results be had the study been performed in an urban setting with minority participants? Longitudinal analyses are also necessary for testing the relationships among stress, coping, and well-being across time, especially in relation to possible gender differences and similarities and trying to learn about the most efficient coping strategies affecting quality of life as a whole. This would also aid in determining the direction of causation among constructs. 
Another limitation and statistical issue was the nature of the latent construct of coping. Although the interitem consistency for coping (.73) and negative cognitive processing (.87) were acceptable to quite good, the coefficient alpha for their combined effects within the latent construct of coping was negligible (.63). See Tables 3-3, 3-4, and 3-6. Improved measures of coping are suggested, as well as more thorough measures of negative cognitive processing. By understanding the various levels and styles of "thinking" about stress and stressors (Ayers et al., 1996; Selye, 1956, Ensel \& Lin, 1991; Fava et al., 1998) it will be beneficial in understanding which levels of processing are most important to which types of stressors, coping strategies, and resulting outcome related to quality of life and well being. The results of this study hint at possible differential coping processes between men and women, however without improved measures, these relationships are difficult to assess.

The final limitation of the study is the SQOLAS instrument itself. This is a relatively new measure and has gone through four major revisions since its inception in 1996 (Disch et al., 1999). A major goal of this study is to use the results to continue to work on the psychometric properties of the SQOLAS, especially related to the creation of models in order to best fit theoretical constructs related to optimal human functioning, quality of life, and well-being. The result will be a quality of life and well-being instrument that can accurately and consistently assess, predict, and parsimoniously describe and explain optimal functioning related to sociopersonal well-being and quality of life. 


\section{References}

Albaili, M. A. (1993). Psychometric properties of the inventory learning processes: Evidence from United Arab Emirates college students. Psychological Reports, 72, 13311336.

American Psychiatric Press. (1988). Anxiety disorders. New York, NY: APP.

American Psychological Association. (1992). Ethical principles of psychologists and code of conduct. American Psychologist, 47, 1597-1611.

Arbuckle, J. L., \& Wothke, W. (1999). AMOS 4.0 user's guide. Chicago, IL: Small Waters.

Argyle, M. (1999). Causes and correlates of happiness. In D. Kahneman, E. Diener, and N. Schwarz (Eds.), Well-being: The foundations of hedonic psychology (pp. 353373). New York, NY: Russell Sage Foundation.

Ayers, T. S., Sandler, I. N., West, S. G., \& Roosa, M. W. (1996). A dispositional and situational assessment of children's coping: Testing alternative models of coping. Journal of Personality, 64(4), 923-958.

Baron, R. M., \& Kenny, D. A. (1986). The moderator-mediator variable distinction in psychological research: Conceptual, strategic, and statistical considerations. Journal of Personality and Social Psychology, 51, 1173-1182.

Bartling, C. A. (1988). Longitudinal changes in the study habits of successful college students. Educational and Psychological Measurement, 48, 527-535. 
Beck, A. T., \& Beck, R. W. (1972). Screening depressed patients in family practice: A rapid technique. Postgraduate Medicine, 52, 81-85.

Beck, A. T., Rial, W. Y., \& Rickles, K. (1974). Short form of depression inventory: Cross-validation. Psychological Reports, 34, 1184-1186.

Bentler, P. M. (1995). EQS structural equations program manual. Encino, CA: Multivariate Software Inc.

Bentler, P. M., \& Wu, E. J. C. (1995). EQS for windows. Encino, CA: Multivariate Software Inc.

Berkowitz, L., \& Donnerstein, E. (1982). External validity is more than skin deep: Some answers to criticisms of laboratory experiments. American Psychologist, 37(3), 245-257.

Britton, B. K., \& Tesser, A. (1991). Effects of time-management practices on college grades. Journal of Educational Psychology, 83(3), 405-410.

Bufford, R. K., Paloutzian, R. F., \& Ellison, C. W. (1991). Norms for the spiritual well-being scale. Journal of Psychology and Theology, 19, 56-70.

Burkholder, G. J., \& Harlow, L. L. (1998). Using structural equation modeling techniques to evaluate HIV risk models. Structural Equation Modeling, 3(4), 348-368.

Byrne, B. M. (1995). One application of structural equation modeling from two perspectives: Exploring the EQS and LISREL strategies. In R. H. Hoyle (Ed.), Structural equation modeling: Concepts, issues, and applications (pp. 138-157). Thousand Oaks, CA: Sage. 
Cantor, N. \& Sanderson, N. C. (1999). Life task participation and well-being: The importance of taking part in daily life. In D. Kahneman, E. Diener, and N. Schwarz (Eds.), Well-being: The foundations of hedonic psychology (pp. 230-243). New York, NY: Russell Sage Foundation.

Carney, C. G., \& Savitz, C. J. (1980). Student and faculty perceptions of student needs and the services of a university counseling center: Differences that make a difference. Journal of Counseling Psychology, 27, 597-604.

Cattell, R. B. (1966). The scree test for the number of factors. Multivariate Behavioral Research, 1(2), 245-276.

Clark, R., Anderson, N. B., Clark, V. R., \& Williams, D. R. (1999). Racism as a stressor for African Americans: A biopsychosocial model. American Psychologist, 54, 805-816.

Cohen, J. (1988). Statistical power analysis for the behavioral sciences $\left(2^{\text {nd }}\right.$ ed. $)$. Hillsdale, NJ: Lawrence Erlbaum Associates.

Cohen, R. J., \& Swerdlik, M. E. (1999). Psychological testing and assessment: An introduction to tests and measurement $\left(6^{\text {th }}\right.$ ed. $)$. Mountain View, CA: Mayfield.

Craik, F. I. M., \& Lockhart, R. S. (1972). Levels of processing: A framework for memory research. Journal of Verbal Learning and Verbal Behavior, 11, 671-684.

Craik, F. I. M., \& Tulving, E. (1975). Depth of processing and retention of words in episodic memory. Journal of Experimental Psychology: General, 104, 268-294.

Cronbach, L. J. (1951). Coefficient alpha and the internal structure of tests. Psychometrica, 16, 297-334. 
Cronbach, L. J., \& Meehl, P. E. (1955). Construct validity in psychological tests. Psychological Bulletin, 52, 281-302.

Csikszentmihalyi, M. (1999). If we are so rich, why aren’t we happy? American Psychologist, 54, 821-827.

Dean, P. J., \& Range, L. M. (1996). The escape theory of suicide and perfectionism in college students. Death Studies, 20, 415-424.

DeMan, A. F., \& Leduc, C. P. (1995). Suicidal ideation in high school students: Depression and other correlates. Journal of Clinical Psychology, 51(2), 173-181.

DeSimone, A., Murray, P, \& Lester, D. (1994). Alcohol use, self-esteem, depression, and suicidality in high school students. Adolescence, 29(116), 939-942.

Diener, E. (2000). Subjective well-being: The science of happiness and a proposal for a national index. American Psychologist, 55, 34-43.

Diener, E., \& Diener, M. (1995). Cross-cultural correlates of life satisfaction and selfesteem. Journal of Personality and Social Psychology, 68(4), 653-663.

Diener, E., Emmons, R. A., Larsen, R. J., \& Griffen, S. (1985). The satisfaction with life scale. Journal of Personality Assessment, 49, 71-76.

Diener, E., Eunkook, M. S., Smith H. L., \& Shao, L. (1995). National differences in reported subjective well-being: Why do they occur? Social Indicators Research, 34, 7-32.

Diener, E., \& Lucas, R. E. (1999). Personality and subjective well-being. In D. Kahneman, E. Diener, and N. Schwarz (Eds.), Well-being: The foundations of hedonic psychology (pp. 213-229). New York, NY: Russell Sage Foundation. 
Disch, W. B., \& Campbell, J. F. (1997). Counseling center survey (Tech. Rep. Vol. 1(8), No. 1). Kingston: University of Rhode Island, Division of Student Affairs, Student Quality of Life and Satisfaction (SQOLAS).

Disch, W. B., \& Campbell, J. F. (1999). Counseling center survey (Tech. Rep. Vol. 3(5), No. 1). Kingston: University of Rhode Island, Division of Student Affairs, Student Quality of Life and Satisfaction (SQOLAS).

Disch, W. B., Dougan, T. R., \& Campbell, J. F. (1997). Student concern areas survey (Tech. Rep. Vol. 7(7), No. 1). Kingston: University of Rhode Island, Division of Student Affairs, Student Quality of Life and Satisfaction (SQOLAS).

Disch, W. B., Fava, J. L., \& Sarkin, J. (2000). Development, exploratory, and confirmatory structure of the Rhode Island Physical Symptoms Inventory. Manuscript in preparation.

Disch, W. B., Harlow, L. L., Campbell, J. T, \& Dougan, T. R. (in press). Student functioning, concerns, and sociopersonal well-being. Social Indicators Research.

Disch, W. B., Nolan, M. F., Shapiro, S. B., Dougan, T. R., \& Campbell, J. F. (1999). [1999 student quality of life and satisfaction survey (SQOLAS). Division of Student Affairs, University of Rhode Island]. Unpublished Raw Data.

Disch, W. B., \& Olick, K. (1998). Student concern and importance areas: A replication study. Manuscript in preparation, University of Rhode Island.

Douglas, K. A., Collins, J. L., Warren, C., Kann, L., Gold, R., Clayton, S., Ross, J. G., \& Kolbe, L. J. (1997). Results from the 1995 national college health risk behavior survey. Journal of American College Health, 46, 55-66. 
Ellison, C. W. (1983). Spiritual well-being: Conceptualization and measurement. Journal of Psychology and Theology, 11(4), 330-340.

Ensel, W. M., \& Lin, N. (1991). The life stress paradigm and psychological distress. Journal of Health and Social Behavior, 32(4), 321-341.

Fava, J. L., Ruggiero, L., \& Grimley, D. M. (1998). The development and structural confirmation of the Rhode Island Stress and Coping Inventory. Journal of Behavioral Medicine, 21, 601-611.

Folkman, S., \& Lazurus, R. S. (1985). If it changes it must be a process: Study of emotion and coping during three stages of a college examination. Journal of Personality and Social Psychology, 48, 150-170.

Frankl, V. E. (1959). Man's search for meaning. Boston: Beacon Press.

Frankl, V. (1978). The unheard cry for meaning. New York: Simon \& Schuster (Touchstone).

Gallagher, R. P., Golin, A., \& Kelleher, K. (1992). The personal, career, and learning skills needs of college students. Journal of College Student Development, 33, 301-309.

Goldman, J. A., \& Harlow, L. L. (1993). Self-perception variables that mediate AIDSpreventive behavior in college students. Health Psychology, 12(6), 489-498.

Gorsuch, R. L. (1983). Factor analysis $\left(2^{\text {nd }}\right.$ ed.). Hillsdale, NJ: Erlbaum.

Gould, J. (1982). A psychometric investigation of the standard and short form Beck Depression Inventory. Psychological Reports, 51, 1167-1170. 
Graham, S. (1992). "Most of the subjects were white and middle class:" Trends in published research on African Americans in selected APA journals, 1970-1989. American Psychologist, 47(5), 629-639.

Guardino, M. (1995). Planning and promotion guide: National Anxiety Disorders Screening Day, 1995. New York, NY: APP.

Harlow, L. L., \& Newcomb, M. D. (1990). Towards a general hierarchical model of meaning and satisfaction in life. Multivariate Behavioral Research, 25(3), 387-405.

Harris, H. J., \& Anttonen, R. G. (1986). Assessing needs of male and female college freshmen. Journal of College Student Personnel, 27, 277.

Hasse, J. E., Britt, T., Coward, D. D., \& Leidy, N. K. (1992). Simultaneous concept analysis of spiritual perspective, hope, acceptance and self-transcendence. IMAGE Journal of Nursing Scholarship, 24(2), 141-147.

Howell, D. C. (1992). Statistical methods for psychology ( $3^{\text {rd }}$ ed.). Belmont, CA: Wadsworth.

Hoyle, R. H. (1995). (Ed.). Structural equation modeling: Concepts, issues and applications. Thousand Oaks, CA: Sage.

Hoyle, R. H., \& Panter, A. T. (1995). Writing about structural equation models. In R. H. Hoyle (Ed.), Structural equation modeling: Concepts, issues and applications (pp. 158176). Thousand Oaks, CA: Sage.

Hu, L., \& Bentler, P. M. (1995). Evaluating model fit. In R. H. Hoyle (Ed.), Structural equation modeling: Concepts, issues and applications (pp. 76-99). Thousand Oaks, CA: Sage. 
Illovsky, M. E. (1997). Effects of counseling on grades and retention. Journal of College Student Psychotherapy, 12, 29-44.

Janis, I. L., \& Mann, L. (1977). Decision making: A psychological analysis of conflict, choice, and commitment. New York: Free Press.

Kahneman, D., Diener, E. \& Schwarz, N. (1999). (Eds.). Well-Being: The foundations of hedonic psychology. New York, NY: Russell Sage Foundation.

Kozma, A., \& Stones, M. J. (1983). Predictors of happiness. Journal of Gerontology, $\underline{38(5), 626-628 . ~}$

Lazarus, R. S. (1966). Psychological stress and the coping process. New York: McGraw Hill.

Lazarus, R. S., \& Folkman, S. (1984). Stress, appraisal, and coping. New York: Springer.

Maney, D. W. (1990). Predicting university students' use of alcoholic beverages. Journal of College Student Development, 31, 23-32.

Maslow, A. H. (1968). Toward a psychology of being. $\left(2^{\text {nd }}\right.$ ed.). New York: Van Nostrand.

Maslow, A. H. (1971). The farther reaches of human nature. New York: Viking.

Menzies, T. V., \& Boak, R. T. (1994). The quality of life as perceived by students in a college of applied arts and technology. College Student Journal, 28, 46-56.

Michalos, A. C. (1985). Multiple discrepancy theory (MDT). Social Indicators Research, 16, 347-413. 
Mischel, W. (1973). Toward a cognitive social learning reconceptualization of personality. Psychological Review, 80, 252-283.

Mischel, W. (1984). Convergences and challenges in the search for consistency. American Psychologist, 39, 351-364.

Mischel, W. (1986). Introduction to personality (4th ed.). Orlando, FL: Holt, Rinehart, and Winston.

Moberg, D. O. (1979). The development of social indicators for quality of life research. Sociological Analysis, 40(1), 11-26.

Myers, D. G. (1995). Psychology ( $4^{\text {th }}$ ed.). New York: Worth Publishers.

Myers, D. G. (1999). Close relationships and quality of life. In D. Kahneman, E. Diener, and N. Schwarz (Eds.), Well-being: The foundations of hedonic psychology (pp. 374-391). New York, NY: Russell Sage Foundation.

Myers, D. G. (2000). The funds, friends, and faith of happy people. American Psychologist, 55, 56-67.

Myers, D, G., \& Diener, E. (1995). Who is happy? American Psychological Society, $\underline{6}(1), 10-19$.

Oswalt, R., \& Finkelberg, S. (1995). College depression: Causes, duration, and coping. Psychological Reports, 77, 858.

Paloutzian, R. F., \& Ellison, C. W. (1982). Loneliness, spiritual well-being, and quality of life. In L. A. Peplau and D. Perlman (Eds.), Loneliness: A sourcebook of current theory, research, and therapy. New York: Wiley. 
Pavot, W., Diener, E., \& Suh, E. (1998). The temporal satisfaction with life scale. Journal of Personality Assessment, 70(2), 340-354.

Pavot, W., \& Diener, E. (1993). Review of the satisfaction with life scale.

Psychological Assessment, 5(2), 164-172.

Perlin, L. I., Lieberman, M. A., Menaghan, E. G., \& Mullan, J. T. (1981). The stress process. Journal of Health and Social Behavior, 22, 337-356.

Ross, L. (1995). The spiritual dimension: Importance to patients' health, well-being and quality of life and its implications for nursing practice. International Journal of Nursing Studies, 32(5), 457-468.

Ryff, C. D. (1989). Happiness is everything, or is it? Explorations on the meaning of psychological well-being. Journal of Personality and Social Psychology, 57(6), 10691081.

Sandler, I. N., Wolchick, S. A., MacKinnon, D., Ayers, T. S., \& Roosa, M. W. (1997). Developing linkages between theory and intervention in stress and coping processes. In S. A. Wolchick \& I. N. Sandler (Eds.). Handbook of children's coping: Linking theory and intervention (pp. 3-40). New York, NY: Plenum.

Schmeck, R. R. (1983). Learning styles of college students. In R. Dillon, \& R. Schmeck (Eds.), Individual differences in cognition. New York: Academic Press.

Schmeck, R. R., Geisler-Brenstein, E., \& Cercy, S. P. (1991). Self-concept and learning: The revised Inventory of Learning Processes. Educational Psychology, 11, 343362. 
Schmeck, R. R., \& Grove, E. (1979). Academic achievement and individual differences in learning processes. Applied Psychological Measurement, 3, 43-49.

Schmeck, R. R., \& Ribich, F. (1977). Construct validation of the inventory of learning processes. Applied Psychological Measurement, 2, 551-562.

Schnoll, R. A., Harlow, L. L., Brandt, U., \& Stolbach, L. L. (1998). Using two factor structures of the Mental Health Adjustment to Cancer (MAC) scale for assessing adaptation to breast cancer. Psycho-Oncology, 7(5), 424-435.

Seligman, M. P., \& Csikszentmihalyi, M. (2000). Positive psychology: An introduction. American Psychologist, 55, 5-14.

Selye, H. (1956). The stress of life. New York, NY: McGraw-Hill.

Skinner, E. A., \& Wellborn, J. G. (1994). Coping during childhood and adolescence: A motivational perspective. In R. Lerner, D. Featherman, \& M. Perlmuter (Eds.). Lifespan development and behavior, Vol. 12 (pp. 91-123). Hillsdale, NJ: Erlbaum.

Solomon, L. J., \& Rothblum, E. D. (1984). Academic procrastination: Frequency and cognitive-behavioral correlates. Journal of Counseling Psychology, 31(4), 503-509.

SPSS Inc. (1999). Statistical Package for the Social Services - version 9.0. Chicago, IL: SPSS, Inc.

Staats, S., Armstrong-Stassen, M., \& Partilo, C. (1995). Student well-being: Are they better off now? Social Indicators Researcher, 34, 93-112.

Stewart, A. L., Hays, R. D., \& Ware, J. E., Jr. (1988). The MOS short form general health survey: Reliability and validity in a patient population. Medical Care, 26, 724-735. 
Stones, M. J., \& Kozma, A. (1993). The relationships of affect intensity to happiness. Social Indicators Research, 31, 159-173.

Tabachnick, B. G., \& Fidell, L. S. (1996). Using Multivariate Statistics (3rd ed.). New York: Harper Collins.

Taylor, S. E., \& Brown, J. D. (1988). Illusion and well-being: A social psychological perspective on mental health. Psychological Bulletin, 103(2), 193-210.

Taylor, S. E., Kemeny, M. E., Reed, G. M., Bower, J. E., \& Gruenewald, T. L. (2000). Psychological resources, positive illusions, and health. American Psychologist, 55, 99109.

Valliant, P. M. (1995). Personality, peer influence, and use of alcohol and drugs by first-year university students. Psychological Reports, 77, 401-402.

Veenhoven, R. (1991). Is happiness relative? Social Indicators Research, 24, 1-34.

Veenhoven, R. (1994). Is happiness a trait?. Social Indicators Research, 32, 101-160.

Veenhoven, R. (1995). The cross-national pattern of happiness: Test of predictions implied in three theories of happiness. Social Indicators Research, 34, 33-68.

Volk, R. J., Pace, T. M., \& Parchman, M. L. (1993). Screening for depression in primary care patients: Dimensionality of the short form of the Beck Depression inventory. Psychological Assessment, 5(2), 173-181.

Waterman, A. S. (1993). Two conceptions of happiness: Contrast of personal expressiveness (eudaimonia) and hedonic enjoyment. Journal of Personality and Social Psychology, 64(4), 678-691. 
Table 3-1

Comparison of the Overall Concern and Importance Area Rankings from Three Independent Samples

\begin{tabular}{|c|c|c|c|}
\hline & $\begin{array}{l}1999 \text { (16 Categories), Spring } \\
\mathrm{N}=720,57 \% \text { response rate }\end{array}$ & $\begin{array}{l}1998 \text { (16 Categories), Spring } \\
N=100,100 \% \text { response rate }\end{array}$ & $\begin{array}{l}1997 \text { (10 Categories), Spring } \\
N=467,15 \% \text { response rate }\end{array}$ \\
\hline $\begin{array}{c}\text { Most } \\
\text { Important }\end{array}$ & Future Career Issues & Future Career Issues & Career and Employment \\
\hline 1 & Physical Health & Physical Health & Use of Time \\
\hline 1 & Academic Issues & Academic Issues & Physical and Mental Health \\
\hline I & Mental Health & Mental Health & Consumer and Finance \\
\hline 1 & Use of Time & Use of Time & Living Issues \\
\hline 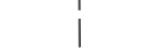 & Consumer/Finance & Consumer/Finance & Socio-Sexual Behavior \\
\hline 1 & Social Behavior & Social Behavior & Crime and Violence \\
\hline$!$ & Sexual Behavior & Sexual Behavior & Learning Styles \\
\hline 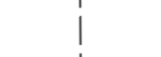 & Living Issues (safety, security) & Living Issues (safety, security) & Multicultural and Gender \\
\hline 1 & Current Employment Issues & Current Employment Issues & Drug/Alcohol Consumption \\
\hline  & Crime/Violence & Crime and Violence & \\
\hline 1 & Multicultural/Diversity Issues & Gender Issues & \\
\hline i & Gender Issues & Multicultural Issues & \\
\hline T & Alcohol Use/Abuse & Alcohol Use/Abuse & \\
\hline$\downarrow$ & Drug Use/Abuse & Sexual Orientation & \\
\hline $\begin{array}{c}\text { Least } \\
\text { Important }\end{array}$ & Sexual Orientation & Drug Use/Abuse & \\
\hline
\end{tabular}

Note. The 1999 version employed group sampling that produced a homogeneous sample of undergraduates. The 1998 version employed group sampling that produced a homogeneous sample of undergraduates. The 1997 version was a mail survey that produced a heterogeneous sample of undergraduates and graduates. 
Table 3-2

Demographics by Overall and Gender

\section{Gender \\ Men \\ Women}

Age

Mean (20 yrs.)

Median (19 yrs.)

Mode (19 yrs.)

$18 \mathrm{yrs}$.

19 yrs.

20 yrs.

21 yrs.

22 yrs.

23 yrs.

24 yrs.

$25+$ yrs.

\section{Class Year}

Freshmen

Sophomore

Junior

Senior

Undergraduate Total

\section{Living Status}

On-Campus

Down the Line

Live with Parents

Fraternity/Sorority

Not Down Line or w/Parents

Relationship Status

Single
Married
Divorced/Separated

\section{Overall \\ $(\mathbf{N}=\mathbf{7 2 0})$ \\ N (Percent) \\ $204(28 \%)$ \\ $516(72 \%)$}

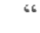

66

$$
\begin{gathered}
210(29 \%) \\
230(32 \%) \\
139(19 \%) \\
73(10 \%) \\
22(3 \%) \\
13(2 \%) \\
9(1 \%) \\
24(3 \%)
\end{gathered}
$$

$322(45 \%)$
$205(29 \%)$
$144(20 \%)$
$49(7 \%)$
$720(100 \%)$

$419(58 \%)$
$91(13 \%)$
$88(12 \%)$
$74(10 \%)$
$41(6 \%)$
$702(98 \%)$
$10(<2 \%)$
$6(<2 \%)$

\section{Men}

( $\mathrm{n}=204$ )

n (Percent)

Women

$(\mathrm{n}=\mathbf{5 1 6})$

(Percent)

\section{Note. Percentages not totaling 100 indicate participant non-response (missing data), percentages totaling over 100} indicate multiple responses on an item by a participant. 
Table 3-2 (cont.)

Demographics by Overall and Gender

\begin{tabular}{|c|c|c|}
\hline $\begin{array}{l}\text { Overall } \\
(\mathrm{N}=720) \\
\mathrm{N}(\text { Percent })\end{array}$ & $\begin{array}{l}\text { Men } \\
(n=204) \\
n(\text { Percent })\end{array}$ & $\begin{array}{l}\text { Women } \\
(\mathrm{n}=\mathbf{5 1 6}) \\
\mathrm{n} \text { (Percent) }\end{array}$ \\
\hline \multicolumn{3}{|c|}{ its) Time Student? } \\
\hline $\begin{array}{c}698(97 \%) \\
16(2 \%)\end{array}$ & $\begin{array}{c}194(95 \%) \\
6(3 \%)\end{array}$ & $\begin{array}{c}504(98 \%) \\
10(2 \%)\end{array}$ \\
\hline
\end{tabular}
Full-time
$16(2 \%)$
$6(3 \%)$
$10(2 \%)$

Overall GPA (self-reported)

(mean, standard deviation)

$\begin{array}{lccc}\text { Freshperson } & 3.0(0.6) & 3.0(0.5) & 3.0(0.6) \\ \text { Sophomore } & 2.9(0.5) & 2.9(0.6) & 3.0(0.5) \\ \text { Junior } & 3.0(0.5) & 2.8(0.4) & 3.0(0.5) \\ \text { Senior } & 3.0(0.4) & 3.1(0.4) & 3.0(0.4) \\ & & & 8(2 \%) \\ \text { cademic Status (self-reported) } & & 2(1 \%) & 63(12 \%) \\ \text { Far Ahead in Academic Program } & 10(1 \%) & & 294(57 \%) \\ \text { Somewhat Ahead in Academic } & & 19(9 \%) & \\ \quad \text { Program } & 82(11 \%) & 114(56 \%) & 9(2 \%) \\ \text { On-Track in Academic Program } & 408(57 \%) & 131(25 \%) & \\ \text { Somewhat Behind in Academic } & & 7(3 \%) & 24(5 \%) \\ \quad \text { Program 193 (27\%) } & 62(30 \%) & & 300(58 \%) \\ \text { Behind in Academic Program } & 16(2 \%) & 13(6 \%) & 192(37 \%) \\ & & 110(54 \%) & 79(39 \%) \\ \text { Y You Work? } & 37(5 \%) & & \\ \text { Full-time } & 410(57 \%) & & \\ \text { Part-time } & 271(38 \%) & & \\ \text { Do not work } & & & \end{array}$

How many hours of work did you average per week during the past year? (mean, standard deviation; including those who stated they do not work)

$\begin{array}{lccc}\text { Freshperson } & 13(8) & 16(10) & 12(7) \\ \text { Sophomore } & 16(9) & 19(11) & 15(8) \\ \text { Junior } & 17(9) & 20(9) & 16(8) \\ \text { Senior } & 17(9) & 17(9) & 17(9) \\ & & & \\ \text { You Own a Computer? } & & & 332(64 \%) \\ \text { yes } & 457(64 \%) & 125(61 \%) & 177(34 \%) \\ \text { no } & 253(35 \%) & 76(37 \%) & \end{array}$

Note. Percentages not totaling 100 indicate participant non-response (missing data), percentages totaling over 100 indicate multiple responses on an item by a participant. 
Table 3-3

Component Loadings (C), Alpha ( $\alpha$ ), and Percents of Total Variance for Principal Components Extraction using Direct Oblimin (Oblique) Rotation on 35 Variables Related to Past Satisfaction with Life (SWL), Current SWL, Future SWL, Religious Well-Being (RWB), Perceived Coping, Perceived Psychological Stress, and Depression

\begin{tabular}{lcccc} 
Items & Overall & Men & Women & Overall $\alpha$ \\
\hline Past Satisfaction with Life $(\mathrm{SWL})\left(\mathrm{C}_{1}\right)$ & & & & .87 \\
\hline Ideal past & -.92 & -.85 & .92 & \\
Past life satisfaction & -.87 & -.82 & .84 \\
Past life conditions & -.86 & -.77 & .86 \\
Change past & -.71 & -.84 & .59 \\
Having important things in past & -.57 & -.47 & .69
\end{tabular}

Current SWL $\left(\mathrm{C}_{2}\right)$

Having important things presently

Ideal current life

Current life conditions

$\begin{array}{ll}.48 & .73\end{array}$

Change current life

Future SWL $\left(\mathrm{C}_{3}\right)$

Have important things in future

Future life conditions

$-.81$

.46

Ideal future expectations

.82

.79

$-.80$

.80

Future life satisfaction

$-.75$

Religious Well-Being $\left(\mathrm{C}_{4}\right)$

Sense of well-being

Religious strength

Positive relationship with God

Religious participation

Belief in God

Perceived Coping $\left(\mathrm{C}_{5}\right)$

Difficult situations

Unexpected problems

Successfully solve problems

Cope with stress

Meet demands

Perceived Psychological Stress $\left(\mathrm{C}_{6}\right)$

Feeling overwhelmed

More stress than usual

Lack of time

Pressure from others

$-.66$

$-.54$

$-.61$

Depression $\left(\mathrm{C}_{7}\right)$

Self-dislike

Sense of failure

Pessimism

Guilt

Sadness

Dissatisfaction

$\begin{array}{ll}.78 & .70 \\ & .75\end{array}$


Table 3-4

Component Loadings (C) and Alpha ( $\alpha$ ) for Principal Components Extraction on Variables Related to Anxiety, Existential Well-Being (EWB), Negative cognitive processing, Physical Symptoms of Stress, and Mental/Physical Health and Esteem (MPH)

\begin{tabular}{lllll} 
Items & Overall & Men & Women & Overall $\alpha$ \\
\hline Anxiety $(\mathrm{SWL})\left(\mathrm{C}_{8}\right)$ & & & & .74 \\
\hline Problems with people & .76 & .76 & .76 & \\
Problems controlling worrying & .71 & .68 & .74 & \\
Problems in social situations & .67 & .64 & .71 & \\
Fear of performing tasks & .66 & .73 & .60 \\
Multiple worries & .58 & .61 & .54
\end{tabular}

Existential Well-Being (EWB) $\left(\mathrm{C}_{9}\right)$

Sense of future $\quad .74$

Fulfilled and satisfied $\quad .74$

Positive about future $\quad .73$

Positive about life experience $\quad .68$

Enjoyment in life $\quad .67$

Meaning in life

Self-knowledge and direction

Sense of conflict and unhappiness $\quad .59$

Purpose in life $\quad .58$

Sense of stability of future

Negative Cognitive Processing $\left(\mathrm{C}_{10}\right)$

Difficulty in critical thinking $\quad .80$

Difficulty with comparisons

Trouble in discriminating similarities $\quad .76$

Difficulty learning study techniques $\quad .75$

Trouble planning with complex tasks $\quad .67$

Trouble finding words for expressions $\quad .67$

Difficulty organizing information $\quad .66$

Trouble making inferences $\quad .58$

Difficulty with fast lectures $\quad .58$

$\begin{array}{ll}.80 & .68\end{array}$

68
75

$.74 \quad .75$

$.79 \quad .65$

$\begin{array}{ll}.71 & .65 \\ .63 & .63\end{array}$

$\begin{array}{ll}.63 & .73\end{array}$

$.60 \quad .62$

$59-62$
.51

$.51 \quad .69$

$.61 \quad .54$

$\begin{array}{ll}.60 & .49\end{array}$

hysical Symptoms of Stress $\left(\mathrm{C}_{11}\right)$

Fatigue/low energy $\quad .80$

Nervousness/restlessness $\quad .79$

Irritability $\quad .77$

Forgetfulness/difficulty concentrating $\quad .75$

Shortness of breath/heart palpitations $\quad .68$

Insomnia/restless sleep

Stomach/gastro-intestinal distress

General aches and pains (muscles/back)

Nausea

Headaches

$.60 \quad .56$

Mental/Physical Health and Esteem $\left(\mathrm{C}_{12}\right)$

Mental/psychological self-satisfaction

Self-esteem/self-worth

Physical/physiological self-satisfaction 
Table 3-5

Correlations between the Major Composite Variables from the Total Set of Composite Measures including:

Past Satisfaction with Life (SWL), Current SWL, Future SWL, Religious Well-Being (RWB), Perceived

Coping, Perceived Psychological Stress, Depression, Anxiety, Existential Well-Being (EWB), Negative

Cognitive Processing. Physical Stress Symptoms, and Mental/Physical Health and Esteem

\begin{tabular}{lllllllllll}
1 & 2 & 3 & 4 & 5 & 6 & 7 & 8 & 9 & 10 & 11 \\
\hline
\end{tabular}

1. Past SWL

2. Current SWL

$.58^{*}$

3. Future SWL

$.35 * \quad .51^{*}$

4. Religious Well-Being

$.01 \quad .02 \quad .02$

5. Perceived Coping

$.18^{*} \quad .23^{*} \quad .26^{*} \quad-.10$

6. Perceived Psych. Stress

$\begin{array}{lllll}-.24 * & -.32^{*} & -.11^{*} \quad .14^{*}-.09\end{array}$

7. Depression

$\begin{array}{llllll}-.32^{*} & -.51^{*} & -.31^{*} & .08 & -.33^{*} & .40^{*}\end{array}$

8. Anxiety

$\begin{array}{llllll}-.32 * & -.43^{*} & -.26^{*} & .08 & -.27^{*} & .51^{*} \quad .50^{*}\end{array}$

9. Existential Well-Being

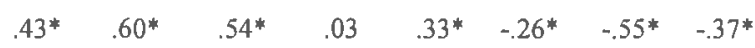

10. Negative Cognitive Processing

$\begin{array}{lllllllll}-.12^{*} & -.23^{*} & -.21^{*} & .12^{*} & -.33^{*} & .31^{*} & .41^{*} & .37^{*} & -.30^{*}\end{array}$

11. Physical Stress Symptoms

$\begin{array}{llllllllll}-.37^{*} & .37^{*} & .17^{*} & .07 & -.23^{*} & .45^{*} & .43^{*} & .55^{*} & -.26^{*} & .24^{*}\end{array}$

12. Men/Phy Health/Esteem

$\begin{array}{lllllllllll}.45^{*} & .55^{*} & .43^{*} & -.03 & .31^{*} & -.27^{*} & -.60^{*} & -.47^{*} & .62^{*} & -.27^{*} & -.38^{*}\end{array}$

Note. $\underline{N}=400$ (200 men and 200 women $)$

${ }^{*} \underline{\mathrm{p}}<.05$, two-tailed. 
Table 3-6

Component Loadings (C), Alpha ( $\alpha$ ), and Percents of Total Variance for Principal Components Extraction

Using Direct Oblimin (Oblique) Rotation on 10 Composite Variables Related to Stress, Coping/Negative

Cognitive Processing, and Sociopersonal Well-Being and Quality of Life

Composite Variables and Components Overall Men Women Overall $\alpha$

Sociopersonal Well-Being \& Quality of Life

Current satisfaction with life

Future satisfaction with life

Existential well-being .79

.79

.82

.79

.81

.73

Past satisfaction with life

Mental/physical health \& esteem

.77

.72

$\begin{array}{ll}.81 & .70\end{array}$

.67

.73

.75

$\begin{array}{ll}.68 & .70\end{array}$

$\underline{\text { Stress }}$

Perceived psychological stress

Physical symptoms of stress

Anxiety

Coping/Negative Cognitive Processing

Perceived coping

Negative cognitive processing

$\begin{array}{lll}.74 & -.85 & .71 \\ -.74 & .55^{*} & -.78\end{array}$

Total Variance Accounted for (3 components) $65.6 \%$ $64.4 \%$ $67.0 \%$

Note. For men, negative cognitive processing also loaded .55 onto the stress component. 


\section{Table 3-7}

Means, Standard Deviations, and Adjusted and Nonadjusted Significance of the 10 Composite Variables by

Gender

\begin{tabular}{|c|c|c|c|c|}
\hline & Men & Women & \multicolumn{2}{|c|}{ Significant Gender Difference } \\
\hline Composite Measure & Mean (SD) & $\operatorname{Mean}(S D)$ & Adjusted (.005) & Unadjusted $(.05)$ \\
\hline Past SWL & $23.12(7.1)$ & $20.99(7.0)$ & yes & yes \\
\hline Current SWL & $25.03(6.3)$ & $22.82(6.7)$ & yes & yes \\
\hline Future SWL & $22.63(3.6)$ & $22.51(3.9)$ & no & no \\
\hline Existential Well-Being & $46.23(7.9)$ & $46.38(7.3)$ & no & no \\
\hline Physical/Mental Health/Esteem & $12.05(2.6)$ & $10.72(2.7)$ & yes & yes \\
\hline Perceived Coping & $16.70(2.5)$ & $16.02(2.6)$ & no & yes \\
\hline Negative Cognitive Processing & $21.41(6.1)$ & $22.32(5.8)$ & no & no \\
\hline Perceived Stress & $12.93(3.3)$ & $14.33(3.3)$ & yes & yes \\
\hline Physical Symptoms & $30.18(27.4)$ & $47.45(35.2)$ & yes & yes \\
\hline Anxiety & $7.76(1.6)$ & $8.14(1.7)$ & no & yes \\
\hline
\end{tabular}

Note. Bold-faced type indicates difference in significance based upon the adjusted or unadjusted p-values (perceived coping and anxiety). 
Table 3-8

Summary and Results of Confirmatory Factor Analysis and Structural Equation Modeling including Nested Models and Chi Square Difference Tests

$\begin{array}{lcccccc}\text { Model } & \text { Fig. \# } & (\mathrm{df}) \chi^{2} & \chi^{2} / \mathrm{df} \text { Ratio } & \text { CFI } & \text { SRMR } & \text { (df) } \chi_{\text {diff }}^{2} \\ \text { Confirmatory } & 3-1 & (32)=121.34 & 3.79 & .93 & .05 & \\ \text { Full } & 3-3 & (32)=121.34 & 3.79 & .93 & .05 & \\ \text { Nested Models } & & & & & & \\ \quad \text { Mediational Coping } & 3-4 & (33)=129.43 & 3.80 & .93 & .05 & (1)=8.09, \mathrm{p}<.05 \\ \quad 3-5 & (34)=214.54 & 6.31 & .87 & .14 & (2)=93.20, \mathrm{p}<.05 \\ \quad \text { Stress Only } & 3-6 & (34)=267.22 & 7.86 & .83 & .19 & (2)=145.88, \mathrm{p}<.05 \\ \quad \text { Coping Only } & & (64)=167.13 & 2.61 & .92 & .06 & \\ \text { Multiple Sample Test } & 3-7 & (32)=71.95 & 2.25 & .93 & .06 & \\ \text { Final Men } & 3-8 & (32)=95.18 & 2.97 & .91 & .06 & \\ \text { Final Women } & 3-9 & (31)=62.96 & 2.03 & .95 & .05 & \\ \text { Coping/Cognitive Men } & 3-10 & (31)=93.98 & 3.03 & .91 & .05 & \\ \text { Coping/Cognitive Women } & & & & & \end{array}$

Note. Fig \# = figure number in manuscript; $(\mathrm{df}) \chi^{2}=$ degrees of freedom and chi square value obtained; $\chi^{2} / \mathrm{df}$ Ratio $=$ chi square divided by degrees of freedom; CFI = comparative fit index; SRMR = standardized root mean residual; (df) $\chi_{\text {diff }}^{2}=$ degrees of freedom, obtained chi square value, and significance after performing $\chi^{2}$ difference tests. 
Figure 3-1

Standard Parameters for 3 Correlated Components Related to Stress, Coping/Negative Cognitive Processing, and Sociopersonal Well-Being and Quality of Life



Note. $\chi^{2}(32)=121.34$, Standardized RMR $=.05, \chi^{2} / \mathrm{df}=3.79, \mathrm{CFI}=.93$.

$* \underline{\mathrm{p}}<.05$. 
Figure 3-2

Simple Hypothesized Mediational Coping Model of Sociopersonal Well-Being and Quality of Life






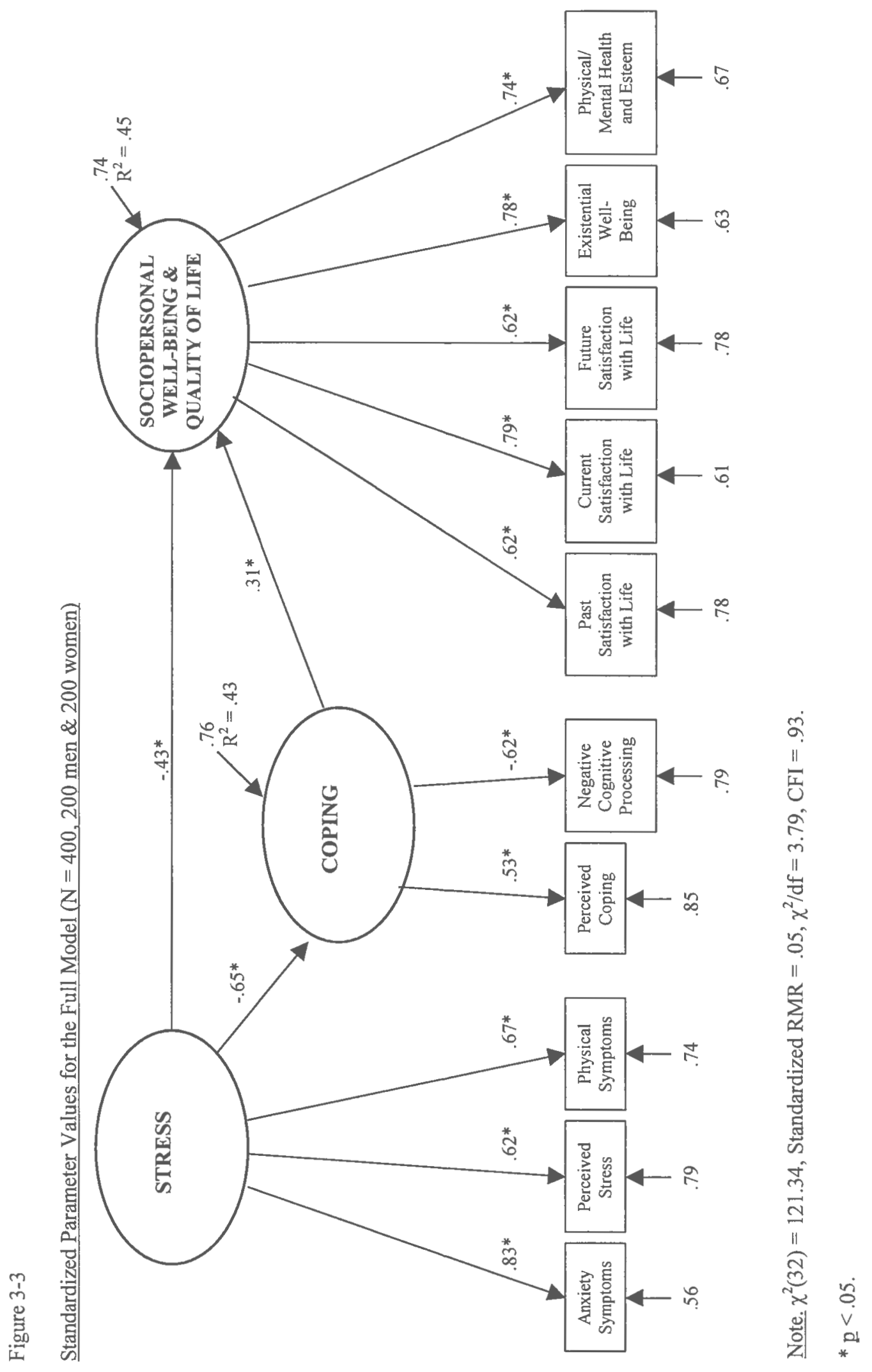




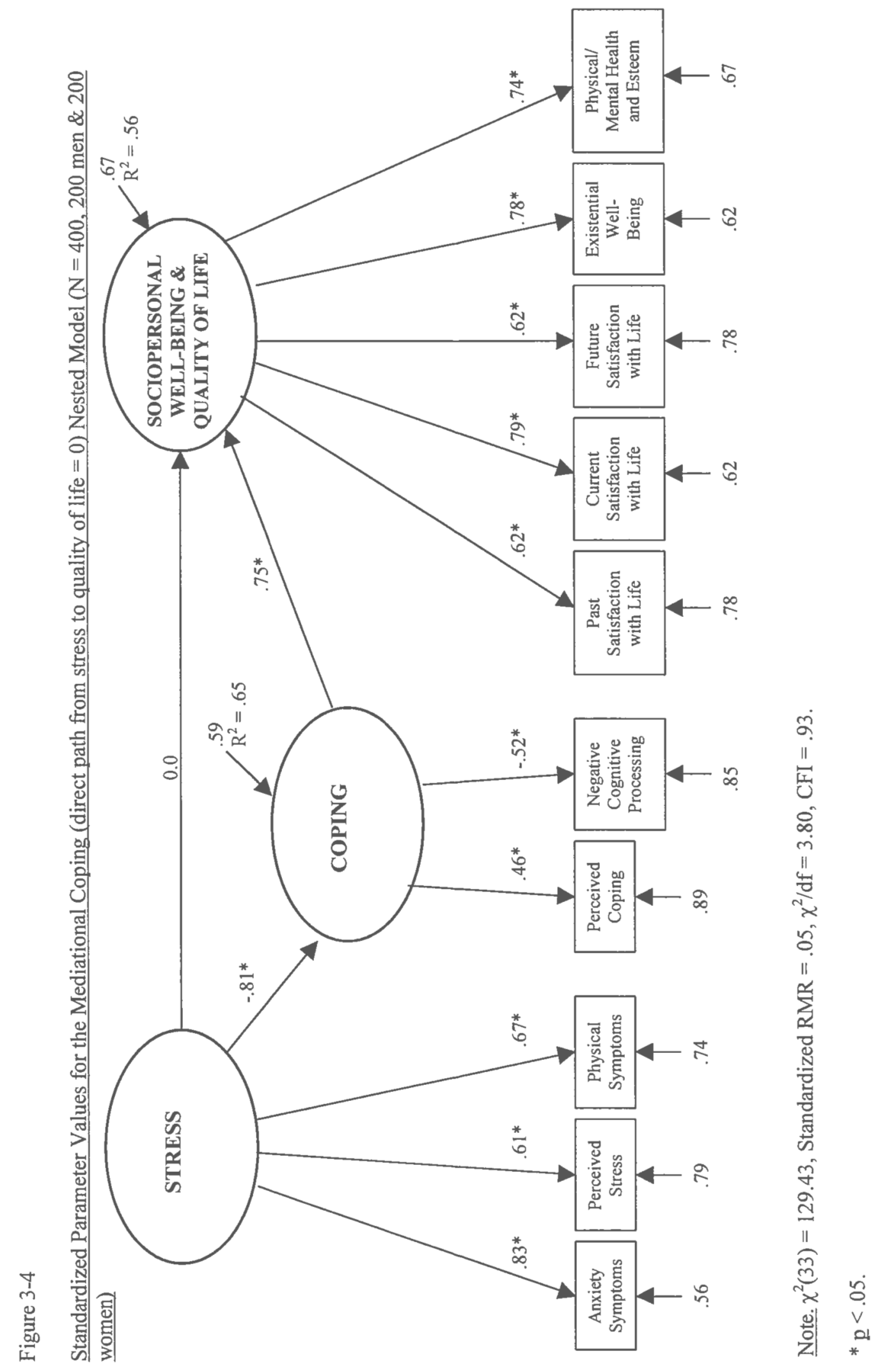




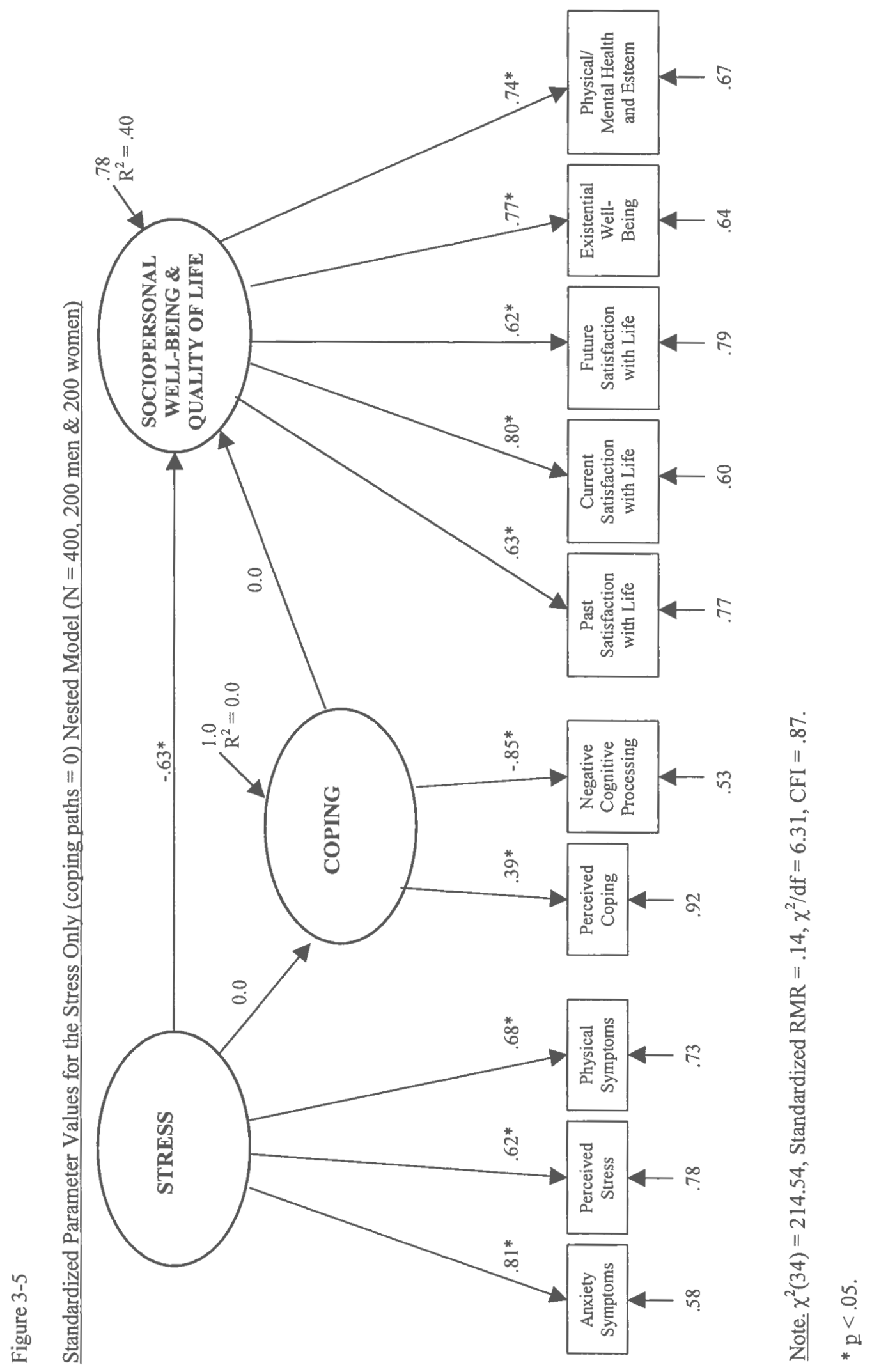




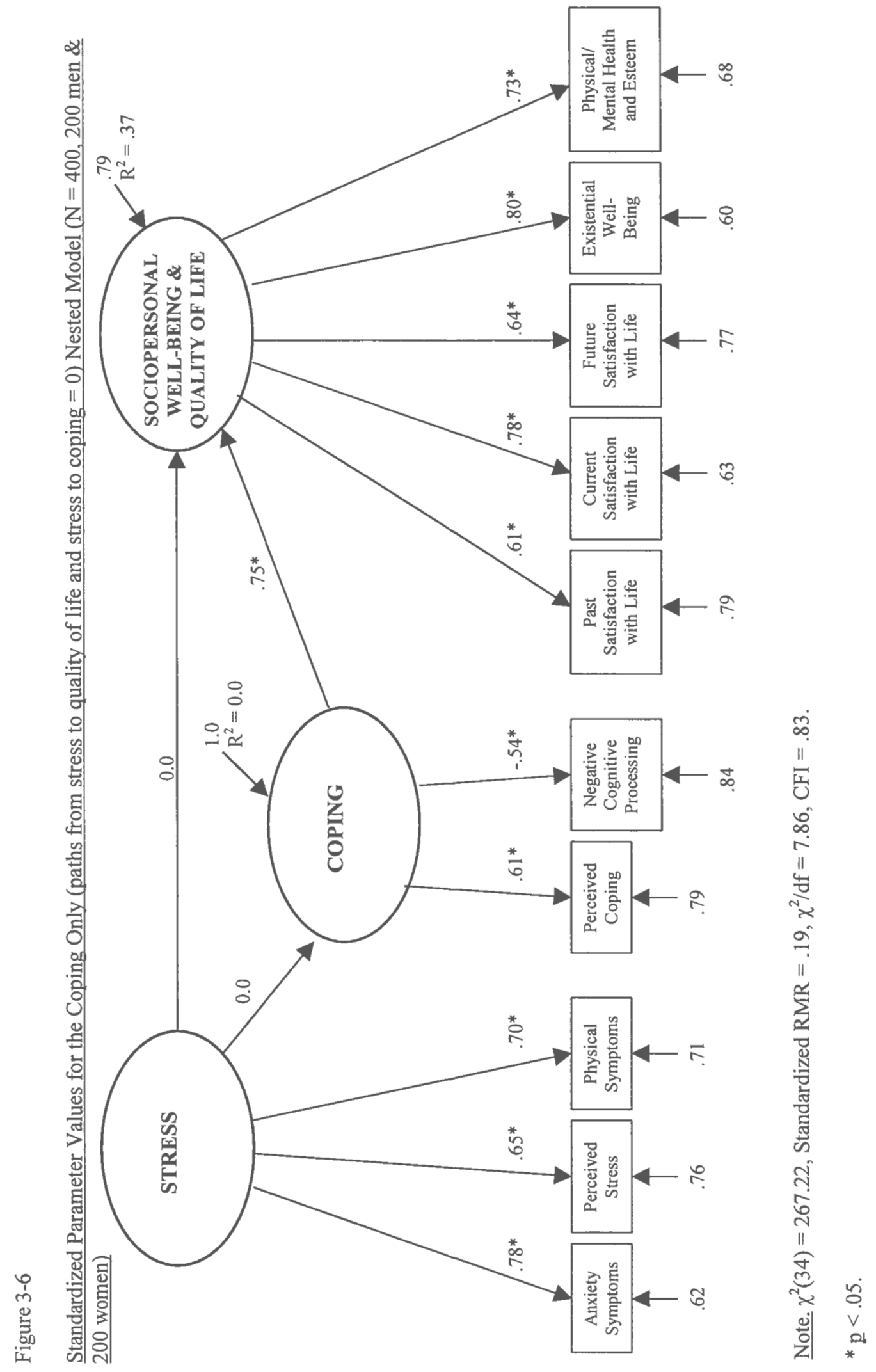




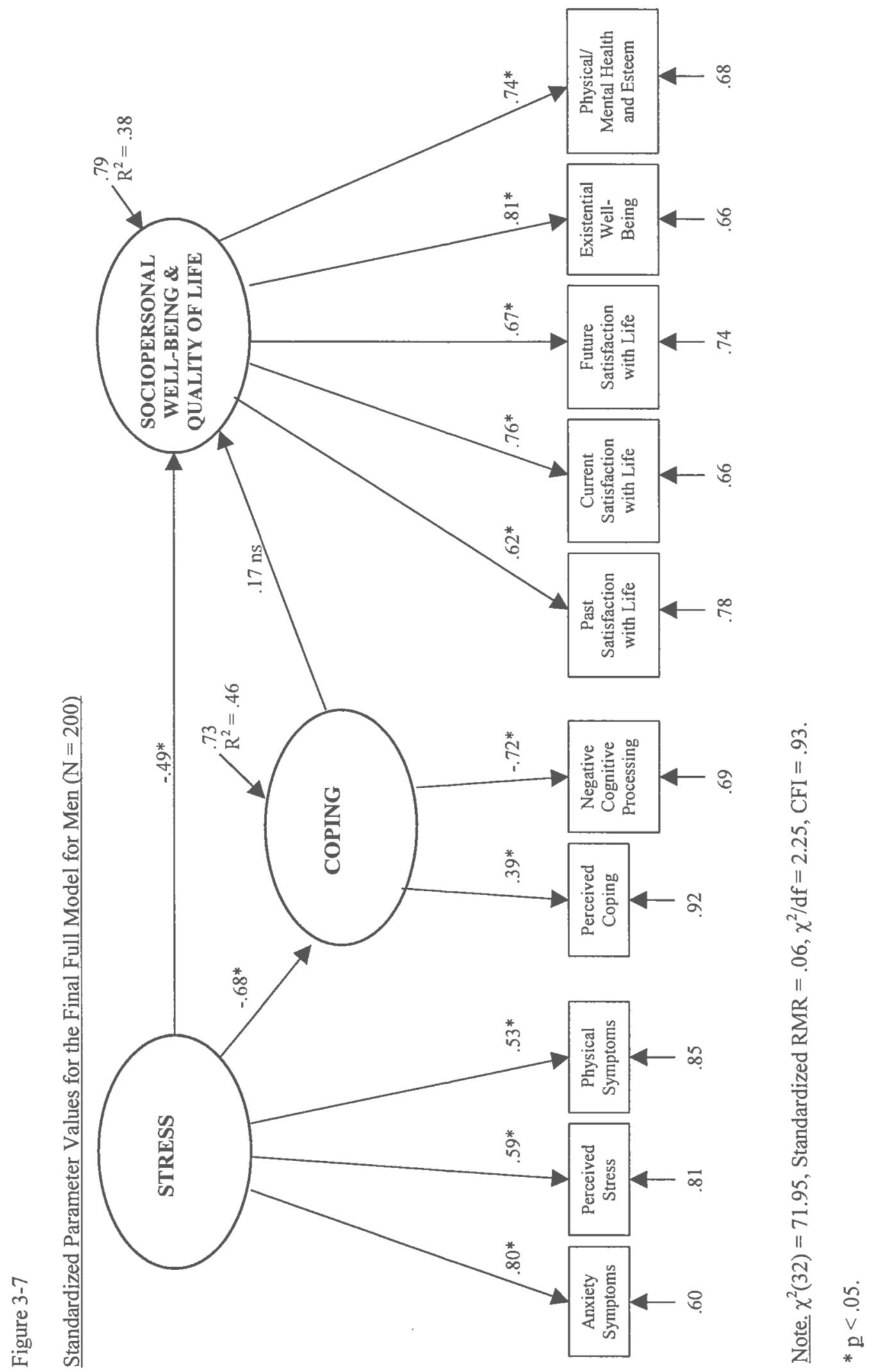




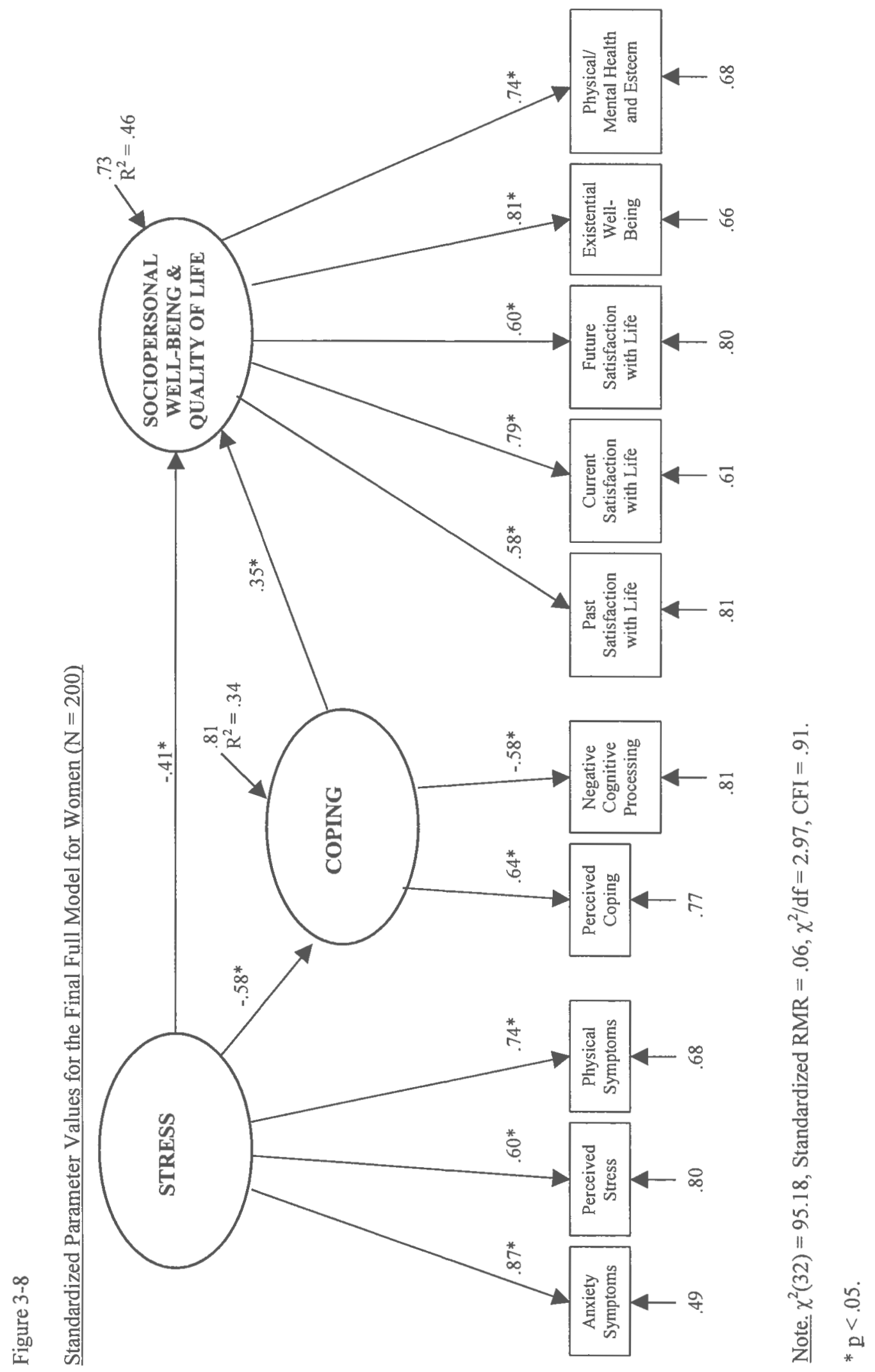




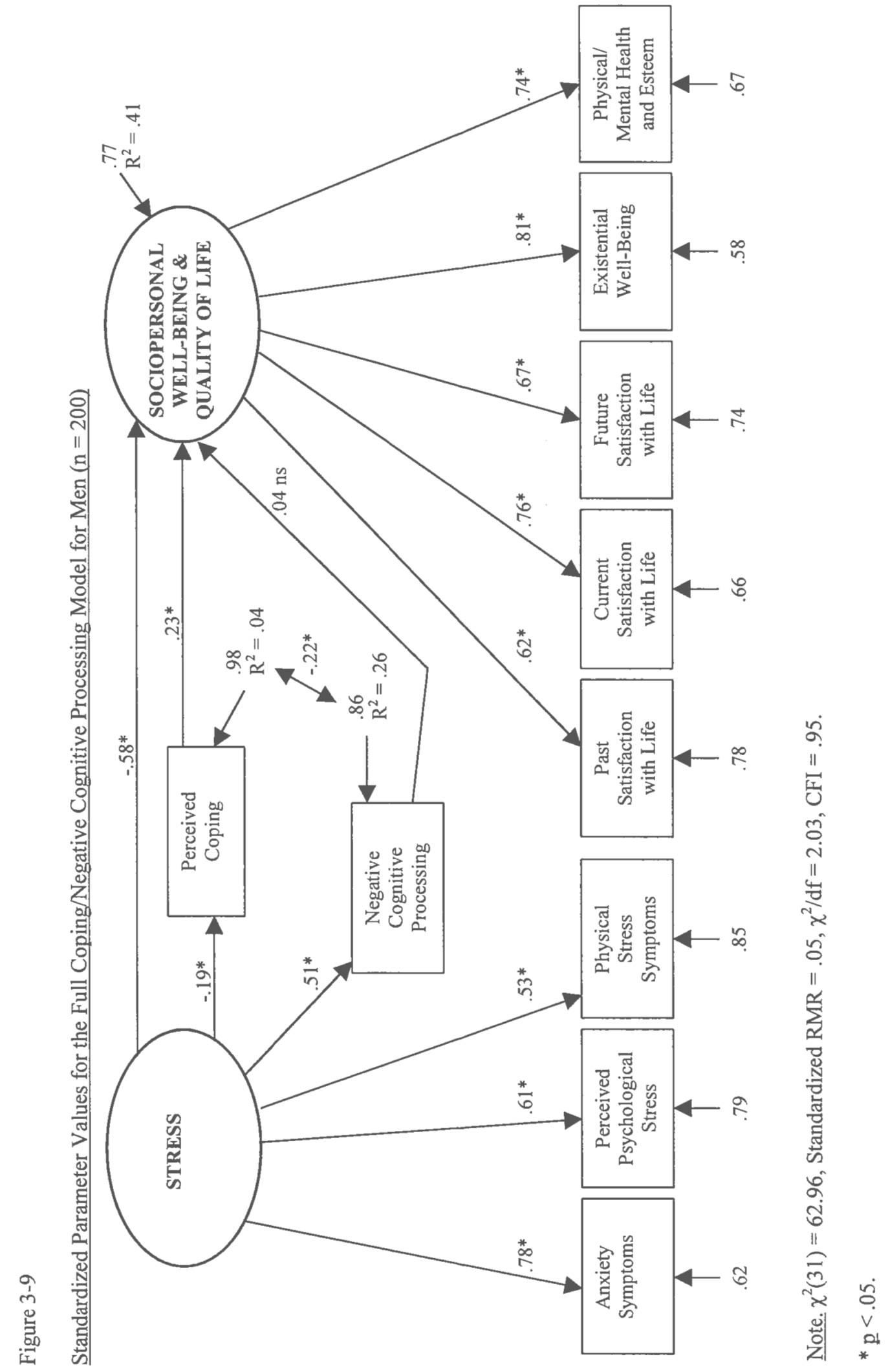




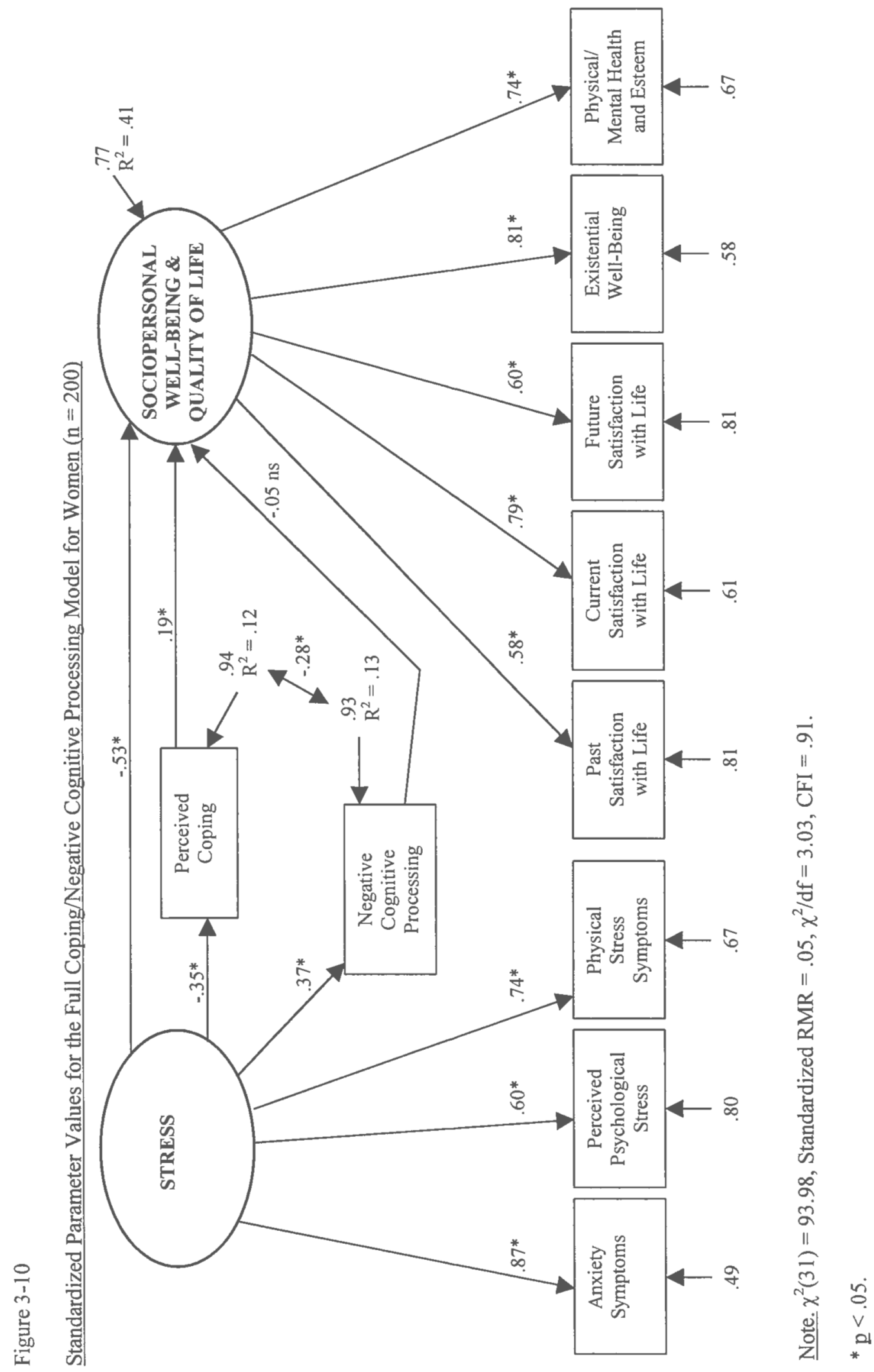




\section{Chapter 4}

\section{General Discussion}

The two manuscripts presented were meant to shed light on the area of sociopersonal well-being and quality of life. Included were some basic elements, conceptual frameworks, and theoretical overviews. The first manuscript (Chapter 2) presented a philosophy of science component that highlighted the ontology, epistemology, and methodology related to sociopersonal well-being and quality of life. It was posited that a teleologically pragmatic linking of specific components of Maslow's $(1968,1971)$ concepts of need motivation and goal-directed behavior, and Mischel's (1973, 1984, 1986) concepts of behavioral specificity and delay of gratification are sufficient in terms of being able to parsimoniously describe and explain a broad model of quality of life and well-being. As proposed by Kahneman, Diener, and Schwarz (1999), a suggested model for the study of well-being and quality of life contains a complete spectrum of life's elements from basic physiological components at the neuronal level to national, institutional, cultural, and social and economic components at the global level.

The second manuscript (Chapter 3) consisted of a study examining a mediational model of coping and sociopersonal well-being and quality of life. The manuscript included an extensive section related to the design, development, measures, and psychometrics related to the study. It was posited that coping and related measures would mediate, and act as a filter between measures of life stress and measures of quality of life and well-being. It was also posited that there would be significant gender differences 
associated with the relationships among stress, coping, and well-being measures, especially in terms of perceptions and experiences of stress. A latent variable mediational coping model was proposed and it was hypothesized that coping would be a significant mediator between measures of stress and measures of well-being and quality of life.

Results indicated that 10 composite variables resulted in a well-fitting 3 -factor confirmatory model $(\mathrm{CFI}=.93)$. The factors were: 1$)$ sociopersonal well-being and quality of life (past, current, future satisfaction with life; existential well-being; mental/physical health satisfaction), 2) stress (perceived psychological stress, physical symptoms, anxiety), and 3) coping (perceived coping, negative cognitive processing). Latent variable modeling results that included the testing of several competing models indicated that a full model that included a direct path from stress to quality of life and well-being was optimal. Further multiple sample analysis revealed significant standardized parameter differences that led to the acceptance of two gender specific final models having good fit indices ( $\mathrm{CFI}=.93$ for men and $\mathrm{CFI}=.91$ for women).

Post hoc modeling was performed to assess the possible gender differences related to the latent variable of coping. Two additional gender-specific models were presented with perceived coping and negative cognitive processing analyzed as separate measured mediator variables. Both models fit the data well $(\mathrm{CFI}=.95$ for men, $\mathrm{CFI}=.91$ for women). A review of the models indicated that there were differential gender relationships related to stress, coping, and negative cognitive processing. For men, the relationship between negative cognitive processing and stress was much greater relative to the relationship between stress and coping. For women, the relationships were 
relatively equal. For both men and women, negative cognitive processing was not a significant predictor of quality of life and well-being. Further investigation into the possible gender specific coping strategies and mechanisms, especially related to cognitive processing, is suggested.

Multiple analysis of variance (MANOVA) by gender revealed significant differences on five of the 10 composite variables. Familywise corrected mean scores showed that women reported significantly higher levels of perceived psychological stress and physical stress symptoms, and significantly lower levels of past satisfaction with life, current satisfaction with life, and mental/physical health and esteem than men. However, an important finding that can easily be overlooked was that there were no significant gender differences related to future satisfaction with life, existential well-being, and negative cognitive processing. The results were discussed in terms of the implications to largescale multivariate quality of life and well-being assessment. Methodological issues related to context and micro/macro level variables and interpretation of results were also discussed. The results are currently being used for psychometric normalization work on the family of Quality of life and Satisfaction instruments (SQOLAS for students, QOLAS for adults, and A-QOLAS for athletes). 
Appendix

By completing this survey, you are eligible to

WIN one of 5 (FIVE) GRAND PRIZES

worth $\$ 100$ each!

FIVE (5) \$100 GIFT CERTIFICATES

will be awarded by a random drawing.

You will be notified by Monday, April $12^{\text {th }}$

if you are a winner.

To enter the drawing please write your

FIRST NAME OR NICKNAME ONLY

AND A PHONE NUMBER.

First Name/Nickname

Phone Number

NOTE: To be eligible, survey must be completed and this portion (above dotted line) must remain attached to the survey.

Do not worry, the survey is confidential and anonymous, and you cannot be identified in any manner!

detach (tear or cut) along dotted line and keep lower portion

detach (tear or cut) along dotted line and keep this portion

SQOLAS 1999

Student Quality of Life and Satisfaction

Note: This instrument is confidential and anonymous. You cannot be identified in any manner. You must be at least 18 years old to participate in this study. We ask you to please respond to all items as honestly as possible. This survey is a general attitude and concerns survey related to how students feel about various aspects concerning their lives as college students. You can refuse to participate and you can refuse to respond to any item. We ask you to PLEASE respond to all of the items if possible.

If you are at least 18 years old, if you have read the above note, and if your questions have been answered, you have agreed to be a participant in this study. Thanks!

Survey questions? Call $x 2451$

If you have any need for or concern about any socio-personal issues related to yourself or anyone you know, please call the

URI Counseling Center for information.

874-2288 


\section{Appendix (cont.)}

\section{SQOLAS 1999 \\ Student Quality of Life and Satisfaction}

Note: This instrument is confidential and anonymous. You cannot be identified in any manner. You must be at least 18 years old to participate in this study. We ask you to please respond to all items as honestly as possible. This survey is a general attitude and concerns survey related to how students feel about various aspects concerning their lives as college students. You can refuse to participate and you can refuse to respond to any item. We ask you to PLEASE respond to all of the items if possible.

If you are at least 18 years old, if you have read the above note, and if your questions have been answered, you have agreed to be a participant in this study. Thanks! Survey questions? Call $\times 2451$

Please circle or fill in the best response for each item.

1. Age

2. Gender... Female

3. I am a... First Year Student Sophomore Junior Senior Grad Student

4. I work... full-time part-time don't work

a. If you work, approximately how many hours PER WEEK do you spend working?

b. If you work, is your job part of work-study or other financial aid-type program or package? yes

5. I live... (circle ONE only) down the line at home with parents

not down the line/not with parents

$$
\text { fraternity/sorority graduate student housing }
$$

residence hall (NAME of residence hall

6. College Major College Minor (if applicable)

7. Current GPA (last semester) Overall GPA (all college)

8. How many units/credits are you taking? How many units/credits do you usually take?

9. In my academic program, I am... (circle ONE)
far behind
somewhat behind yes

no on track

somewhat ahead

Do you own a computer? yes far ahead

no

11. I sell approximately $\%$ (percent) of my books back at the end of each semester.

12. Ethnic/Cultural background (please indicate/describe)

13. Marital status... single (never married) married

separated/divorced widowed

14. Are your natural parents presently living together? (circle ONE)

yes no, due to separation/divorce

no, due to death of one/both parents

other

15. What is your \#1 CURRENT personal "quality of life" concern?

16. What is your \#1 personal "quality of life" concern OVER THE NEXT 5 YEARS? 


\section{Appendix (cont.)}

We are interested how people are getting along financially these days compared to a year ago, and in the future. Please circle the most appropriate response for the next two items.

a. Would you say that YOU PERSONALLY are better off or worse off financially than a year ago?

$$
\text { worse off the same better off }
$$

b. Would you say that YOUR PARENTS/FAMILY are better off or worse off financially than a year ago?

$$
\text { worse off the same better off }
$$

Now, looking ahead, please circle the most appropriate response for the next two items.

c. Would you say that YOU PERSONALLY will be better off or worse off financially one year from now?

$$
\text { worse off the same better off }
$$

d. Would you say that YOUR PARENTS/FAMILY will be better off or worse off financially one year from now? worse off the same better off

Below are fifteen statements with which you may agree or disagree. Using the 1-7 scale below, indicate your agreement with each item by placing the appropriate number on the line preceding that item.

The 7-point scale is:

$1=$ strongly disagree

2 = disagree

3 = slightly disagree

$4=$ neither agree nor disagree

5 = slightly agree

$6=$ agree

7 = strongly agree
I will have the important things I want in the future.

The conditions of my future life will be excellent.

If I had my past life to live over, I would change nothing.

I am satisfied with my life in the past.

My life in the past was ideal for me.

The conditions of my life in the past were excellent.

I had the important things I wanted in my past.

I would change nothing about my current life.

I am satisfied with current life.

My current life is ideal for me.

The current conditions of my life are excellent.

I have important things I want right now.

There will be nothing that I will change about my future

I will be satisfied with my life in the future.

I expect my future life will be ideal for me. 


\section{Appendix (cont.)}

Please rate the following items as to how IMPORTANT they are to you PERSONALLY and how CONCERNED you are about them as far as how they affect you PERSONALLY. Please circle only one number for each item.

\begin{tabular}{|c|c|c|c|c|}
\hline & $\begin{array}{c}\text { Strong personal } \\
\text { importance \& } \\
\text { concern }\end{array}$ & $\begin{array}{c}\text { Moderate personal } \\
\text { importance \& } \\
\text { concern }\end{array}$ & $\begin{array}{c}\text { Slight personal } \\
\text { importance \& } \\
\text { concern } \\
\end{array}$ & $\begin{array}{r}\text { No perso } \\
\text { importar } \\
\text { conce }\end{array}$ \\
\hline Drug Use/Abuse & 4 & 3 & 2 & 1 \\
\hline Future Career lssues & 4 & 3 & 2 & 1 \\
\hline Social Behavior & 4 & 3 & 2 & 1 \\
\hline Sexual Behavior & 4 & 3 & 2 & 1 \\
\hline Use of Time & 4 & 3 & 2 & 1 \\
\hline Consumer/Financial lssues & 4 & 3 & 2 & 1 \\
\hline Physical Health & 4 & 3 & 2 & 1 \\
\hline Mental Health & 4 & 3 & 2 & 1 \\
\hline Multicultural/Diversity lssues & 4 & 3 & 2 & 1 \\
\hline Gender lssues & 4 & 3 & 2 & 1 \\
\hline Academic Issues & 4 & 3 & 2 & 1 \\
\hline Alcohol Use/Abuse & 4 & 3 & 2 & 1 \\
\hline Sexual Orientation & 4 & 3 & 2 & 1 \\
\hline Current Employment Issues & 4 & 3 & 2 & 1 \\
\hline Crime/Violence Issues & 4 & 3 & 2 & 1 \\
\hline Living Issues (safety, security) & 4 & 3 & 2 & \\
\hline
\end{tabular}

Please circle the appropriate response using the 1 to 6 point scale. Thanks!

\begin{tabular}{cccccc}
1 & 2 & 3 & 4 & 5 & 6 \\
$\begin{array}{c}\text { Strongly } \\
\text { Mgree }\end{array}$ & $\begin{array}{c}\text { Moderately } \\
\text { Agree }\end{array}$ & Agree & Disagree & $\begin{array}{c}\text { Moderately } \\
\text { Disagree }\end{array}$ & $\begin{array}{c}\text { Strongly } \\
\text { Disagree }\end{array}$ \\
\hline
\end{tabular}

1. I don't know who I am, where I came from, or where I am going.

2. I feel that life is a positive experience.

3. I feel unsettled about my future.

4. I feel very fulfilled and satisfied with my life.

5. I feel a sense of well being about the direction my life is headed in

6. I don't enjoy much about life.

7. I feel good about my future.

8. I feel that life is full of conflict and unhappiness.

9. Life doesn't have much meaning.

10. 1 believe there is some real purpose for my life.

$\begin{array}{llllll}1 & 2 & 3 & 4 & 5 & 6 \\ 1 & 2 & 3 & 4 & 5 & 6 \\ 1 & 2 & 3 & 4 & 5 & 6 \\ 1 & 2 & 3 & 4 & 5 & 6 \\ 1 & 2 & 3 & 4 & 5 & 6 \\ 1 & 2 & 3 & 4 & 5 & 6 \\ 1 & 2 & 3 & 4 & 5 & 6 \\ 1 & 2 & 3 & 4 & 5 & 6 \\ 1 & 2 & 3 & 4 & 5 & 6 \\ 1 & 2 & 3 & 4 & 5 & 6\end{array}$




\section{Appendix (cont.)}

In the last MONTH, how often was each of the following statements true of your own life? Using the 1-5 scale below, indicate your choice with each item by placing the appropriate number on the line preceding that item.

\begin{tabular}{|l|}
\hline This is the 5-point scale \\
(during the past MONTH): \\
$1=$ Never \\
$2=$ Seldom \\
$3=$ Occasionally \\
$4=$ Often \\
$5=$ Frequently
\end{tabular}

I was able to cope with difficult situations
I felt overwhelmed.
I was able to cope with unexpected problems.
I felt stressed by unexpected events.
I successfully solved problems that came up.
I felt that I had more stress than usual.
I felt able to cope with stress.
I I felt that there was not enough time to complete my daily tasks.
I felt able to meet demands.

Please circle the appropriate response using the 1 to 5 point scale.

\begin{tabular}{ccccc}
1 & 2 & 3 & 4 & 5 \\
Never & & Sometimes & & Always \\
\hline
\end{tabular}

1. I have trouble making inferences.

2. I have trouble organizing the information that I remember.

3. I often memorize material that I do not understand.

4. I have difficulty planning work when confronted with a complex task.

5. I often have difficulty finding the right words for expressing my ideas.

6. I find it difficult to handle questions requiring comparison of different concepts.

7. I have difficulty learning how to study for a course.

8. I find it difficult to handle questions requiring critical evaluation.

9. Most of my instructors lecture too fast.

10. I have trouble seeing the difference between apparently similar ideas.

$\begin{array}{lllll}1 & 2 & 3 & 4 & 5 \\ I & 2 & 3 & 4 & 5 \\ I & 2 & 3 & 4 & 5 \\ I & 2 & 3 & 4 & 5 \\ 1 & 2 & 3 & 4 & 5 \\ I & 2 & 3 & 4 & 5 \\ 1 & 2 & 3 & 4 & 5 \\ I & 2 & 3 & 4 & 5 \\ 1 & 2 & 3 & 4 & 5 \\ I & 2 & 3 & 4 & 5\end{array}$

Please fill in the blank where applicable or circle ALL ITEMS THAT APPLY. Please respond to all items.

1. What is your... Height ft. in.

Weight pounds

2. I have participated in counseling at some point in the past? yes no

in the past year? yes no

3. If you answered "yes" to any part of question \#2, please circle up to 3 items that you addressed or were concerned with: psychological testing family issues alcohol/drugs academic testing loneliness sexual/physical assault eating issues self-esteem depression relationships eating stress/coping grief/loss sleep issues other 


\section{Appendix (cont.)}

4. If you were to seek counseling, which of the following areas might you explore? (please circle up to 3 items.)

\begin{tabular}{|c|c|c|c|}
\hline $\begin{array}{l}\text { psychological testing } \\
\text { family issues }\end{array}$ & $\begin{array}{l}\text { academic testing loneliness } \\
\text { sexual/physical assault }\end{array}$ & $\begin{array}{l}\text { depression } \\
\text { stress/coping }\end{array}$ & $\begin{array}{l}\text { relationships } \\
\text { grief/loss }\end{array}$ \\
\hline alcohol/drugs & eating issues & ethnic/cultural issues & anger/rage \\
\hline sleep issues & other & & \\
\hline
\end{tabular}

5. My social support system from my FRIENDS is... (please circle one)

non-existent poor fair good very good excellent

6. My social support system from my FAMILY is... (please circle one)

non-existent poor fair good very good excellent

7. My current feelings about my own self-esteem and self worth are... (please circle one)

non-existent poor fair good very good excellent

8. On how many occasions have you had a drink of alcohol in the past $\mathbf{3 0}$ days? (please circle one)

$\begin{array}{lllllllllllllllllllll}\text { I do not drink } & 1 & 2 & 3 & 4 & 5 & 6 & 7 & 8 & 9 & 10 & 11 & 12 & 13 & 14 & 15 & 16 & 17 & 18 & 19 & 20 \text { or more }\end{array}$

9. In the past $\mathbf{3 0}$ days on those occasions when you drank alcohol, how many drinks did you usually have?

(please indicate)

10. Since the beginning of the school year, how often has your drinking caused you to...?

$\begin{array}{llll}\text { Have a hangover } & \text { not at all } & \text { one time } & \text { two or more times } \\ \text { Miss a class } & \text { not at all } & \text { one time } & \text { two or more times } \\ \text { Do something you later regretted } & \text { not at all } & \text { one time } & \text { two or more times } \\ \text { Forget where you were or what you did } & \text { not at all } & \text { one time } & \text { two or more times } \\ \text { Argue with friends } & \text { not at all } & \text { one time } & \text { two or more times }\end{array}$

11. The following members of my family abused alcohol or drugs before I was $\mathbf{1 8}$ years old (circle all that apply) mother father brothers and/or sisters, including step/half grandparent(s) stepparent or guardian

12. Please check (on line before item) all statements that describe your feelings and behavior in the past year.

Being afraid of gaining weight and becoming fat

__ Consuming large amounts of food during short periods of time

__ Using any or all of the following to try to prevent weight gain: vomiting, laxatives, diuretics, fasting, vigorous exercise more than $1 \mathrm{hr} /$ day

Feeling personal distress and significantly limiting activities because of feeling overweight

Going on extremely low calorie diets

13. How satisfied are your "mental/psychological" self?

unsatisfied not very satisfied satisfied mostly satisfied very satisfied

14. How satisfied are your "physical/physiological" self?

unsatisfied not very satisfied mostly satisfied vatisfied vatisfied

15. Are you aware that the URI Counseling Center is available to ALL URI students? yes no 


\section{Appendix (cont.)}

For the following questions, please circle "yes" or "no" if they apply. Thanks!

1. During the past month, did you experience a sudden, unexplained attack of intense fear, anxiety, or panic for no apparent reason? yes no

If you answered "yes" to $\# 1$, please answer a and b. If you answered "no," go to $\# 2$.

a. Were you afraid that you might have more of these attacks? yes no

b. Did you have unexplained heart palpitations, a racing heart, or shortness of breath for no apparent reason? yes no

2. During the past month, have you been afraid or unable to travel alone without a companion or friend? yes no

3. During the past month, have you persistently worried about several different things (work, school, family, money, etc.)? yes no

4. During the past month, did you find it difficult to control your worrying? yes no

5. During the past month, did your persistent worrying or nervousness cause problems with your work or dealing with people?

yes no

6. During the past month, were you afraid to do things in front of people such as speak, eating, perform, etc.? yes no

7. During the past month, did you either avoid or feel very uncomfortable in situations

involving people, such as parties, weddings, dating, dances, and other social events? yes no

I have experienced...(circle all that apply)

Serious threat to my life or physical integrity

Sudden destruction to my home or community

Sexual abuse before the age 18
Serious threat to my family or close relatives or friends

Seeing other person(s) seriously injured or killed

If you circled any of the above statements, please answer the next questions (a. - e.), otherwise, go to \#8.

a. Have you ever relived the traumatic experience through recurrent dreams, preoccupations, or flashbacks? yes no

b. Did you seem less interested in important things, not "with it" or unable to experience or express emotions? yes no

c. Did you have problems sleeping, concentrating, or have a short temper? yes no

d. Did you avoid any place or anything that reminded you of the original horrible event? yes no

e. Did you have some of the above problems for more than one month? yes no

8. Please circle the appropriate response related to how you feel RIGHT NOW using the $\mathbf{I}$ to $\mathbf{5}$ point scale.

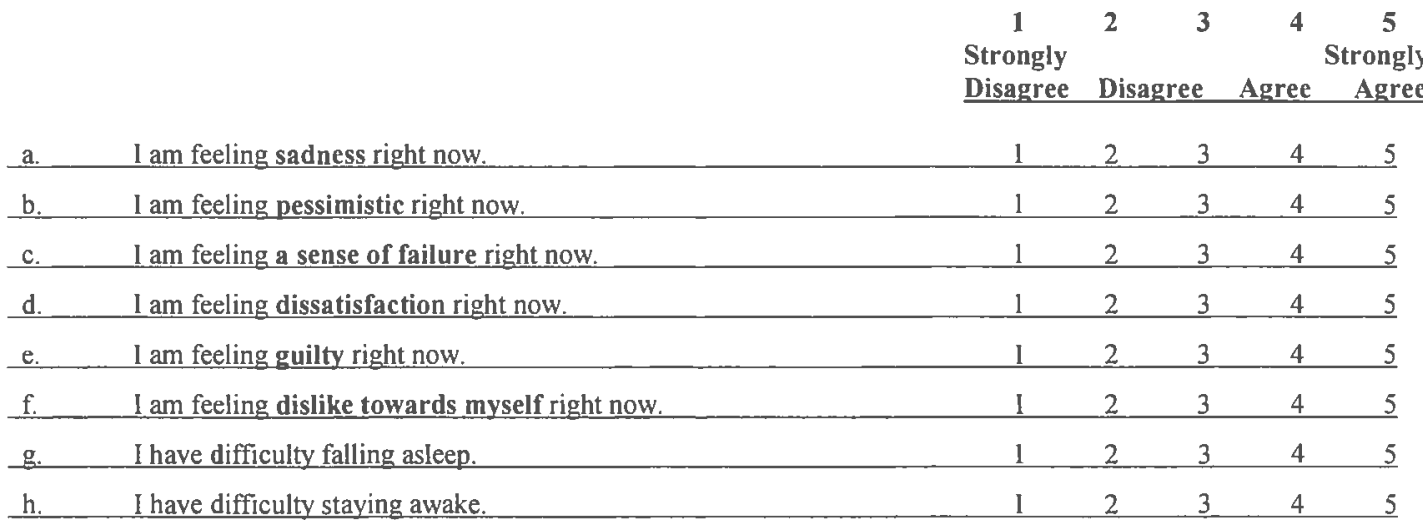

9. Have you experienced either significant weight gain or loss (without dieting)? yes no

10. How much of the time does your anxiety interfere with your daily life? (circle ONE)

Not at all $(0 \%)$

About half the time (40-60\%)
Rarely (5-10\%)

Most of the time (70-80\%)
Some of the time (20-30\%)

Almost all the time (90-100\%) 


\section{Appendix (cont.)}

11. If you are not in treatment, how ready are you to get professional help? (circle the BEST answer)
Not even thinking about getting help
Occasionally thinking about getting help
Considering getting help
Almost ready to get help
Ready to get help now

Please circle the appropriate response using the 1 to 5 point scale. Responding with your immediate reaction will increase accuracy. Thanks!

1. I consider myself a religious person.

\begin{tabular}{|c|c|c|c|c|c|}
\hline 1 & 2 & 3 & 4 & 5 & 6 \\
\hline Strongly & Moderately & & & Moderately & Strongly \\
\hline Agree & Agree & Agree & Disagree & Disagree & Disagree \\
\hline 1 & 2 & 3 & 4 & 5 & 6 \\
\hline 1 & 2 & 3 & 4 & 5 & 6 \\
\hline 1 & 2 & 3 & 4 & 5 & 6 \\
\hline 1 & 2 & 3 & 4 & 5 & 6 \\
\hline 1 & 2 & 3 & 4 & 5 & 6 \\
\hline 1 & 2 & 3 & 4 & 5 & 6 \\
\hline Jod. 1 & 2 & 3 & 4 & 5 & 6 \\
\hline
\end{tabular}

\begin{tabular}{|c|c|c|c|c|c|c|c|c|c|c|c|}
\hline \multirow[t]{2}{*}{$\begin{array}{c}\text { In the last month, how often did you } \\
\text { experience any of the following physical } \\
\text { symptoms? }\end{array}$} & \multicolumn{5}{|c|}{$\begin{array}{l}\text { Please respond to the items } \\
\quad \text { using the scale: } \\
0=\text { Did not experience } \\
1=\text { Seldom ( } 1 \text { or } 2 \text { times) } \\
2=\text { Occasionally ( } 3 \text { to } 5 \text { times) } \\
3=\text { Often ( } 6 \text { to } 10 \text { times) } \\
4=\text { Repeatedly (more than } 10 \\
\text { times) }\end{array}$} & $\begin{array}{l}\text { If you } \\
\text { answer } \\
\text { "YES" } \\
\text { to an } \\
\text { item in } \\
\text { the } \\
\text { column } \\
\text { on left, } \\
\text { please } \\
\text { respond } \\
\text { to same } \\
\text { item } \\
\text { using } \\
\text { column } \\
\text { on right. }\end{array}$ & \multicolumn{5}{|c|}{$\begin{array}{l}\text { If you experienced any of } \\
\text { the physical symptoms in } \\
\text { the last month, how much } \\
\quad \text { did it bother you? } \\
\text { using the scale: } \\
0=\text { None } \\
1=\text { Slightly } \\
2=\text { Moderately } \\
3=\text { Very Much } \\
4=\text { Extremely }\end{array}$} \\
\hline & \multicolumn{5}{|c|}{$\begin{array}{l}\text { if you respond from } 1 \text { to } 4 \text { in } \\
\text { this column, }\end{array}$} & then & \multicolumn{5}{|c|}{$\begin{array}{c}\text { respond to same item using } \\
\text { this column. }\end{array}$} \\
\hline Headaches? & 0 & 1 & 2 & 3 & 4 & if yes $\rightarrow$ & $\mathbf{0}$ & 1 & 2 & 3 & 4 \\
\hline Insomnia or Restless Sleeping? & $\mathbf{0}$ & 1 & 2 & 3 & 4 & if yes $\rightarrow$ & $\mathbf{0}$ & 1 & 2 & 3 & 4 \\
\hline Stomach or Gastro-Intestinal Distress? & 0 & 1 & 2 & 3 & 4 & if yes $\rightarrow$ & $\mathbf{0}$ & 1 & 2 & 3 & 4 \\
\hline Irritability? & $\mathbf{0}$ & 1 & 2 & 3 & 4 & if yes $\rightarrow$ & $\mathbf{0}$ & 1 & 2 & 3 & 4 \\
\hline General Aches and Pains in Muscles or Back? & 0 & 1 & 2 & 3 & 4 & if yes $\rightarrow$ & $\mathbf{0}$ & 1 & 2 & 3 & 4 \\
\hline Nausea? & 0 & 1 & 2 & 3 & 4 & if yes $\rightarrow$ & $\mathbf{0}$ & 1 & 2 & 3 & 4 \\
\hline Forgetfulness or Difficulty Concentrating? & o & 1 & 2 & 3 & 4 & if yes $\rightarrow$ & $\mathbf{0}$ & 1 & 2 & 3 & 4 \\
\hline Nervousness or Restlessness? & $\mathbf{0}$ & 1 & 2 & 3 & 4 & if yes $\rightarrow$ & $\mathbf{0}$ & 1 & 2 & 3 & 4 \\
\hline Shortness of Breath or Pounding Heart? & 0 & 1 & 2 & 3 & 4 & if yes $\rightarrow$ & $\mathbf{0}$ & 1 & 2 & 3 & 4 \\
\hline Fatigue or Low Energy? & 0 & 1 & 2 & 3 & 4 & if yes $\rightarrow$ & 0 & 1 & 2 & 3 & 4 \\
\hline
\end{tabular}

Thank you very much for your participation! 


\section{Bibliography}

Albaili, M. A. (1993). Psychometric properties of the inventory learning processes: Evidence from United Arab Emirates college students. Psychological Reports, 72, 13311336.

American Psychiatric Press. (1988). Anxiety disorders. New York, NY: APP.

American Psychological Association. (1992). Ethical principles of psychologists and code of conduct. American Psychologist, 47, 1597-1611.

Arbuckle, J. L., \& Wothke, W. (1999). AMOS 4.0 user's guide. Chicago, IL: Small Waters.

Argyle, M. (1999). Causes and correlates of happiness. In D. Kahneman, E. Diener, and N. Schwarz (Eds.), Well-being: The foundations of hedonic psychology (pp. 353373). New York, NY: Russell Sage Foundation.

Atkinson, R. C. (1977). Reflections on psychology's past and concerns about its future. American Psychologist, 32, 205-210.

Ayers, T. S., Sandler, I. N., West, S. G., \& Roosa, M. W. (1996). A dispositional and situational assessment of children's coping: Testing alternative models of coping. Journal of Personality, 64(4), 923-958.

Baron, R. M., \& Kenny, D. A. (1986). The moderator-mediator variable distinction in psychological research: Conceptual, strategic, and statistical considerations. Journal of Personality and Social Psychology, 51, 1173-1182. 
Bartling, C. A. (1988). Longitudinal changes in the study habits of successful college students. Educational and Psychological Measurement, 48, 527-535.

Beck, A. T., \& Beck, R. W. (1972). Screening depressed patients in family practice: A rapid technique. Postgraduate Medicine, 52, 81-85.

Beck, A. T., Rial, W. Y., \& Rickles, K. (1974). Short form of depression inventory: Cross-validation. Psychological Reports, 34, 1184-1186.

Bentler, P. M. (1995). EQS structural equations program manual. Encino, CA: Multivariate Software Inc.

Bentler, P. M., \& Wu, E. J. C. (1995). EQS for windows. Encino, CA: Multivariate Software Inc.

Berkowitz, L., \& Donnerstein, E. (1982). External validity is more than skin deep: Some answers to criticisms of laboratory experiments. American Psychologist, 37(3), 245-257.

Britton, B. K., \& Tesser, A. (1991). Effects of time-management practices on college grades. Journal of Educational Psychology, 83(3), 405-410.

Bufford, R. K., Paloutzian, R. F., \& Ellison, C. W. (1991). Norms for the spiritual well-being scale. Journal of Psychology and Theology, 19, 56-70.

Burkholder, G. J., \& Harlow, L. L. (1998). Using structural equation modeling techniques to evaluate HIV risk models. Structural Equation Modeling, 3(4), 348-368.

Byrne, B. M. (1995). One application of structural equation modeling from two perspectives: Exploring the EQS and LISREL strategies. In R. H. Hoyle (Ed.), Structural 
equation modeling: Concepts, issues and applications (pp. 138-157). Thousand Oaks, CA: Sage.

Cantor, N. \& Sanderson, N. C. (1999). Life task participation and well-being: The importance of taking part in daily life. In D. Kahneman, E. Diener, and N. Schwarz (Eds.), Well-being: The foundations of hedonic psychology (pp. 230-243). New York, NY: Russell Sage Foundation.

Carney, C. G., \& Savitz, C. J. (1980). Student and faculty perceptions of student needs and the services of a university counseling center: Differences that make a difference. Journal of Counseling Psychology, 27, 597-604.

Cattell, R. B. (1966). The scree test for the number of factors. Multivariate Behavioral Research, 1(2), 245-276.

Clark, R., Anderson, N. B., Clark, V. R., \& Williams, D. R. (1999). Racism as a stressor for African Americans: A biopsychosocial model. American Psychologist, 54, 805-816.

Cohen, J. (1988). Statistical power analysis for the behavioral sciences $\left(2^{\text {nd }}\right.$ ed.). Hillsdale, NJ: Lawrence Erlbaum Associates.

Cohen, R. J., \& Swerdlik, M. E. (1999). Psychological testing and assessment $\left(6^{\text {th }}\right.$ ed.). Mountain View, CA: Mayfield Publishing Co.

Corey, G. (1986). Theory and practice of counseling and psychotherapy $\left(3^{\text {rd }} \mathrm{ed}.\right)$. Pacific Grove, CA: Brooks/Cole.

Craik, F. I. M., \& Lockhart, R. S. (1972). Levels of processing: A framework for memory research. Journal of Verbal Learning and Verbal Behavior, 11, 671-684. 
Craik, F. I. M., \& Tulving, E. (1975). Depth of processing and retention of words in episodic memory. Journal of Experimental Psychology: General, 104, 268-294.

Cronbach, L. J. (1951). Coefficient alpha and the internal structure of tests. Psychometrica, 16, 297-334.

Cronbach, L. J., \& Meehl, P. E. (1955). Construct validity in psychological tests. Psychological Bulletin, 52, 281-302.

Csikszentmihalyi, M. (1999). If we are so rich, why aren't we happy? American Psychologist, 54(10), 821-827.

Dean, P. J., \& Range, L. M. (1996). The escape theory of suicide and perfectionism in college students. Death Studies, 20, 415-424.

DeMan, A. F., \& Leduc, C. P. (1995). Suicidal ideation in high school students: Depression and other correlates. Journal of Clinical Psychology, 51(2), 173-181.

DeSimone, A., Murray, P, \& Lester, D. (1994). Alcohol use, self-esteem, depression, and suicidality in high school students. Adolescence, 29(116), 939-942.

Diener, E. (1984). Subjective well-being. Psychological Bulletin, 95(3), 542-575.

Diener, E. (2000). Subjective well-being: The science of happiness and a proposal for a national index. American Psychologist, 55, 34-43.

Diener, E., \& Diener, M. (1995). Cross-cultural correlates of life satisfaction and selfesteem. Journal of Personality and Social Psychology, 68(4), 653-663.

Diener, E., Emmons, R. A., Larsen, R. J., \& Griffen, S. (1985). The satisfaction with life scale. Journal of Personality Assessment, 49, 71-76. 
Diener, E., Eunkook, M. S., Smith H. L., \& Shao, L. (1995). National differences in reported subjective well-being: Why do they occur? Social Indicators Research, 34, 7-32.

Diener, E., Horwitz, J., \& Emmons, R. A. (1985). Happiness of the very wealthy. Social Indicators, 16, 263-274.

Diener, E., \& Lucas, R. E. (1999). Personality and subjective well-being. In D. Kahneman, E. Diener, and N. Schwarz (Eds.), Well-being: The foundations of hedonic psychology (pp. 213-229). New York, NY: Russell Sage Foundation.

Disch, W. B., \& Campbell, J. F. (1997). Counseling center survey (Tech. Rep. Vol. 1(8), No. 1). Kingston: University of Rhode Island, Division of Student Affairs, Student Quality of Life and Satisfaction (SQOLAS).

Disch, W. B., \& Campbell, J. F. (1999). Counseling center survey (Tech. Rep. Vol. 3(5), No. 1). Kingston: University of Rhode Island, Division of Student Affairs, Student Quality of Life and Satisfaction (SQOLAS).

Disch, W. B., Dougan, T. R., \& Campbell, J. F. (1997). Student concern areas survey (Tech. Rep. Vol. 7(7), No. 1). Kingston: University of Rhode Island, Division of Student Affairs, Student Quality of Life and Satisfaction (SQOLAS).

Disch, W. B., Fava, J. L., \& Sarkin, J. (2000). Development, exploratory, and confirmatory structure of the Rhode Island Physical Symptoms Inventory. Manuscript in preparation.

Disch, W. B., Harlow, L. L., Campbell, J. T, \& Dougan, T. R. (in press). Student functioning, concerns, and sociopersonal well-being. Social Indicators Research. 
Disch, W. B., Nolan, M. F., Shapiro, S. B., Dougan, T. R., \& Campbell, J. F. (1999). [1999 student quality of life and satisfaction survey (SQOLAS). Division of Student Affairs, University of Rhode Island]. Unpublished Raw Data.

Disch, W. B., \& Olick, K. (1998). Student concern and importance areas: A replication study. Manuscript in preparation, University of Rhode Island.

Douglas, K. A., Collins, J. L., Warren, C., Kann, L., Gold, R., Clayton, S., Ross, J. G., \& Kolbe, L. J. (1997). Results from the 1995 national college health risk behavior survey. Journal of American College Health, 46, 55-66.

Ellison, C. W. (1983). Spiritual well-being: Conceptualization and measurement. Journal of Psychology and Theology, 11(4), 330-340.

Ensel, W. M., \& Lin, N. (1991). The life stress paradigm and psychological distress. Journal of Health and Social Behavior, 32(4), 321-341.

Fava, J. L., Ruggiero, L., \& Grimley, D. M. (1998). The development and structural confirmation of the Rhode Island Stress and Coping Inventory. Journal of Behavioral Medicine, 21, 601-611.

Folkman, S., \& Lazurus, R. S. (1985). If it changes it must be a process: Study of emotion and coping during three stages of a college examination. Journal of Personality and Social Psychology, 48, 150-170.

Frankl, V. E. (1959). Man's search for meaning. Boston: Beacon Press.

Frankl, V. (1978). The unheard cry for meaning. New York: Simon \& Schuster (Touchstone). 
Gallagher, R. P., Golin, A., \& Kelleher, K. (1992). The personal, career, and learning skills needs of college students. Journal of College Student Development, 33, 301-309.

Goldman, J. A., \& Harlow, L. L. (1993). Self-perception variables that mediate AIDSpreventive behavior in college students. Health Psychology, 12(6), 489-498.

Gorsuch, R. L. (1983). Factor analysis $\left(2^{\text {nd }}\right.$ ed.). Hillsdale, NJ: Erlbaum.

Gould, J. (1982). A psychometric investigation of the standard and short form Beck Depression Inventory. Psychological Reports, 51, 1167-1170.

Graham, S. (1992). "Most of the subjects were white and middle class:" Trends in published research on African Americans in selected APA journals, 1970-1989. American Psychologist, 47(5), 629-639.

Guardino, M. (1995). Planning and promotion guide: National Anxiety Disorders Screening Day, 1995. New York, NY: APP.

Guba, E. G. (1990). (Ed.). The paradigm dialog. Newberry Park, CA: Sage.

Harlow, L. L., \& Newcomb, M. D. (1990). Towards a general hierarchal model of meaning and satisfaction in life. Multivariate Behavioral Research, 25(3), 387-405.

Harris, H. J., \& Anttonen, R. G. (1986). Assessing needs of male and female college freshmen. Journal of College Student Personnel, 27, 277.

Hasse, J. E., Britt, T., Coward, D. D., \& Leidy, N. K. (1992). Simultaneous concept analysis of spiritual perspective, hope, acceptance and self-transcendence. IMAGE Journal of Nursing Scholarship, 24(2), 141-147. 
Hempel, C. G. (1998). Science and human values. In E. D. Klemke, R. Hollinger, D. W. Rudge, \& D. A. Kline (Eds.), Introductory readings in the philosophy of science $\left(3^{\text {rd }}\right.$ ed., pp. 499-514). Amherst, NY: Prometheus.

Howell, D. C. (1992). Statistical methods for psychology ( $3^{\text {rd }}$ ed.). Belmont, CA: Wadsworth.

Hoyle, R. H. (1995). (Ed.). Structural equation modeling: Concepts, issues and applications. Thousand Oaks, CA: Sage.

Hoyle, R. H., \& Panter, A. T. (1995). Writing about structural equation models. In R. H. Hoyle (Ed.), Structural equation modeling: Concepts, issues and applications (pp. 158176). Thousand Oaks, CA: Sage.

Hu, L., \& Bentler, P. M. (1995). Evaluating model fit. In R. H. Hoyle (Ed.), Structural equation modeling: Concepts, issues and applications (pp. 76-99). Thousand Oaks, CA: Sage.

Hwang, A. (1996). Positivist and constructivist persuasions in instructional development. Instructional Science, 24, 343-356.

Illovsky, M. E. (1997). Effects of counseling on grades and retention. Journal of College Student Psychotherapy, 12, 29-44.

Janis, I. L., \& Mann, L. (1977). Decision making: A psychological analysis of conflict, choice, and commitment. New York: Free Press.

Kahneman, D., Diener, E. \& Schwarz, N. (1999). (Eds.). Well-Being: The foundations of hedonic psychology. New York, NY: Russell Sage Foundation. 
Kendler, H. H. (1999). The role of value in the world of psychology. American Psychologist, 54(10), 828-835.

Kozma, A., \& Stones, M. J. (1983). Predictors of happiness. Journal of Gerontology, $\underline{38}(5), 626-628$.

Lazarus, R. S. (1966). Psychological stress and the coping process. New York: McGraw Hill.

Lazarus, R. S., \& Folkman, S. (1984). Stress, appraisal, and coping. New York: Springer.

Maney, D. W. (1990). Predicting university students' use of alcoholic beverages. Journal of College Student Development, 31, 23-32.

Markus, K. A. (1998a). Science, measurement, and validity: Is completion of Samuel Messick's synthesis possible? Social Indicators Research, 45, 7-34.

Markus, K. A. (1998b). Validity, facts, and values sans closure: Reply to Messick, Reckase, Moss, and Zimmerman. Social Indicators Research, 45, 73-82.

Messick, S. (1998). Test validity: A matter of consequence. Social Indicators Research, 45, 35-44.

Maslow, A. H. (1968). Toward a psychology of being ( $2^{\text {nd }}$ ed.). New York: Van Nostrand.

Maslow, A. H. (1970). Motivation and personality (rev. ed.). New York: Harper \& Row.

Maslow, A. H. (1971). The farther reaches of human nature. New York: Viking. 
Menzies, T. V., \& Boak, R. T. (1994). The quality of life as perceived by students in a college of applied arts and technology. College Student Journal, 28, 46-56.

Michalos, A. C. (1985). Multiple discrepancy theory (MDT). Social Indicators Research, 16, 347-413.

Miller, J. R., \& Burbank, P. M. (1994). Congruence among philosophy, theory, and method in nursing research. In Workgroup of European Nurse Researchers, The contribution of nursing research: past, present, future, Vol. II. Proceedings at the $7^{\text {th }}$ Biennial Conference, Oslo, Norway: Falch Hurtigtrykk (pp. 704-709).

Mischel, W. (1968). Personality and assessment. New York: Wiley.

Mischel, W. (1973). Toward a cognitive social learning reconceptualization of personality. Psychological Review, 80, 252-283.

Mischel, W. (1979). On the interface of personality and cognition: Beyond the personsituation debate. American Psychologist, 34, 740-754.

Mischel, W. (1984). Convergences and challenges in the search for consistency. American Psychologist, 39, 351-364.

Mischel, W. (1986). Introduction to personality (4th ed.). Orlando, FL: Holt, Rinehart, and Winston.

Mischel, W. (1993). Introduction to personality ( $5^{\text {th }}$ ed.). Fort Worth, TX: Harcourt, Brace, Jovanovich.

Moberg, D. O. (1979). The development of social indicators for quality of life research. Sociological Analysis, 40(1), 11-26. 
Munhall, P. L. (1982). Nursing philosophy and nursing research: In apposition or opposition? Nursing Research, 31(3), 176-177, 181.

Myers, D. G. (1993). The pursuit of happiness. New York: Avon.

Myers, D. G. (1995). Psychology ( $4^{\text {th }}$ ed.). New York: Worth Publishers.

Myers, D. G. (1999). Close relationships and quality of life. In D. Kahneman, E. Diener, and N. Schwarz (Eds.), Well-being: The foundations of hedonic psychology (pp. 374-391). New York, NY: Russell Sage Foundation.

Myers, D. G. (2000). The funds, friends, and faith of happy people. American Psychologist, 55, 56-67.

Myers, D. G., \& Diener, E. (1995). Who is happy? Psychological Science, 6, 10-19.

Oswalt, R., \& Finkelberg, S. (1995). College depression: Causes, duration, and coping. Psychological Reports, $77,858$.

Paloutzian, R. F., \& Ellison, C. W. (1982). Loneliness, spiritual well-being, and quality of life. In L. A. Peplau and D. Perlman (Eds.), Loneliness: A sourcebook of current theory, research, and therapy. New York: Wiley.

Parducci, A. (1995). Happiness, pleasure, and judgment. Mahwah, NJ: Erlbaum.

Pavot, W., Diener, E., \& Suh, E. (1998). The temporal satisfaction with life scale. Journal of Personality Assessment, 70(2), 340-354.

Pavot, W., \& Diener, E. (1993). Review of the satisfaction with life scale. Psychological Assessment, 5(2), 164-172.

Perlin, L. I., Lieberman, M. A., Menaghan, E. G., \& Mullan, J. T. (1981). The stress process. Journal of Health and Social Behavior, 22, 337-356. 
Rachlin, H. (1992). Teleological behaviorism. American Psychologist, 47, 1371-1382.

Rachlin, H. (1996). Can we leave cognition to cognitive psychologists? Comments on an article by George Lowenstein. Organizational Behavior and Human Decision Processes, 65(3), 296-299.

Ross, L. (1995). The spiritual dimension: Importance to patients' health, well-being and quality of life and its implications for nursing practice. International Journal of Nursing Studies, 32(5), 457-468.

Ryff, C. D. (1989). Happiness is everything, or is it? Explorations on the meaning of psychological well-being. Journal of Personality and Social Psychology, 57(6), 10691081.

Sandler, I. N., Wolchick, S. A., MacKinnon, D., Ayers, T. S., \& Roosa, M. W. (1997). Developing linkages between theory and intervention in stress and coping processes. In S. A. Wolchick \& I. N. Sandler (Eds.). Handbook of children's coping: Linking theory and intervention (pp. 3-40). New York, NY: Plenum.

Schmeck, R. R. (1983). Learning styles of college students. In R. Dillon, \& R. Schmeck (Eds.), Individual differences in cognition. New York: Academic Press.

Schmeck, R. R., Geisler-Brenstein, E., \& Cercy, S. P. (1991). Self-concept and learning: The revised Inventory of Learning Processes. Educational Psychology, 11, 343362.

Schmeck, R. R., \& Grove, E. (1979). Academic achievement and individual differences in learning processes. Applied Psychological Measurement, 3, 43-49. 
Schmeck, R. R., \& Ribich, F. (1977). Construct validation of the inventory of learning processes. Applied Psychological Measurement, 2, 551-562.

Schnoll, R. A., Harlow, L. L., Brandt, U., \& Stolbach, L. L. (1998). Using two factor structures of the Mental Health Adjustment to Cancer (MAC) scale for assessing adaptation to breast cancer. Psycho-Oncology, 7(5), 424-435.

Seligman, M. P., \& Csikszentmihalyi, M. (2000). Positive psychology: An introduction. American Psychologist, 55, 5-14.

Selye, H. (1956). The stress of life. New York, NY: McGraw-Hill.

Silverstein, A. (1995). Teleological behaviorism and internal control of behavior. Behavior and Brain Sciences, 18, 142-143.

Skinner, E. A., \& Wellborn, J. G. (1994). Coping during childhood and adolescence: A motivational perspective. In R. Lerner, D. Featherman, \& M. Perlmuter (Eds.). Lifespan development and behavior, Vol. 12 (pp. 91-123). Hillsdale, NJ: Erlbaum.

Solomon, L. J., \& Rothblum, E. D. (1984). Academic procrastination: Frequency and cognitive-behavioral correlates. Journal of Counseling Psychology, 31(4), 503-509.

SPSS Inc. (1999). Statistical Package for the Social Services - version 9.0. Chicago, IL: SPSS, Inc.

Staats, S., Armstrong-Stassen, M., \& Partilo, C. (1995). Student well-being: Are they better off now? Social Indicators Researcher, 34, 93-112.

Stewart, A. L., Hays, R. D., \& Ware, J. E., Jr. (1988). The MOS short form general health survey: Reliability and validity in a patient population. Medical Care, 26, 724-735. 
Stones, M. J., \& Kozma, A. (1993). The relationships of affect intensity to happiness. Social Indicators Research, 31, 159-173.

Tabachnick, B. G., \& Fidell, L. S. (1996). Using Multivariate Statistics (3rd ed.). New York: Harper Collins.

Tashakkori, A., \& Teddlie, C. (1998). Mixed methodology: Combining qualitative and quantitative approaches. Thousand Oaks, CA: Sage.

Taylor, S. E., \& Brown, J. D. (1988). Illusion and well-being: A social psychological perspective on mental health. Psychological Bulletin, 103(2), 193-210.

Taylor, S. E., Kemeny, M. E., Reed, G. M., Bower, J. E., \& Gruenewald, T. L. (2000). Psychological resources, positive illusions, and health. American Psychologist, 55, 99109.

Tinkle, M. B., \& Beaton, J. L. (1983). Toward a new view of science: Implications for nursing research. Advances in Nursing Science, 5(2), 27-36.

Valliant, G. E. (2000). Adaptive mental mechanisms: Their role in a positive psychology. American Psychologist, 55, 89-98.

Valliant, P. M. (1995). Personality, peer influence, and use of alcohol and drugs by first-year university students. Psychological Reports, 77, 401-402.

Veenhoven, R. (1988). The utility of happiness. Social Indicators Research, 20, 333354.

Veenhoven, R. (1991). Is happiness relative? Social Indicators Research, 24, 1-34.

Veenhoven, R. (1994). Is happiness a trait?. Social Indicators Research, 32, 101-160. 
Veenhoven, R. (1995). The cross-national pattern of happiness: Test of predictions implied in three theories of happiness. Social Indicators Research, 34, 33-68.

Volk, R. J., Pace, T. M., \& Parchman, M. L. (1993). Screening for depression in primary care patients: Dimensionality of the short form of the Beck Depression inventory. Psychological Assessment, 5(2), 173-181.

Waterman, A. S. (1993). Two conceptions of happiness: Contrast of personal expressiveness (eudaimonia) and hedonic enjoyment. Journal of Personality and Social Psychology, 64(4), 678-691. 